\title{
Three Essays on the Survival Time of Firms and Their Growth
}

\author{
by \\ Hossein Kavand, Ph.D. \\ A dissertation submitted to the \\ Faculty of Graduate and Postdoctoral Affairs \\ in partial fulfillment of the requirements for the degree of
}

Doctor of Philosophy in Economics

\author{
Department of Economics \\ Carleton University \\ Ottawa, Ontario \\ January, 2019 \\ (C)Copyright
}

Hossein Kavand, 2019 


\section{Abstract}

The first essay in this dissertation uses US iron and steel shipbuilding data (18251914) used by Thompson (2005). It proposes a Two-Stage Discrete Finite Mixture hazard model to account for selection effect associated with a high first-year exit rate, and omitted variable bias associated with missing information such as a shipbuilder's pre-entry experience. In the first stage, the model uses a Probit model to explain the selection effect by employing both a firm's production share and productionselection component at the time of entry as exclusion restrictions. The results identify two latent classes as proxies for pre-entry experience used in the Weibull model by Thompson. The model proposed is useful when important factors for the survival of new firms such as human capital, might be missing from databases.

The second essay examines whether starting with different types of bank credit has a heterogeneous effect on the future performance of small business in the Kauffman Firm Survey (2004-2011) (KFS). The analysis uses a structural equation model to account for endogeneity bias, entailing three interrelated equations: one for the firm's survival time, one for its start-up with a type of bank credit, and one for its revenue in 2007. To identify high-quality firms starting with business credit, the model employs three exclusion restrictions: a firm's entry share of tangible assets in its cohort; the entry-selection component of tangible assets, and per-capita state-level secured loans. The results reveal a positive endogenous treatment effect on a firm's future revenue when starting with business credit, and a negative one when starting with personal 
credit.

The third essay evaluates the direct effect of knowledge spillover on small businesses in the KFS. Knowledge spillover can take place when a firm directly collaborates with other institutions or firms. To identify the causality effect, the empirical analysis uses collaboration as a proxy for transforming abstract knowledge into economic knowledge by entrepreneurs. To improve identification, it implements a Combined Difference in Difference approach. The results indicate that firms teaming with other institutions outperform those without such treatment. Teaming induces higher growth in real revenue, employment size, and real wages. 


\section{Acknowledgments}

To appreciate the glory of the universe and its offerings, you may begin by praising those who open their hearts so that you might grow; those who never expect you to compensate them; those in whose debt you remain forever: your teachers and your parents.

I am grateful to my thesis supervisor, Professor Marcel Voia, for his honest academic support, his patience, and his deep knowledge of empirical econometrics, and to thesis committee member Dr. Kim Huynh from the Bank of Canada for contributing far more than his role required. Both Professor Voia and Dr. Huynh were generous with their time and immense knowledge. They gave me insightful comments during our meetings and pushed me forward, though meeting their demands was sometimes challenging. They have profoundly influenced my approach to research.

I would like to thank the other members of my thesis committee, Professors Gamal Atallah and Eric Stephens, for their helpful comments, especially on the second and

third chapters. I wish to thank Professors Linda Khalaf from Carleton University and Myra Yazbeck from the University of Ottawa for their discussion on the empirical model in the third chapter; and also Professor Patrick Coe., Ph.D. program supervisor, for administering the defence. I am grateful as well to my internal referee, Professor Mika Westerlund, and external referee, Dr. Danny Leung.

I would like to thank Professor Joseph Farhat and his colleagues at the Kauffman Foundation for their collaboration with Carleton University to provide me with access 
to the Kauffman Firm Survey Data (2004-2011). Without their generosity the third and fourth chapters could not have been written.

I am grateful to Dr. Baily Seshagiri, Andrew Aitkens, and John Stewart who generously proofread my work and suggested many grammatical and editorial changes to this dissertation.

I dedicate this work to my beloved parents, to my sisters Mansoureh and Marzieh, and to my brother Hassan, for their support and encouragement. 


\section{Preface}

It was my pleasure to work with Professor Voia and Dr. Huynh and having their

comments on this thesis. I also acknowledge their collaboration as co-authors in Chapter 2. 


\section{Table of Contents}

Abstract $\quad$ ii

Acknowledgments $\quad$ iv

Preface $\quad$ vi

Table of Contents vii

List of Tables $\quad$ xi

List of Figures $\quad$ xiii

1 Introduction $\quad 1$

2 The Effects of Initial Entry Conditions and Exit-Time Selection on $\begin{array}{ll}\text { the Survival Time of Shipbuilding Firms } & 6\end{array}$

2.1 Introduction . . . . . . . . . . . . . . . . . . . 6

2.2 Literature review . . . . . . . . . . . . . . . . . 8

2.2.1 Unobserved Heterogeneity and Omitted Variables . . . . . . . 10

2.2.2 More on Selection Effect . . . . . . . . . . . . . . . . . 12

2.3 Thompson's Shipbuilding Data . . . . . . . . . . . . 15

2.4 Empirical Strategy . . . . . . . . . . . . . . . . 16

2.5 Results . . . . . . . . . . . . . . . . . . . . 19 
2.5.1 The Weibull Model . . . . . . . . . . . . . . . . . . . . . . 20

2.5 .2 The DFM Model . . . . . . . . . . . . . . . . 20

2.5 .3 The TS-DFM Model . . . . . . . . . . . . . . . . . . . . 21

2.5.4 TS-DFM Model without pre-entry experience . . . . . . . . 22

2.6 Conclusion . . . . . . . . . . . . . . . . . . . . . . . . . . . . . . . . 23

3 The Endogenous Treatment Effect of Initial Bank Credit on a Startup's Performance $\quad 24$

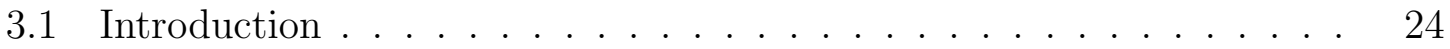

3.2 Credit Rationing and Related Literature . . . . . . . . . . 28

3.3 The Kauffman Firm Survey Data . . . . . . . . . . . . . . . . 31

3.3.1 Initial Conditions and the Performance of Firms . . . . . . . 32

3.4 Building an Empirical Model . . . . . . . . . . . . . . . 33

3.4.1 Structural Equation Modelling (SEM) . . . . . . . . 36

3.5 Identification $\ldots \ldots \ldots \ldots \ldots \ldots \ldots \ldots$

3.5.1 Exclusion Restrictions for the Business-Credit Equation . . . . 38

3.5.2 Exclusion Restrictions for the Survival Equation . . . . . . . 42

3.6 Empirical Results . . . . . . . . . . . . . . . . . . . . . 43

3.6.1 Results of SEM for Business Credit . . . . . . . . . . . . 43

3.6.2 Results of SEM for Personal Credit . . . . . . . . . . . . . 44

3.6 .3 Robustness Check . . . . . . . . . . . . . . . . . . . 45

3.6.4 The Observable Quality Factors . . . . . . . . . . . . . 46

3.7 Summary and Conclusion $\ldots \ldots \ldots \ldots$

4 Evaluating the Impact of Knowledge Spillover on Start-ups: Using Collaboration as a Proxy for Knowledge Spillover 50

4.1 Introduction . . . . . . . . . . . . . . . . . . . . 50

4.2 Literature Review . . . . . . . . . . . . . . . . . . . . 53 
4.3 Empirical Strategy $\ldots \ldots \ldots \ldots$. . . . . . . . . . . . . . . 57

4.3.1 Difference in Difference Approach . . . . . . . . . . . . . 59

4.3.2 Treatment Independence and Selection Bias . . . . . . . . . 61

4.3.3 Combined Difference in Difference . . . . . . . . . . . . . 62

4.3.4 Alternative Matching Algorithms . . . . . . . . . . . . . 64

4.4 Data . . . . . . . . . . . . . . . . . . . 65

4.5 Empirical Results . . . . . . . . . . . . . . . . . . . . . 68

4.5 .1 Balancing tests . . . . . . . . . . . . . 71

4.5.2 Combined Difference in Difference for Teaming . . . . . . . 72

4.6 Conclusion . . . . . . . . . . . . . . . . . . . . . . . . . . . . . 74

$\begin{array}{ll}\text { List of References } & 75\end{array}$

$\begin{array}{lll}\text { Appendix A } & \text { Appendices for Chapter 1 } & 89\end{array}$

A.1 Tables and Figures . . . . . . . . . . . . . . . . . . . . . . . 89

A.2 Selection Effect and Hazard Rates . . . . . . . . . . . . . . . . 92

A.3 Discrete Hazard Model . . . . . . . . . . . . . . . . . . . . . . . . 94

A.4 Unobserved heterogeneity . . . . . . . . . . . . . 96

A.4.1 Discrete Finite Mixture Hazard Model _ . . . . . . . . . 97

A.5 The TS-DFM Model . . . . . . . . . . . . . . . . . 100

A.5.1 The First Stage . . . . . . . . . . . . . . . . 100

A.5.2 The Second Stage . . . . . . . . . . . . . . . . 100

$\begin{array}{lll}\text { Appendix B Appendix for Chapter 2 } & 102\end{array}$

B.1 Tables . . . . . . . . . . . . . . . . . . . . . . . . . . 102

B.2 Optimal Debt Contract . . . . . . . . . . . . . . . . 114

B.2.1 Adverse Selection and Moral Hazard . . . . . . . . . . . 116

B.2.2 No Loan to Low-Quality Firm . . . . . . . . . . . . . . . . 124 
B.2.3 Comparative Statics Analysis . . . . . . . . . . . . . . 125

B.3 Technical Note for Identification . . . . . . . . . . . . . . . . . 128

B.4 The Survival and Selection Componants . . . . . . . . . . . . . . . 130

B.5 Endogenous Treatment Effect . . . . . . . . . . . . . 131

\section{Appendix C Appendix for Chapter 3 133}

C.1 Tables and Figures . . . . . . . . . . . . . . . . . 133 


\section{List of Tables}

A.1 Survival Rate, Exit Rate, and Exclusion Restrictions . . . . . . . . 89

A.2 Estimated Hazard Ratios - Different Model Specifications . . . . . . . 90

B.1 Definition of Variables . . . . . . . . . . . . . . . . . 102

B.2 Initial Conditions and Their Correlations with Survival Time and Revenue Groups . . . . . . . . . . . . . . . . . . . . . 106

B.3 Pre-entry quality revealed by the entry share of Tangible Assets (TA) . . . 108

B.4 Other Exclusion Restrictions . . . . . . . . . . . . . . . . . 108

B.5 Structural Equation Modelling for Business Credit (Framework A) and Personal Credit (Framework B) . . . . . . . . . . . . . . . . 109

B.6 Entry conditions, survival probability, start-up bank credit, and a firm's performance . . . . . . . . . . . . . . . . 111

C.1 Comparison Between Teaming and R\&D . . . . . . . . . . . . . . 134

C.2 The distribution of R\&D employees, the number of firms with comparative advantage, and fraction of them with teaming experience . . . . 135

C.3 The distribution of total employees, the number of firms with a comparative advantage, fraction of them with teaming experience, and fraction of them with R\&D expenditure . . . . . . . . . . . . . 136

C.4 The number and share of teaming for the survivals (2004-2011) . . . . 137

C.5 The types of teaming among all firms with comparative advantage: \# $(\%) \ldots \ldots \ldots \ldots \ldots \ldots$ 
C.6 Estimated Models . . . . . . . . . . . . . . . . . . . . . . . 138

C.7 Balance Tests for Kernel Algorithm Based on MD Measure . . . . . . 142

C.8 Balance Tests for Kernel Algorithm Based on PS Measure . . . . . . 145

C.9 Balance Tests for Kernel Algorithm Based on PS Measure . . . . . . 148

C.10 Combined Difference in Difference: Real Revenue Growth . . . . . . . 151

C.11 Combined Difference in Difference: Employment Growth . . . . . . . 152

C.12 Combined Difference in Difference: Per-capita Real Wage Growth . 153 


\section{List of Figures}

2.1 Empirical Hazard (Source: Thompson (2005)) $\ldots \ldots \ldots$. . . . . 7

3.1 The SEM framework accounts for both surviving selection bias and endogeneity bias . . . . . . . . . . . . . . . 37

A.1 Empirical, TS-DFM: Two-Stage Discrete Finite Mixture (Average, Class 1, and Class 2), and Weibull Hazards . . . . . . . . . . . 91

B.1 The GSEM framework . . . . . . . . . . . . . . . . . . . . . . . . 129

C.1 Selected Bandwidth and the Density Balancing . . . . . . . . . 154 


\section{Chapter 1}

\section{Introduction}

The literature on firm dynamics has been evolving in various theoretical and empirical aspects. Many studies have explored a wide range of factors affecting a firm's performance such as its survival time, its growth and performance, and its ultimate success. Using empirical analysis, this thesis contributes to the studies that underline a firm's heterogeneity at start-up as the major determinant of its future operation.

Though analysing different aspects of firm dynamics, the next three chapters share the common feature of being related to applied microeconometrics and accounting for heterogeneity among firms. They employ different econometric approaches to handle three common issues in firm-level studies: unobserved heterogeneity (missing information), endogeneity bias, and selection bias.

Chapter 2 uses a Discreet Finite mixture hazard model to identify latent classes for classifying firms into different types as proxies for missing information. Chapter 3 evaluates the impact of a firm's starting with different types of bank credit on its growth. It uses Structural Equation Modelling to account for endogeneity bias between the type of start-up credit and a firm's productivity. To mitigate selection effect, Chapter 4 implements a combination of matching and Difference-in-Difference approaches to analyse the causality effect of knowledge spillover on the growth of small businesses. 
Since heterogeneity among firms can arise from different observable and unobservable sources, it has motivated researchers to assign proxies for them. For example, the size of a firm can account for a firm's potential productivity, and its age can describe its learning mechanism.

However, pinpointing the major sources of heterogeneity at start-up, which in turn can lead to heterogeneity in productivity and learning mechanisms among firms, may lessen the significant effect of such proxies on firm dynamics. Classifying firms into different categories based on their entry characteristics (selection into entry) can help explain their performances. Thus those models that do not address unobserved heterogeneity among firms are substantially prone to two sources of bias: omitted variable bias and selection bias. Advanced econometric methods, however, may be useful in alleviating such biases.

The empirical model in Chapter 2 handles such issues for hazard rates in U.S. iron and steel shipbuilding firms (1825-1914) documented in the seminal study by Thompson (2008). He demonstrates that pre-entry experience information not only explains most of the hazard rates in the shipbuilding industry, but also absorbs the conditional age effect. His analysis has two shortcomings, however: first, it fails to predict the high exit rate $(41 \%)$ in the first year; second, the fixed heterogeneity proxies used in his analysis might be missing or hard to access in other databases.

As a counter-factual exercise, the empirical analysis presented in Chapter 2 of this thesis considers the pre-entry experience information as missing, and it proposes an identification strategy that employs a two-stage Discrete Finite Mixture (TS-DFM) hazard model to handle two sources of bias: selection bias and omitted variable bias. To model the selection effect that induces the high exit rate in the first year, the framework relies on a Probit model in the first stage. The Probit model employs both the firm's production share and production-selection component at the time of entry as exclusion restrictions. By allowing the DFM model to classify firms as high- 
and low-quality in the second stage, the TS-DFM model not only satisfies Thompson's focus on long-lasting unobserved initial heterogeneity (quality), but also shows how missing-information issues in empirical studies can be overcome. The model also predicts the high exit rates in the first year.

The initial quality of firms and their selection into entry can also influence a bank's decision for granting credit to businesses. Small businesses substantially rely on bank credit, though their ability to do so is constrained by problems of asymmetric information. For these firms, bank credit can play a substantial role in establishing their optimal capital at start-up. Robb and Robinson (2014) reveal that bank debt constitutes $40 \%$ of the capital structure of the Small and Medium size (SMs) firms in the Kauffman Firm Survey (2004-2011) (KFS) at their start-up. They show that a firm's outside debt has positive impact on its future growth.

However, their analyses have overlooked the presence of credit-size rationing for these firms. Not all of the firms accessed all types of bank credit at start-up. For example, $17 \%$ of the SMs firms in the KFS started with business credit without relying on their owner's personal credit, and $28 \%$ relied only on their owner's personal credit. This evidence reveals the existence of credit-type rationing for the SMs firms, which is the optimal response of a banking system to asymmetric information. The rationing can heterogeneously affect the optimal initial capital, and it subsequently influences the potential productivity of the start-ups.

The analysis presented in Chapter 3 explores two questions: first, what enables a firm to acquire a specific type of bank credit (business or personal) at start-up? Second, can a firm that starts with business credit achieve higher growth in the future, versus starting with only personal credit? The empirical analysis in the chapter differs from previous studies that mainly rely on reduced-form models. These studies do not take into account unobserved factors affecting both their access to a type of bank credit and their growth; thus the results of such studies are prone to endogeneity bias 
(see Robb and Robinson (2014) and Cole and Sokolyk (2018)).

To account for omitted variable bias and endogeneity bias, the empirical analysis in Chapter 3 employs a structural equation model that uses two shared latent variables. The model entails three interrelated equations: one for the firm's survival time, one for their start-up with a type of bank credit, and one for their revenue in 2007.

Identification strategy relies both on functional forms in the structural equation model and on the exclusion restrictions employed. To identify high-quality firms selected by banks for granting business credit, the model uses three exclusion restrictions: a firm's entry share of tangible assets in its cohort, the entry-selection component of tangible assets, and the use of per-capita state-level secured loans. The results indicate that starting with business credit leads to a positive endogenous treatment effect on a firm's future revenue. By contrast, however, starting with personal credit results in a negative endogenous treatment effect.

Entrepreneurs themselves prompt heterogeneity among their cohort. They create new ventures and decide how the ventures appear and operate in the market. They determine the interaction of their firms with sources of knowledge. Entrepreneurs, in fact, can be considered as the missing link in growth theory. The role of entrepreneurs in the transition of abstract knowledge into actual operation can substantially determine a firm's potential productivity (size) and its learning process (age) in the future.

Based on the knowledge spillover theory, accumulated abstract knowledge alone would not provoke endogenous economic growth. It needs entrepreneurs to overcome the knowledge filter, i.e., to commercialize the acquired knowledge. The analysis in Chapter 4 aims to identify the effect of knowledge spillover on the growth of SMs start-ups in the KFS (2004-2011).

Chapter 4 contributes to those studies that evaluate the impact of knowledge spillover at the firm level. Other studies, however, focus on regional macroeconomic 
impacts of localized knowledge spillovers. In those studies, the distance from universities, their research and development (R\&D) expenditures, the presence of specific departments in the universities, and the share of new firms in the economy are some of the proxies employed for assessing the impact of knowledge spillover.

The analysis in Chapter 4 also differs from other firm-level studies in that, rather than focusing on R\&D expenditures, data on the direct collaboration of firms with academic and non-academic institutions is employed to better identify the role and impact of entrepreneurs in converting knowledge into operation. For the firms in KFS, the percentages of firms experiencing such collaborations surpass the percentages of small ventures undertaking R\&D expenditures during 2004 to 2011. Small businesses under six employees that achieved commercializing knowledge such as comparative advantage were more likely to acquire it by the experience of teaming (collaboration) rather than by expending on $\mathrm{R} \& \mathrm{D}$. This is important since this category of firms form the majority of the firms in the KFS.

To improve identification strategy, the empirical analysis contained in Chapter 4 implements a Combined Difference-in-Difference approach. The results indicate that firms teaming with other institutions outperform those without such treatment (control group). Teaming induces higher growth in outcomes such as real revenue, employment size, and per-capita real wages.

[Note: All bibliographical references and appendices have been moved to the end of the thesis.] 


\section{Chapter 2}

\section{The Effects of Initial Entry Conditions and Exit-Time Selection on the Survival Time of Shipbuilding Firms ${ }^{1}$}

\section{$2.1 \quad$ Introduction}

Generally, empirical models of survival time employ the age of a firm as a proxy for learning mechanism, see Jovanovic (1982), and/or the size of a firm as a proxy for entrant productivity, see Hopenhayn (1992). Thompson (2005) proposes an alternative explanation for the positive dependence of the survival time on a firm's age. The age dependence can reflect a persistent unobserved heterogeneity rooted in the selected quality of the firms at the time of entry. The positive age dependence arises since low-quality firms exit earlier than high-quality ones. Thompson analyzes the duration of firms in the U.S. iron and steel shipbuilding industry (1825-1914). He demonstrates that pre-entry experience is a proxy for the variation in initial quality of firms and accounts for this selection bias and removes the survival dependence on age. However, such proxy is usually missing in the public or administrative data.

\footnotetext{
${ }^{1}$ This chapter is co-authored by Professor Marcel Voia and Dr. Kim Huynh.
} 
The empirical model employed in this chapter extends Thompson's paper. First, it narrowly replicates the results of the Weibull model in Thompson (2005) and checks for the selection of firms passing the first year: $41 \%$ of shipbuilders exited in the first year (see Figure 2.1). Second, it proposes an identification strategy that employs a two-stage Discrete Finite Mixture (TS-DFM) hazard model to handle two sources of bias: selection bias and omitted variable bias. The TS-DFM method is based on the work of Huynh and Voia (2017) to better predict the hazard rates. ${ }^{2}$

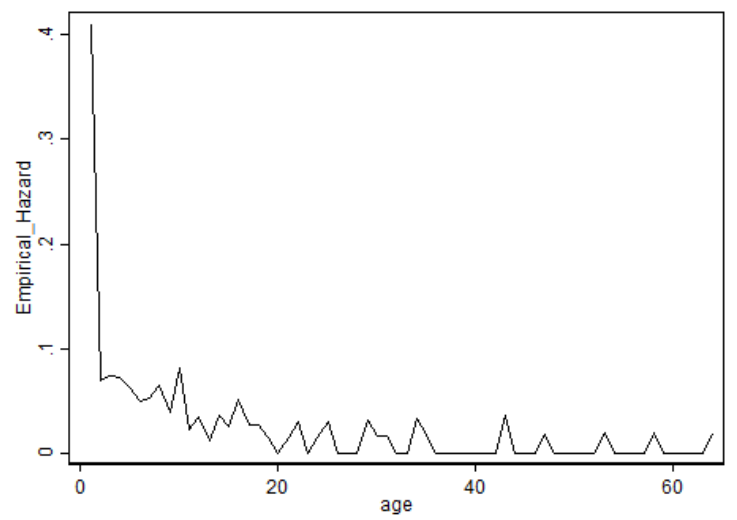

Figure 2.1: Empirical Hazard (Source: Thompson (2005))

In the first stage, a probability model controls for the selection bias associated with the sharp drop in exit rates after the first year (41\%). Here, the selection model reflects the firm's probability of surviving past the first year. To identify this unobserved selection effect within the two-stage model, the survival probability model uses more than one exclusion restriction (see Chen et al. (2016)).

The first two exclusion restrictions are related to a firm's production share in its cohort at the time of entry (based on the number of launched ships and tonnage), and the third one is related to its cohort's entry-selection component calculated using decomposition by Pinto (2008). These variables aim to identify those high-quality

\footnotetext{
${ }^{2} \mathrm{~A}$ hazard function represents the instantaneous rate of failure. If a firm survives until time $t$, the hazard rate measures the (limiting) probability that it exits right after time $t$, see Cleves et al. (2008).
} 
firms that successfully pass the first year. The estimated survival probability plays the role of a control function that transfers the initial quality information into the second stage for capturing the high exit rate in the first year (see Wrenn et al. (2017)).

In the second stage, the pre-entry experience variables used by Thompson are dropped from the empirical model to be considered as omitted variables. We can then examine whether the DFM model can classify firms into different types as proxies for the missing information (a counter-factual exercise). Allowing the DFM model to classify firms as high- and low-quality, not only can satisfy Thompson's focus on longlasting unobserved initial heterogeneity (quality), but also would show how missinginformation issues in empirical studies can be overcome. The proposed TS-DFM hazard model captures the high exit rate in the first year (41\%) and the dynamics of hazard rates past first year. The results illustrate the power of the model in correcting both biases.

The rest of the chapter is organized as follows. Section 2.2 reviews related studies in the literature. Section 2.3 introduces the shipbuilding data. Section 2.4 provides a brief review of DFM models and empirical strategy. Section 2.5 presents the estimation results, some robustness, and compares the hazard prediction of the final TS-DFM model with Thompson's results. Finally, section 2.6 concludes the chapter.

\subsection{Literature review}

The literature on firm's dynamics has been evolving in various empirical and theoretical aspects. Many studies have explored a wide range of factors affecting a firm's performance such as its growth rate (in terms of its employees or its sales), its growth volatility, its job creation, its job destruction, and its entry and exit time (Cooley and Quadrini (2001)). Though a large portion of these studies consider the size and the age of a firm as the major factors affecting its dynamics, Gibrat's law rejects any 
relationship between a firm's size and its growth. Some studies confirm the validity of the law. Simon and Bonini (1958) and Lucas (1978) find no evidence that a firm's size affects its growth (see Evans (1987)). Others, however, report different findings.

Conditional on age, some studies suggest that a firm's size has an ultimate negative impact on the growth rate of the firm (the inverse size-growth relationship), and that it has a positive effect on the firm's survival time. For instance, Nelson and Winter (2009) find that a firm's size has a non-linear impact on the firm's growth: at first the firm's growth increases by size, then it reduces (see also Evans (1987)).

Conditional on size, some studies find a negative impact of a firm's age on its growth, and a positive one on its survival time. Cooley and Quadrini (2001), citing Hall (1987), argue that the age and the size of manufacturing firms negatively affect the growth rates of the firms and their corresponding variances. To explain these empirical findings, researchers have also striven to develop theories to clarify these findings.

The early theories focus on justifying the conventional wisdom that a firm's size, its age, or both are relevant proxies for describing its dynamics. The two proxies aim to explain unobserved heterogeneity nested in firm-level data, thus accounting for two sources of bias such as omitted variable bias and sample selection bias.

To deal with omitted variables (missing information), Hopenhayn (1992) delineates a firm's size as a proxy for unobserved productivity. In his model, a firm's productivity shock causes idiosyncratic uncertainty and provides heterogeneity among firms. The resulting heterogeneity explains the size dynamics of the firm and its survival period. The model also suggests a size distribution for a cohort of firms such that as they age, their size and their survival rates increase.

Selection effect can also explain some of a firm's unobserved heterogeneity and its dynamics. As Klepper and Thompson (2006) discuss, the selection model in Jovanovic (1982) considers the age of a firm as a proxy for its owner's belief (or learning) about 
its quality. The model uses Cobb-Douglas technology with decreasing returns to scale and predicts no role for the size of a firm in affecting its dynamics, confirming Gibrat's law. Conditional on its size, however, a firm's age negatively affects both its growth rate and hazard rate. Jovanovic argues that a firm can be uncertain about its efficiency, namely its type, and gradually learns about it. So, he models the firm's understanding of its type as a Martingle process. The firm selects its entry size based on its belief about its efficiency. It is this selection, not the fixity of capital, that causes heterogeneity among the firms in terms of their initial size and their dynamics.

For example, a firm's understandign about its efficiency affects its production cost. The high cost of an inefficient firm causes its production or its sale to shrink and leads to exit earlier than an efficient one in its cohort. Therefore, the entry size of a firm and its later success in an industry reflect its efficiency. The model predicts that a firm's age is a proxy for its efficiency, and it negatively affects its hazard rate and its growth variance. Klepper and Thompson (2006), however, mention that age in this model does not affect a firm's mean growth.

As outlined above, the size provides a proxy for an unobserved, omitted variable such as productivity, and age provides a proxy for a firm's learning about its type and its initial entry decision. Other ways of accounting for unobserved heterogeneity, however, rely on either using econometric methods or accessing more firm-specific information. The next two sections discuss studies relying on both approaches in dealing with omitted variable bias and selection bias.

\subsubsection{Unobserved Heterogeneity and Omitted Variables}

Why is handling unobserved heterogeneity important? Uncontrolled unobserved heterogeneity can result in spurious state dependence. The spurious state dependency prevents the baseline hazard to represent the correct duration dependence. In this case, we cannot expect that two firms with similar characteristics will be faced with 
the same hazard rates (see Cameron and Trivedi (2005)). To deal with unobserved heterogeneity, we can rely on either econometric methods or accessing more firmspecific information or both.

Random effect models and non-parametric models can account for unobserved heterogeneity. A parametric distribution needs to be specified to manage random effect. Using a wrong parametric distribution for random effect, however, may raise the danger of misspecification in estimating hazard rates. To avoid the misspecification issue, using semi-parametric models such as latent class models can be an option.

For example, Huynh and Voia (2016) examine the power of latent class models or finite mixture models in identifying the unobserved heterogeneity. They compare different hazard predictions with an empirical hazard. The finite mixture model identifies two latent classes of firms, with $30 \%$ of them categorized in the high-hazard class. Their results show that the finite mixture hazard model improves the prediction of hazard rates. Limited access to firm-specific information can also justify the method.

The lack of firm-specific information in administrative and private firm-level data leads to unobserved heterogeneity, and hence omitted variable bias. Access to this information can mitigate the bias. For example, a firm's initial entry conditions may capture some parts of the heterogeneity among firms. Telser (1966), Dunne et al. (1989), and Zingales (1998) declare that a firm's initial entry size (number of employees) positively affects its post-entry survival. We can also use the information to check for the validity of their proxies such as the age and the size of a firm. This process may absorb the conventional explanatory power of a firm's size, its age, or both on the firm's dynamic (see also Thompson (2005)).

To finesse the unobserved heterogeneity, Huynh et al. (2010) use Gamma distribution to control for the random effect in Gompertz and Cox hazard models. They find that initial leverage (debt-to-asset ratio) of a Canadian manufacturing firm has a non-linear effect on its post-entry survival: for firms in each cohort, the higher 
their initial level of leverage, the higher their risk of exit. Over time, survival firms improve their financial status, and the effect of this initial financial heterogeneity on the hazard rates diminishes for each cohort.

By calculating the selection and survival components using the decomposition formula by Pinto (2008), the above study shows that surviving firms of a cohort entered with low leverage, big size and higher productivity. These initial heterogeneities, rather than firms' improved conditions over time, form the main reasons for the cohorts' distributional change. Log-likelihood decomposition indicates that identified unobserved heterogeneity together with the firm's initial information, specifically its initial leverage, explain $80 \%$ to $95 \%$ of the hazard rates.

Sometimes dealing with unobserved heterogeneity needs more attention. For example, Figure 2.1 denotes that $41 \%$ of the shipbuilding firms exited in the first year. As later will be discussed, Thompson's strategy to account for omitted variables such as human capital, though absorbs the age effect, it might not be enough to explain the sharp drop in hazard rates. Accounting for selection effect may improve this shortcoming.

The next section reviews studies that reveal the presence of selection bias and its effect on the performance of firms.

\subsubsection{More on Selection Effect}

A firm's decision about its entry to or exit from an industry usually leads to selection bias. These non-stochastic decisions constitute some parts of the unobserved heterogeneity among firms. The uncontrolled selection effect results in an endogeneity problem which in turn causes inconsistent hazard rate estimations.

Selection effect can appear in different ways in data. Sometimes, a high exit rate among young firms of a cohort implies the cause of selection effect. The effect can also change the firm-size distribution in a cohort over time. Previous studies, however, 
differently evaluate the importance of the selection effect on firms' dynamics: some find it insignificant; others, a major factor. Their findings depend on the used data and the time-interval that the data covers.

Evans (1987) shows that $30 \%$ of the young firms in his data exit, whereas the exit rate among surviving firms reduces to less than 10\%. He finds sample selection a minor issue because of a negligible correlation between the error terms of jointly estimated survival probability and growth rate models. The estimation undermines Mansfield (1962) who considers the inverse size-growth relationship as an accidental event that appears as a consequence of sample selection resulting from the exit of slow-growing firms.

Olley and Pakes (1992) employ a semi-parametric method to estimate a production function while accounting for both the endogeneity problem related to omitted variables and the selection effect related to a firm's decision to shut down. They show that the entry, the exit, and the growth rates of firms that survived heavily depend on persistent productivity. In their assessment, the endogeneity problem arises from the correlation between unobserved measures of productivity and inputs (capital, labour, and a firm's age). An entrepreneur's belief about a firm's productivity guides her to decide about these inputs.

To account for endogeneity, Olley and Pakes (1992) link unobserved productivity to a fourth order polynomial expansion of inputs. For selection effect, they link exit decisions with a lower bound of a firm's productivity that decreases with capital. The process leads to a survival probability as a function of inputs (see appendix A.2). Accounting for both unobserved heterogeneity and selection effect reduces the over-estimated parameter of labour and increases the under-estimated parameter of capital.

In contrast, some other studies find no evidence of selection effect in their data. 
For example, Cabral and Mata (2003) find a stable firm-size distribution for all Portuguese manufacturing firms, but an unstable one for each cohort. The cohort distribution evolves, its mean and variance rise, and its shape deviates from an initial right skewed distribution toward a symmetric log-normal distribution. Financial restrictions confine young firms to operate first below their efficient size and to grow later toward their optimal sizes, though some of them may optimally choose to operate in small sizes.

To assess the role of selection effect, Cabral and Mata (2003) compare the sizedistribution of the firms that survived in a cohort with their corresponding initial distribution in the first year. They find a similar pattern for the constructed sizedistribution of survivals in the first year and the corresponding size-distribution for all the firms in that year. Therefore, the firms' age explains most of the distributional changes; whereas selection effect, which allegedly results in higher exit rates among young firms of a cohort, plays a negligible role.

As discussed before, Jovanovic (1982) considers the age of a firm as a proxy for selection effect resulted from its type. Klepper and Thompson (2006), however, show that accounting for submarkets in the laser industry captures the age effect without relying on either selection effect or financial-market friction. Submarkets in an industry manifest the evolution of the industry in different dimensions such as in using technology, diversifying in productions and services, targeting different markets, or operating in different geographical areas. Since submarkets appear and vanish, operating in one or several of them distinguishes firms from each other. The number of submarkets in which a firm operates has positive effects on a firm's survival period: as a firm ages, it operates in more submarkets and survives longer. So, accounting for the number of submarkets where firms operate completely absorbs the age effect on their dynamics.

As some of the above studies point out, useful entry-condition information provides 
us with a guideline to handle selection effect if any is evident in the data. Section 2.5.3 presents how a TS-DFM model explains a sharp drop in the exit rates among shipbuilding firms after the first year. To account for the selection bias in the data, the TS-DFM model takes advantage of the rich information in the entry conditions; it links the low exit rates after the first year to the firms' initial entry conditions.

\subsection{Thompson's Shipbuilding Data}

Starting in 1789, all ships with more than 20-ton capacity were registered in the United States (see Thompson (2008) for more information). Thompson's collected data mimic the data constructed by the Bureau of Navigation around 1920 for registered metal vessels between 1825 and 1919. His final sample, however, excludes firms that entered after 1914. The sample comprises only firms with at least one launched vessels over 20 tons to satisfy the minimum size for registration. It contains 273 firms and 4000 vessels, some of which might weigh less than 20 tons. He considers a firm as active even if it launches vessels below the minimum size.

Thompson considers eight categories of exiting mode such as "bankruptcy/unprofitable; exit into one of the shipbuilding trusts; merger; owner died or retired; firm abandoned shipbuilding but continued in another industry; firm sold; non-standard motivation for exit; and destination unknown."

Thompson defines a firm as "new-born" in different situations, including when an old firm extends its capacity; is re-established after bankruptcy; firms merge; or a spin-off is established. He categorizes these "new-born" firms as firms with pre-entry background in metal shipbuilding. He marks each plant of an owner with multiple plants as a separate firm. A change of partners does not lead to a new firm while the main owners stay with the firm. He defines a firm's founding year as its entry date and specifies the year that the firm launched its last vessel as its exit date - even 
if a firm stays active in another industry. For a surviving firm beyond 1914 with no information about its last-produced vessel, he codes the last year of its documented operation as "censored observation".

The shipbuilding data (1825-1914) contain 273 firms categorized based on their

founders' background as a) experienced: with shipbuilding or engine manufacturing backgrounds, b) miscellaneous, c) foundry, or d) unknown. The data also include size variables such as industry output, current market share, the scale of a plant (average annual rate of output since entry), as well as the location- and year-dummy variables. ${ }^{3}$

The next section discusses the empirical model and identification strategy for predicting the hazard rates of the above shipbuilding firms.

\subsection{Empirical Strategy}

Consider the following standard hazard model:

$$
h(t \mid v, x)=v_{i} \phi(x) \lambda(t),
$$

where $h(\cdot)$ is the hazard rate, $t$ is the duration of an individual unit $i, v_{i}$ is unobserved heterogeneity, and $\phi(x)$ is a function of time-invariant regressors that shifts the hazard up or down around $\lambda(t)$, namely the baseline hazard. The Weibull model used by Thompson has a parametric baseline hazard: $h_{i}(t)=\exp \left(\beta^{\prime} X_{i t}\right) p t^{(p-1)} ; p>0$.

As Elbers and Ridder (1982) illustrate, misspecifying the functional form of unobserved heterogeneity will induce spurious state dependence and create bias in the baseline hazard. This issue may occur using standard hazard models such as the Weibull and the Cox models. To avoid that, a Discrete Finite Mixtures (DFM) model is employed (see appendix A.3 and A.4 for more information).

\footnotetext{
${ }^{3}$ The data are available at: http://www.peterthompson.gatech.edu/index.php?page= liberty-ships-1
} 
Heckman and Singer (1984) propose a hazard model which assumes that each observation may belong to one of several latent classes, with each latent class having its own distribution that collapses to a discrete mass point. Unobserved heterogeneity, $v$, may have $K$ discrete points $v=\left\{v_{1}, v_{2}, \ldots, v_{K}\right\}$, with the corresponding probabilities such as $p=\left\{p_{1}, p_{2}, \ldots, p_{K-1}, p_{K}=1-p_{1}-p_{2}-\ldots-p_{K-1}\right\}$. A joint likelihood is used to estimate the parameters of the model, and the number of mixtures, $K$, can be determined based on Bayesian Information Criterion.

Within the two-stage model outlined in Appendix A.5, $h(t \mid v, x)=$ $v_{i} \phi\left(x, \hat{\operatorname{Pr}}\left(t_{i}>1 \mid x, z\right)\right) \lambda(t)$, the dependent variable of the control function in the first stage, $\operatorname{Pr}($.$) , is equal to 1$ for those firms that survive after the first year; and zero, otherwise. The initial production shares in vector $z$ identify unobserved heterogeneity arising from the irreversible entry-scale of a shipbuilder. An appropriate entry scale ensures adequate supply in the first and following years with immediate effects on the long term survival of a firm. Similarly, Abbring et al. (2005) demonstrate that the entry decisions of Texas bars can explain about $40 \%$ of their sales variance in the following years, and justify why $20 \%$ of them exit in less than one year.

To measure the third exclusion in vector $z$, the survivor-selection decomposition is applied to the number of launched ships, and its selection component is extracted. For each cohort, the decomposition formula takes the gap between the average production of firms in period $t$ and its corresponding value in the entry year, and breaks it up into survival and selection components as below:

$$
\begin{array}{r}
\underbrace{\frac{1}{N\left(S_{\tau}\right)} \sum_{i \in S_{\tau}} Y_{i, \tau}-\frac{1}{N\left(S_{1}\right)} \sum_{i \in S_{1}} Y_{i, 1}}_{\text {Overall average gap }}=\underbrace{\frac{1}{N\left(S_{\tau}\right)} \sum_{i \in S_{\tau}} Y_{i, \tau}-\frac{1}{N\left(S_{\tau}\right)} \sum_{i \in S_{\tau}} Y_{i, 1}}_{\text {Survival component }} \\
+\underbrace{\frac{N\left(E_{\tau}\right)}{N\left(S_{\tau}\right)}\left(\frac{1}{N\left(S_{\tau}\right)} \sum_{i \in S_{\tau}} Y_{i, 1}-\frac{1}{N\left(E_{\tau}\right)} \sum_{i \in E_{\tau}} Y_{i, 1}\right)}_{\text {Selection component }},
\end{array}
$$


where $N\left(S_{\tau}\right)$ and $N\left(E_{\tau}\right)$, respectively, refer to the number of survived and exited firms at time $\tau$, and $Y_{i, \tau}$ represents the number of launched vessels at time $\tau$, see Pinto (2008) for more details of this decomposition (see Huynh et al. (2012a) and Huynh et al. (2012b) for the use of this decomposition).

The selection component in the formula calculates the gap between the first-year average output of the firms that survived in a cohort at time $\tau$, and the corresponding average for those firms that exited before and during period $\tau$. The component captures exit effects. For example, if none of the firms in a cohort exits in the first year, this term would be zero for the firms that pass the first year in that cohort. The selection component for the firms that pass the first year provides a proxy for revealing the unobserved entry-selection factors (heterogeneity) helping a typical high-quality firm to survive beyond the first year.

We expect that some shipbuilders find it hard to operate at full capacity at the time of entry, or they might launch vessels that weigh less than threshold, 20 tons, without documenting them. ${ }^{4}$ The average nature of the computed selection component can mitigate these biases since the component reflects the average selection effect for each cohort at the time of entry; it also takes into account the economic circumstances that might affect all of them in that and following years.

Part A in Table A.1 unveils the effect of initial quality by pointing out that $60 \%$ of the shipbuilding firms that survive after the first year have pre-entry experience. Among them, survivals with a background in shipbuilding rather than in engine building constitute the majority. Table A.1 shows that among firms exiting in the first year only $27 \%$ of them have pre-entry experience backgrounds. The description statistics of this data are in line with the results of Dunne et al. (1989), Zingales (1998), and Huynh et al. (2010) who show that a firm's entry conditions substantially affect its post-entry survival.

\footnotetext{
${ }^{4}$ We thank Peter Thompson for his comment on these cases.
} 
Part B in Table A.1 demonstrates that the three exclusion restrictions significantly have higher average values for the firms with pre-entry experience (Pre-Exp) in the first year. Following Thompson, if pre-entry experience conveys useful information, so do these exclusion restrictions. Also, the exclusion restrictions have strong and significant correlations in the first year with the dummy variable used in the control function $(\mathrm{S} \mid \mathrm{t}=1)$. Their correlations with the survival status of the firms turn out to be low and insignificant over the following years, however.

The note in Table A.2 indicates that the exclusion restrictions have positive and significant effects on the firm's survival probability beyond the first year. These results delineate the relevance of the initial conditions in identifying the selection mechanism. This finding may also justify our use of the DFM model in the second stage. The DFM model can identify the remaining long lasting heterogeneity among the firms that survived beyond the first year.

\subsection{Results}

This section starts with repeating the Weibull model as specified in the second column of Table 4 in Thompson (2005). Then, it demonstrates that a DFM model, which captures missing information, has shortcomings in explaining the full dynamic of exit rates. It shows that by accounting for selection effect, a TS-DFM model can explain the drop in the exit rates after the first year. Then, for the final TS-DFM model the firm's quality information is treated as missing. The estimated coefficients in Table A.2 represent hazard ratios. Those coefficients that are smaller than one reduce the hazard rate - the smaller the coefficient, the stronger the effect will be. 


\subsubsection{The Weibull Model}

Thompson (2005) preferred hazard model is a Weibull that uses a firm's location and entry-year dummy variables. ${ }^{5}$ The first column of Table A.2 reveals that the size proxies negligibly affect the hazard rates. In contrast, however, the pre-entry experience in shipbuilding and engine manufacturing substantially reduces the hazard rates by $37 \%$ and $48 \%$, respectively. As Thompson argues, it is accounting for preentry heterogeneity, not the size, that substantially weakens the age effect. Age reduces the hazard rates only by $7 \% .{ }^{6}$ Also, note that the Weibull under predicts the first-year empirical hazard of 41\%, see Figure C.1a.

\subsubsection{The DFM Model}

To investigate the flexibility of latent class models in capturing unobserved heterogeneity associated with the quality of firms, the pre-entry information is dropped and a DFM model (DFM1) is estimated. The second column of Table A.2 indicates that the DFM1 model identifies two classes of firms as proxies for the missing information. One class represents high-hazard firms and the other represents low-hazard firms, see Figure C.1a. Compared with the Weibull model, these classes absorb the age effect and leave the size coefficients almost intact. Figure C.1a shows that the DFM1 model, however, needs to be enriched with other features to account for the sharp drop in the exit rate from the first year.

Figure C.1b illustrates that after returning the pre-entry experience information, the resulting DFM2 model does not account for the downward shift in the hazard rates after the first year - it takes 10 years to get to 0.15 rate. It predicts that the

\footnotetext{
${ }^{5}$ Since the entry-year dummy variables were dropped out from the model, the results of the first column in Table A.2 slightly differ in magnitude from those reported in the second column of Table 4 in Thompson (2005).

${ }^{6}$ The Weibull model decrease in hazard rate relies on the functional form of the baseline hazard: $\lambda(t)=p t^{(p-1)}$, where $\hat{p}=0.929$, which results in almost $7 \%$ drop in the estimated Weibull hazard rates.
} 
probability of being in the low-hazard class is $86 \%$, which does not have any support in the data with $41 \%$ exit rate in the first year (see the third column of Table A.2). In contrast to Thompson (2005), age significantly reduces the exit rates by $49 \%$. Our DFM2 model estimates finds that class 2 mass point is 25.1 times higher than class 1 (normalized to 0) but has a low probability of 0.14 . This extremely high estimate of the mass point 2 implies that there is a large amount of unobserved heterogeneity, or the model is misspecified.

\subsubsection{The TS-DFM Model}

The second stage of the TS-DFM model relies on augmenting the previous DFM2 model with the estimated survival probability: $\hat{\operatorname{Pr}}\left(t_{i}>1 \mid x, z\right)$. The findings in the fourth column of Table A.2 indicate that the selection effect is important as the model's control for selection into entry substantially reduces the likelihood of exit by 98\%, and absorbs the age effect. However, the estimate of mass point 2 increases to 27.27 with a probability of 0.40 , resulting in a high predicted average hazard rates (PAHRs), see Figure C.1c.

The fifth column provides the estimates of the TS-DFM2 model to address the issue of high unobserved heterogeneity estimate. The insignificant age variable is replaced with $d 1$ or a dummy variable that models the discrete decrease in the baseline hazard. This baseline hazard function identifies age effects after controlling for the selection effect. The inclusion of this $d 1$ results in a decrease in the mass point 2 parameter from 27.27 to 7.48 with a high probability of 0.827 . However, the model cannot distinguish between two classes of firms. This shortcoming causes the hazard ratio of pre-entry variables to become equivalent to those of Thompson. The experiment of adding more dummy variables indicates that one is optimal, see Figure C.1d.

Finally, Figure A.1e illustrates that the selection effect combined with a discrete 
baseline hazard results in a lower predicted average hazard rates (PAHRs) that mimics the data. As a robustness check and to delineate the role of selection effect, the survival probability is dropped from the previous TS-DFM2 model. The resulting model, however, is imprecisely estimated and the absence of the selection variable shifts up the PAHRs and leads to a positive duration dependence, see Figure A.1f. Also, the mass point 2 parameter rises from 7.48 to 34.58 .

\subsubsection{TS-DFM Model without pre-entry experience}

As a robustness check, the pre-entry information is dropped from the original TSDFM2 model to ascertain whether DFM provides useful proxies. The last column of Table A.2 reports no significant change in the coefficient of the selection variable and reduces the mass point 2 parameter to 6.915 with probability 0.404 . Without altering other coefficients, the resulting final TS-DFM model now identifies the second latent class of the firms, and likely classifies the high-risk firms in that class. Figure A.1g reveals that the predicted hazard rates by the low-hazard function approximate those of the Weibull model. It indicates the success of the final model in accounting for the missing information present in the Weibull model. The final TS-DFM model also estimates the probability of being in the low-hazard class (class 1 ) to be 0.596 . It can reflect the $60 \%$ value in Table A.1 representing the share of the experienced firms among survivals beyond the first year. As Figure A.1g illustrates, accounting for the missing information keeps the shape of the predicted hazard rates almost intact, and captures the most of the drop in the hazard rates beyond the first year.

The results also show that compared with the DFM1 and DFM2 models, the last three TS-DFM models have lower AIC and BIC criteria. These statistics are more relevant for comparing non-nested models. Based on BIC that puts more penalty on extra explanatory variables, the final model performs better than TS-DFM1. The value of this criterion for the model without a time dummy but with pre-experience 
variables (TS-DFM1) is equal to 1232.101 whereas its value for the final TS-DFM is lower at 1211.271.

Also, this section tests if the model is selecting the experienced firms. Figure A.1h demonstrates empirical hazard rates for these firms. It demonstrates that like the Weibull model, the predicted hazard rates for the low-hazard class can, on average, represent the empirical one. It cannot track the empirical bumps because the smoothed duration dependence is based on only one discrete dummy in the model.

\subsection{Conclusion}

This chapter proposes a Two-Stage Discrete Finite Mixture (TS-DFM) hazard model for two reasons. First, it models the selection process of the high exit rate in the first year and captures the sharp drop in hazard rates. The selection model identifies the selection effect by linking a firm's post-entry survival to its relative initial production share and the entry-selection component. Second, the DFM accounts for unobserved heterogeneity by identifying two latent classes as replacements for fixed pre-entry experience variables used by Thompson (2005). The low-hazard class of the proposed TS-DFM model predicts observationally similar hazard ratios to those of the Weibull model in Thompson (2005). Accounting for selection effect removes age effect in the TS-DFM model. This model can be used to mitigate the issue of missing human capital information in either public or administrative data. 


\section{Chapter 3}

\section{The Endogenous Treatment Effect of Initial Bank Credit on a Start-up's Performance}

\subsection{Introduction}

Asymmetric information makes opaque, small- and medium-size (SMs) start-ups more susceptible to credit rationing. Credit rationing is also the optimal response of a banking system to asymmetric information. Conventional wisdom expects that SMs start-ups lack bank credit in their initial investment portfolio. However, $72 \%$ of startups in the Kauffman Firm Survey (KFS) started with business credit, personal credit, or both in 2004. In fact, among all firms, $17 \%$ started with only business credit, while $28 \%$ started with only personal credit. This chapter investigates empirically the reasons behind the observed credit-type or credit-size rationing (Gale and Hellwig (1985)) among the start-ups.

Credit-type rationing can heterogeneously affect the optimal initial capital as well

\footnotetext{
${ }^{1}$ Data included herein are derived from the Kauffman Firm Survey (KFS). Any opinions, findings, and conclusions or recommendations expressed in this material are those of the author and do not necessarily reflect the views of the Ewing Marion Kauffman Foundation.
} 
as the potential productivity of these start-ups. This chapter uses the KFS data (2004-2007) to examine two hypotheses. First, what enables a firm to acquire a specific type of bank credit (business credit or personal credit) at start-up? Second, can a firm that starts with business credit achieve higher growth in the future, versus starting with only personal credit? ${ }^{2}$

By examining the firms in the KFS at start-up, Robb and Robinson (2014) disclose that bank financing accounts for $40 \%$ of the capital structure of the firms, and that a firm starting with a higher ratio of outside debt to total capital attains higher future growth. The focus of their study on aggregate outside debt, however, overlooks the real impact of credit-size rationing on a firm's success. The access to a type of bank credit would not necessarily alleviate financing constraints at start-ups.

Robb and Robinson (2014) report that firms starting up in 2004 with previous revenues $^{3}$ had higher size of capital than home-based firms, and the latter had higher start-up capital than those without employees. The three groups had similar averages of personal bank loans of about $\$ 12000$, while their corresponding business credit monotonically decreased from $\$ 18474$ to $\$ 9180$, and to $\$ 5201$, respectively. The analysis in Robb and Robinson (2014), however, shows no link between the quality of the firms and their access to a specific type of bank credit. This chapter follows the definition of business credit and personal credit from Cole and Sokolyk (2018) to account for these kinds of heterogeneity among firms.

The two studies above fail to account for unobserved factors that might affect a firm's access to bank debt and its future performance. They evaluate factors affecting a firm's obtaining bank debt, disconnected from the impact of such debt on its success. As an extension, the model in this chapter attempts to identify high-quality firms starting with a type of bank credit and simultaneously evaluates the impact of such

\footnotetext{
${ }^{2}$ See Table B.1 in appendix B for the definition of business credit and personal credit.

${ }^{3}$ Most of these firms had inventories or external operation plants at the time of entry (Robb and Robinson (2014)).
} 
credit on their performance. The model employed accounts for unobserved factors influencing both of those relationships, as well as a firm's survival time.

To distinguish whether a firm's productivity affects its chances of accessing a type of bank credit, or whether access to such credit fosters productivity, can be challenging. Unobservable characteristics can stay with a firm over a long period and can simultaneously influence both its access to bank credit and its future productivity. If it failed to account for the shared-unobserved heterogeneity factor, a reduced form equation for a firm's performance would be prone to both omitted variable bias and endogeneity bias.

To address this concern, this chapter employs a Structural Equation Modelling (SEM) with three interrelated equations (Section 3.4 builds the model up theoretically). One equation explains a firm's access to a type of bank credit; a second equation evaluates the direct effect of this access on the firm's future growth; and the third equation accounts for the selection of firms that survived until the end of 2007. Identification can be achieved via functional forms in the structural equation model and the exclusion restrictions employed (see Appendix B.3 and section 3.5).

Unfortunately, most of how a banking system evaluates a firm's quality at start-up is unobservable. However, start-ups are likely to have disclosed any relevant evidence about their business plans and their potential scales of entry to the banking system in order to increase their chances of obtaining bank credit. A bank would presumably want this information as evidence as to whether their loans are secured and as to whether the firm seeking the loan is likely to prosper.

To identify high-quality firms selected by banks for granting business credit, the analysis uses three informative proxies as exclusion restrictions in the credit equation: a firm's entry share of tangible assets in its two-digit $\mathrm{NAICS}^{4}$ cohort, the first-year selection component calculated for tangible assets based on the decomposition in

\footnotetext{
${ }^{4}$ North American Industry Classification System
} 
Pinto (2008), and the per-capita state-level secured loans to small businesses in 2004. To identify firms that survived until 2007, the model uses the surviving component of the decomposition calculated for the revenue variable (see section 3.5).

To mitigate omitted variable bias, the SEM employs two latent variables with normal distributions. One is a proxy for the shared unobserved heterogeneity factor between starting with a type of bank credit in 2004 and revenue in 2007; the other accounts for the shared factor between a firm's survival probability until 2007 and its revenue in 2007. The maximum likelihood method used to estimate the model assumes that the latent variables are independent of all error terms in the model. ${ }^{5}$ Altogether, the resulting structural equation framework is expected to evaluate the direct effect of starting with business credit or starting with personal credit on a firm's revenue in 2007, namely endogenous treatment effect.

The results indicate that starting with business credit leads to a positive endogenous treatment effect on a firm's future revenue. By contrast, however, starting with personal credit results in a negative endogenous treatment effect. The model also pinpoints the observable entry conditions that a firm may need to have in order to secure business credit at start up. It points to factors such as a firm's better credit score, its legal status such as being incorporated, its entry size measured by its first-year revenue, and its owner's pre-entry human capital such as work experience.

The findings illustrate that of the two sources of bias for which latent variables were employed, both turn out to be important. The shared factor in the business credit equation has two effects which oppose each other: it increases the probability of obtaining business credit but reduces the future revenue of the firm. This evidence may reflect the mixed impact of adverse selection and moral hazard issues existing in the bank-credit market.

\footnotetext{
${ }^{5}$ See the Stata manual for Generalized Structural Equation Modelling.
} 
Even though banks are challenged with asymmetric information of opaque startups, they successfully select those likely to prosper (see also Cole and Sokolyk (2018)) and grant them heterogeneous types (or sizes) of bank credit. Business credit does indeed promote a firm's future growth.

The rest of the chapter is organized as follows. Section 3.2 reviews related literature. Section 3.3 describes the Kauffman Firm Survey (KFS) data. Section 3.4 provides a brief review of optimal debt contract and develops the empirical model. Section 3.5 explains the identification strategies and specifies exclusion restrictions. Section 3.6 presents the results of the estimation and discusses some robustness checks. Finally, section 3.7 presents the major conclusions reached through this analysis.

\subsection{Credit Rationing and Related Literature}

Credit rationing occurs since a banking system optimally lowers the interest rate offered on loans to attract better quality borrowers. The issue of adverse selection arises since banks cannot always accurately characterize the quality of firms seeking loans. A high interest rate may also induce the issue of moral hazard since active entrepreneurs may harvest less returns from their effort and become less motivated in maintaining their effort. A low-optimal interest rate, however, induces excess demand in the credit market (see Parker (2009)).

Credit rationing Type I refers to how, at a low interest rate, all firms of a group obtain smaller loan sizes than the amount they had applied for. Credit rationing Type II refers to how, faced with observationally identical firms, banks randomly select some firms and lend them the full amount of loans they had applied for, while turning away the remaining firms. These denied applicants cannot obtain any loan even if they are willing to pay the same repayment rate (see Keeton (1976) and Freixas and Rochet (2008)). 
Even during periods of low credit supply, Type II rationing may not necessarily occur (Berger and Udell (1992)). By contrast, however, Type I rationing seems more persistent among SMs firms. For example, the credits of Dutch entrepreneurs were cut by $20 \%$ of the amount they had initially applied for (Parker and Van Praag (2006)). For start-ups in KFS, on average, bank credit outweighs other forms of initial financing (Robb and Robinson (2014)). However, the high degree of heterogeneity in these start-ups' access to bank credit reflects a separated equilibrium in bank-credit market known as credit-size rationing (Gale and Hellwig (1985)).

Some researchers explain separated equilibrium by focusing on collateral as a nonprice term (see Stiglitz and Weiss (1981) and Williamson (1987)). Collateral functions as a self-selection mechanism through which firms may reveal their type and obtain different loan contracts (Bester (1985)). Since these models assume a fixed size of initial investment, they fail to explain loan-size rationing (Gray and Wu (1995)).

To explain the heterogeneous size of loans, some existing models rely on fctors such as bankruptcy risk, repayment rate, and a non-price term such as an applicant's funds to loan ratio (Keeton (1976), Roll et al. (1978), and Koskela (1983)). Auditing cost is another tool. In a framework where only an entrepreneur observes the revenue and banks face an auditing cost to observe it, if the venture goes bankrupt, a standard debt contract becomes an optimal contract (see Gale and Hellwig (1985) and Diamond (1984)).

A standard debt contract forces entrepreneurs to devote more effort: they surrender all outcomes to the lenders if bankruptcy occurs, but they harvest all returns above a fixed repayment if a high profit state materializes (Innes (1990)). Conditional on the Monotone Likelihood Ratio Property (MLRP), a debt contract outweighs a monotonic non-debt contract in encouraging entrepreneurs to exert effort. ${ }^{6}$

\footnotetext{
${ }^{6}$ MLRP: For any given outcome, a rise in effort leads to an increase in the probability of all higher outcomes.
} 
A two-period model encompassing both collateral and auditing cost can improve the shortcomings of a debt contract by separating a high-quality firm from a lowquality one. A high-quality firm prefers a contract asking for a lower repayment rate in the second period if the firm succeeds in the first period, while asking for a higher rate if the firm defaults in the first period. By contrast, the low-quality firm prefers the contract with the same rate in both periods. (Webb (1991)).

Freixas and Laffont (1990) add adverse selection to the model in Gale and Hellwig (1985) to address greater heterogeneity in loan sizes. The resulting second-best solution indicates how uncertainty about a firm's type, its default rate, and a bank's auditing cost reduces the loan size granted to the firm (Freixas and Laffont (1990)). Given a debt contract and the presence of loan-size rationing, a tighter credit-supply can result in both a lower interest rate and a smaller loan size (Gray and Wu (1995)).

The severity of asymmetric information for opaque SMs start-ups arises from several causes. SMs start-ups have diverse default rates that escalate monitoring costs for banks; the firms are small in scale with less diversified investment portfolios that make them more prone to exit; they may lack sufficient collateral; some of them may not pursue maximum profit, nor plan on operating for a long period; some of them might even abscond with the loan (see Tajnikar et al. (2006) and Parker (2009)).

Appendix B.2 in this chapter adds moral hazard to the framework introduced by Freixas and Laffont (1990) and abstracts to only two types of firms: high- and lowquality. Adding the uncertainty about an entrepreneur's effort enriches asymmetric information. The resulting model explains more about the observed heterogeneity in credit-size or -type granted to SMs firms with severe asymmetric information. 


\subsection{The Kauffman Firm Survey Data}

This chapter uses the confidential version of the longitudinal Kauffman Firm Survey (KFS) for the period 2004-2007. The survey considers a firm as a start-up, in 2004, if its owner(s) established it, bought the firm or bought a franchise. The survey starts with 4,928 start-ups in 2004 and tracks them annually for the following seven years until 2011. On average, $10 \%$ of them exited each year for different reasons such as acquisition, merging, or stopping operation. For each firm, KFS provides information about the demographics of a firm's owners (at most ten people) and their share of ownership, the firm's legal status, its strategy and innovation, its commercial credit score class reported by Dun \& Bradstreet, and its capital structure.

The firm's main financial information contains: trade credit, equity and assets of owner(s), personal bank loans provided by the owner(s), business bank loans obtained under the title of the firm, other personal and business loans, the maximum credit limit on both lines of credit (personal and business) and credit cards (also personal and business), insiders' debt and equity contributions (such as friends and family members), and outsider-equity providers (such as venture capital and angel investors and government).

The SEM framework in this chapter employs revenue as a proxy for the performance of a nascent firm, see Cole and Sokolyk (2018), Harkins and Forster-Holt (2014), and Hmieleski and Baron (2009). Profit might be another option for measuring the performance of a firms. Though a firm's profitability is essential at start-up, the profitability would not be guaranteed beyond the first year if the firm does not grow or expand. Identifying the opportunities for larger sales (or larger revenue) makes a firm bigger and improves its market. This growth can ultimately make the firm more profitable in the future. A proxy for a firm's growth such as revenue growth can be key to its profitability and its long-term success. 
Table B.1 in the appendix summarizes the definition of the variables used to estimate the empirical model in section 3.6.

\subsubsection{Initial Conditions and the Performance of Firms}

This section examines the types of credit that KFS firms employ to finance their capital in 2004. The first column of Table B.2 reports that $76 \%$ of them start with at least one type of credit, namely business credit, personal credit, and / or trade credit. Among all the firms, $72 \%$ begin with business credit, personal credit or both, which makes the cohort more prone to credit rationing Type I. The huge heterogeneity among the firms, however, diversifies their access to bank credit.

Among all the firms, $45 \%$ use business credit, though they may also rely on personal credit; and $55 \%$ use personal credit, though they may also rely on business credit. Up to $17 \%$ of the firms finance their ventures by business credit but not personal credit, though trade credit might still be part of their financing. Among the cohort, $13 \%$ inject only business credit. Similarly, $28 \%$ of the cohort use personal credit but not business credit, and $22 \%$ of them rely on only personal credit. The cohort also uses other types of financing: $13 \%$ of the firms start with insider debt; $4 \%$ with insider equity; and $5 \%$ with outside equity.

The second column of Table B.2 shows that, regardless of the initial entryconditions of the firms, about $62 \%$ of them survive until the end of 2007 . This column reports a survival rate of $65 \%$ for those firms that start with at least one type of credit, hereafter called any credit. The lowest rate, $58 \%$, points to the firms that use outside equity; whereas the highest rate, $69 \%$, refers to the firms that enter with only business credit.

Columns three and four focus on the correlations of initial conditions with both the survival time and the revenue of the survived firms. The third column of Table B.2 denotes that all entry conditions have very low correlations with the survival of 
firms till the end of 2007. The positive correlations range from 0.006 , related to firms with multiple owners, to 0.098 associated to the firms whose owners have at least one year of experience. The correlation is positive for variables such as any credit, business credit, white owners, owners with some college, and those with a graduate degree. The correlation appears negative for variables such as personal credit, insider debt, insider equity, outside equity, and owners who are female, are black, and are Asian.

The fourth column of Table B.2 reports the correlation between the entry conditions of start-ups and the logarithm of their revenues in 2007. This column denotes that initial access to business credit, to business but not personal credit, or to only business credit is positively correlated with the revenue at $0.142,0.111$, or 0.055 . However, starting with personal but not business credit, or with only personal credit appears negatively correlated at -0.056 or -0.090 .

The next section briefly discusses the link between credit rationing and a firm's performance to construct an empirical model. Section 3.4.1 reviews the empirical model.

\subsection{Building an Empirical Model}

This section illustrates how severe asymmetric information and heterogeneity in the quality of SMs start-ups limit their access to business credit. It also delineates the sources of endogeneity bias arising from a firm's unobserved heterogeneity factor.

Most small businesses lack adequate initial investment. For simplicity, suppose that a small business has no assets. To build its initial optimal capital to produce potential output $\tilde{y}$, the venture needs to rely on the amount of business credit, $l$, at start-up. Consider the following production function (see appendix B.2 for more 
details):

$$
\tilde{y}=\tilde{s} \theta f(l) ; \quad f^{\prime}(l)>0, f^{\prime \prime}(l)<0, \quad \lim _{x \rightarrow 0} f^{\prime}(l)=\infty, \lim _{x \rightarrow \infty} f^{\prime}(l)=0
$$

The stochastic variable $\tilde{s}$ represents the uncertainty about the firm's production. To account for adverse selection, assume that $\bar{\theta}>\underline{\theta}$, and that a bank can identify a high-productive firm, $\bar{\theta}$, with the probability of $v$, and a low-productive one, $\underline{\theta}$, with the probability of $1-v$.

If the firm goes bankrupt the bank spends auditing cost, $c$, to observe and to take away the firm's output, $\tilde{y}$ (limited liability assumption). The framework also entails a standard debt contract with repayment $R(l, \theta, y)=\operatorname{Min}(R(l, \theta), y)$ for a loan size of $l$.

To mirror the asymetric information among SMs firms, the model also accommodates for moral hazard. It assumes $p_{1}$ as the probability that a state with a higher outcome occurs if a firm exerts effort, and $p_{0}$ the probability of similar state without exerting effort $\left(p_{1}>p_{0}\right)$. As in Freixas and Laffont (1990), it also has a failure rate such as $\psi(\theta)=\frac{R(\theta)}{\theta f(l)}$. Thus the high-quality firm is characterized by $\{\bar{l}, \bar{\theta}, \bar{\psi}\}$ and the low-quality one by $\{\underline{l}, \underline{\theta}, \underline{\psi}\}$.

Based on equation (B.33), the optimal business loan for the high-quality firm becomes:

$$
\frac{1}{2} p_{1} \bar{\theta} f^{\prime}(\bar{l})=1+r
$$

The LHS refers to the marginal benefit of an additional business loan, and the RHS is the opportunity cost of that additional loan ( $r$ is interest rate).

Based on equation (B.37), the optimal business loan for the low-quality firm, however, becomes: 


$$
\frac{p_{1}}{2} \underline{\theta} f^{\prime}(\underline{l})=(1+r)+\frac{1}{2} \frac{\left(1-p_{1}\right) c f^{\prime}(\underline{l})}{f(\underline{l})}(1-\underline{\psi})+\frac{1}{2} \underline{\theta} f^{\prime}(\underline{l})\left(2 p_{1}-1\right) \underline{\psi}
$$

Comparing equation (3.2) with equation (3.3), it is seen that the latter has two additional positive terms on the RHS. The terms summarize a combination of factors related to adverse selection, moral hazard, auditing cost, and the potential productivity of the firm. Together, they prompt heterogeneous amounts of business credit among high- and low- quality firms $\left(\bar{l}>\underline{l}\right.$ since $\left.f^{\prime \prime}(\underline{l})<0\right)$. If the two terms are very large, a bank may decide to avoid granting any business credit to a low-quality firm. This outcome forces the firm to start with its owners' personal credit.

By influencing $p_{1}, \theta$, and/or $\psi$, a firm's unobserved heterogeneity factor may directly affect not only $\underline{l}$ and $\bar{l}$ through equations (3.2) and (3.3), but also $\tilde{y}$ through equation (3.1). The resulting simultaneous impacts may induce endogenity bias.

Appendix B.2.3 summarizes the results of comparative statics for equations (3.2) and (3.3). The results show that an expansionary monetary policy increases the amount of business loan granted to a high-quality firm (see equation (B.45)). However, under the same expansionary policy, the presence of adverse-selection and moralhazard parameters can also cause the banks to reduce the size of business loans granted to a low-quality firm ( see equation (B.47)).

Assuming that banks use all available factors to identify high-quality SMs firms, the results above provide more evidence for explaining Type I credit rationing. We would expect that the chances of high-quality firms starting with business credit increase with a higher supply of money. In other words, the following null hypothesis can be checked for a high-quality firm:

$$
H_{0}: \frac{\partial \operatorname{Pr}(\text { BusCredit })}{\partial M}>0
$$

Based on inequality (B.48) in appendix B.2.3, an increase in the proportion of 
high-quality firms, $\bar{\theta}$, also increases the optimal sizes of business loans that banks grant to them. However, with the presence of asymmetric-information parameters, an increase in the portion of low-quality firms, $\underline{\theta}$, may cause the banks to cut the sizes of business loans to low-quality firms (see equation (B.50)). So, the grant of heterogeneous amounts of business credit to different firms cannot be random. The argument can support Type I credit rationing.

If $X$ reflects information about $\bar{\theta}$, we would expect that, on average, it increases the chances of a representative high-quality firm to start with business credit. In other words, the following null hypothesis can be checked for a high-quality firm:

$$
H_{0}: \frac{\partial \operatorname{Pr}(\text { BusCredit })}{\partial X}>0
$$

\subsubsection{Structural Equation Modelling (SEM)}

This section distinguishes between business credit and personal credit to investigate the role of credit-type rationing on the future growth of a SMs start-up. Two SEM frameworks, one for business credit and one for personal credit, are estimated for this purpose. Figure 3.1 depicts the SEM for business credit. It encompasses: (1) a Probit model to account for whether a firm starts with business credit in 2004, which reveals a firm's type; (2) a Probit model to account for whether a firm survives to the end of 2007, which handles sample selection bias; and (3) a linear model, which uses the logarithm of revenue in 2007 as its dependent variable. The revenue equation also accommodates a dummy variable for business credit with a coefficient such as $a$.

In Figure 3.1, $X$ is a vector of control variables such as the characteristics of a firm and its owner (see Table B.1). Two shared-unobserved heterogeneity factors, SUH1 and $S U H 2$, both with $N\left(0, \sigma_{i}^{2}\right)$ link the equations. Latent factor $S U H 1$ accounts for the endogeneity bias if its coefficient $k 1$ appears significant, and latent factor 


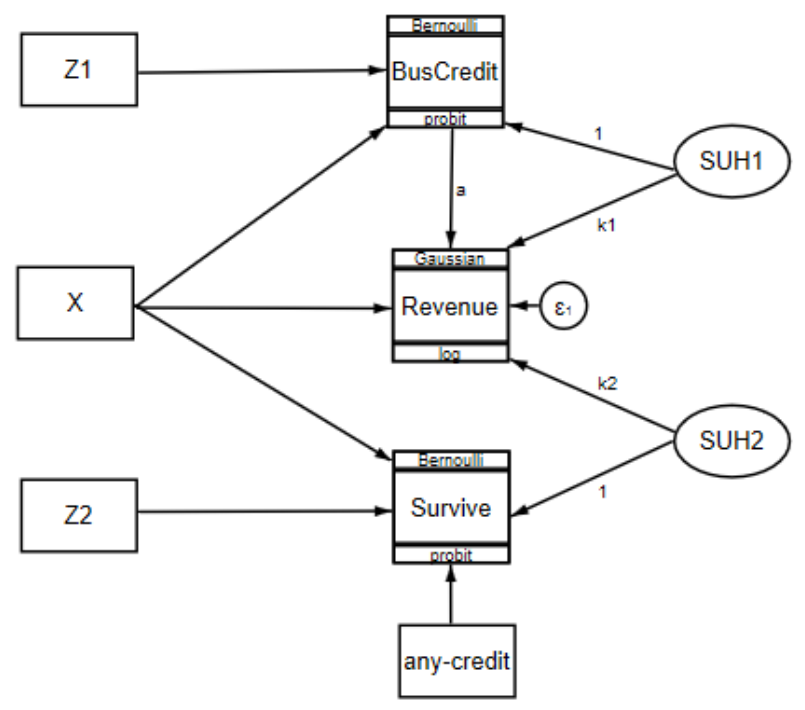

Figure 3.1: The SEM framework accounts for both surviving selection bias and endogeneity bias

SUH2 handles surviving selection bias if its coefficient $k 2$ turns out to be significant. The scale constraints impose unit coefficients for $S U H 1$ in the credit equation and for $S U H 2$ in the survival equation. The error $\epsilon$ in the revenue equation is iid with $N\left(0, \sigma_{\epsilon}^{2}\right)$, and independent of latent variables as well as all exogenous variables in the system.

In Figure 3.1, the dummy variable BusCredit equals 1 if a firm starts with business credit but not personal credit, and the dummy variable Survive equals 1 if a firm has survived by the end of 2007. The dummy variable any credit in the survival equation equals 1 if a firm starts with up to three credits, namely business, personal, and/or trade credit. ${ }^{7}$ In the revenue equation, the dependent variable gets a missing value for those firms that exited before or during 2007. If both coefficients $k 1$ and a turn out to be significant, it is an indication of the endogenous treatment effect arising from starting with business credit on the firm's future revenue (see Skrondal

\footnotetext{
${ }^{7}$ As an experiment the business credit and survival equations were connected by adding $S U H 1$ to the survival equation; however, its coefficient turned out to be insignificant (or the model did not converge). This means that the survival equation can be detached from the credit equation.
} 
and Rabe-Hesketh (2004) and appendix B.5 for more discussion).

The second SEM framework, which is not depicted here, evaluates the role of personal credit. The framework replaces business credit with a dummy variable equal to 1 for the firms that started with personal credit but not business credit, and 0 otherwise.

\subsection{Identification}

In Figure 3.1, vector $Z 1$ contains three exclusion restrictions to identify high-quality firms that obtained business credit. Vector $Z 2$ contains an exclusion restriction to identify firms that survived until 2007. The following sections discuss these exclusion restrictions.

\subsubsection{Exclusion Restrictions for the Business-Credit Equa- tion}

Each of the three exclusion restrictions in the credit equation, $Z 1$, need to satisfy two conditions. First, they should not be correlated with the error term of the revenue equation. With the SUH1 taking care of the shared unobserved heterogeneity factor affecting both credit and revenue equations, and the fact that all exclusion restrictions explained below are pre-determined in 2004, we can assume that they have no correlation with the shock or the error term in the revenue equation in 2007. The model could also be considered as a recursive one. Second, the exclusion restrictions should directly affect a firm's access to business credit at start-up without directly affecting the firm's future revenue. ${ }^{8}$ What follows explores this condition.

The first exclusion restriction in the credit equation is a firm's entry share of

\footnotetext{
${ }^{8}$ There is no way that revenue in 2007 affects either variables determined in 2004 or the chance of obtaining a type of bank-credit in 2004.
} 
tangible assets among its two-digit North American Industry Classification System (NAICS) in the cohort. It can inform banks about the relative scale of a firm among its cohort. With a promising entry scale and thus potential productivity, a bank will be more willing to contribute to the capital of the firm by granting it business credit. This additional funding helps the firm to start with its optimal capital and thus to succeed.

The entry share may also provide valuable information about a firm's commitment as well as its low risk for repaying the loans. Panel A in Table B.3 unveils the way that the entry share of tangible assets may perform as a proxy for unobserved-quality information; the information that helps a banking system to select high-quality firms for granting business credit. If the entry share could pinpoint firms likely to prosper because of better observable entry conditions, it would also contain some information about other relevant unobserved-quality factors.

Table B.3 illustrates that the average entry share of tangible assets for the firms that started with only business credit is higher than for the others. The difference between these two averages in the third column is statistically significant. In contrast, however, the average value for the firms starting with only personal credit is significantly much smaller than the average value for the rest of the firms. The entry share seems to be relevant in distinguishing between these two groups.

Almost half of the firms in the Kauffman Firm Survey enter with one or no employee other than their owners. However, larger scale firms with more than one employee have a significantly higher average share of tangible assets.

Table B.3 reveals the importance of pre-entry human capital in accessing the bankcredit market. Experienced entrepreneurs who had run at least two other businesses in the past, as well as those with graduate degrees started with a relatively higher average scale of tangible assets. Also firms that can commercialize abstract knowledge are in a better position to present themselves to the credit market. The average entry 
share turns out to be significantly higher for firms with intellectual property, with comparative advantages, and with corporate legal status at the time of entry.

Altogether, the entry share of tangible assets pinpoints firms with higher potential productivity for success. Conditional on the above observable elements, we would expect that the entry share is also associated with other unobserved-quality factors affecting a bank's decision. The entry share of tangible assets might be relevant to identify high-quality firms that could convince banks to give them business credit.

Panel B in Table B.3 indicates that the entry share of tangible assets has a significant positive correlation with business credit and a significant negative one with personal credit. Further, the share has insignificant correlation with the logarithm of revenue in 2007. The evidence suggests that a firm's entry scale of tangible assets may affect the revenue of the firm indirectly through the firm's access to a type of bank credit.

The second exclusion restriction in the credit equation reflects the first-year selection component of tangible assets. It is separately calculated for agricultural and non-agricultural sectors based on the formula in Pinto (2008) (see appendix B.4 for the decomposition).

The selection component measures the exit effect. If none of the firms exit in the first year, the exit effect is zero. However, if some firms exit in the first year, the component can reveal the average difference between the quality of tangible assets selected by surviving firms and those selected by exited firms both at the time of entry. The entry component also entails information about the effectiveness and the reliability of initially selected tangible assets by those firms passing the first year.

Opaque, small businesses with limited social network and low-quality entry factors are more subject to the life-cycle theory of small-business finance (Berger and Udell (1998)); they need to rely on their personal credit and/or lending from friends and relatives to kick-start their business. In contrast, however, firms with higher quality 
at start up would be less subject to this theory and may directly start with external funding such as business credit. Besides, Abbring et al. (2005) demonstrate that the entry decisions of Texas bars can explain why $20 \%$ of them exit in less than one year. Thus, the initially selected tangible assets of those firms in KFS that started with heterogeneous amounts of business credits, and which survived the first year, should have revealed their relatively higher quality to a bank.

The first column in panel A of Table B.4 unveils the way that the entry selection component informs us about the quality of these firms. The entry component has a significant and positive correlation with the initial tangible assets of the firms starting with business credit; however, it has an insignificant correlation with the initial tangible assets of the firms starting with personal credit. It also has an insignificant correlation with the logarithm of revenue in 2007. We may expect that the proxy would inform us about other unobserved quality elements used by banks to select firms for business credit.

The third exclusion restriction in the credit equation represents the per-capita state-level secured loans to small businesses in 2004, calculated separately for agricultural and non-agricultural sectors. If a firm has enough high-quality factors to convince banks and to secure the repayment of loans, such status resembles collateral and could function as a self-selection mechanism in screening borrowers (Bester (1985)). If secured loans are given to firms with better quality, there should be a positive correlation between the tangible assets of firms starting with a business credit and the per-capita state-level secured loans.

The third column in panel A of Table B.4 illustrates this relationship. The percapita secured loans have a positive and significant correlation of 0.231 with tangible assets of the firms starting with business credit, but an insignificant one with the tangible assets of the firms starting with personal credit in 2004 . We would expect this proxy to reflect some of the unobserved-quality information useful for distinguishing 
high-quality firms. Also, these firms would have a greater chance of getting larger size of business credit if the supply of these secured loans was larger. The proxy is also significantly correlated with the logarithm of revenue in 2007; however, its small value of 0.088 compared to 0.231 mitigates our concerns.

\subsubsection{Exclusion Restrictions for the Survival Equation}

In the survival equation, the exclusion restriction is defined as the average value of survival components of revenue during a firm's years of operation (calculated separately for agricultural and non-agricultural sectors using the formula in Pinto (2008)).

For each year, the survival term measures the difference between the average revenue of the surviving firms in that year and the corresponding value for them in the first year. Based on the review of KFS data, Robb et al. (2009), firms with higher revenues survived longer. The survival component reveals information about the part of revenue that is associated with the survival time of a typical survived firm.

If a firm survives for three years, the exclusion is calculated as the average of the survival components in those three years. So, all the firms in the non-agricultural sector that survived three years would have the same value for this exclusion restriction. The proxy can account for the average impact of all economic conditions affecting the survival time of a typical firm through revenue. Panel B of Table B.3 reports a positive and significant correlation of 0.38 between the survival component and the surviving dummy variable. The component is not correlated with the revenue of the firms in 2007.

The next section discusses which factors can make firms heterogeneous in starting with different types of credit, and how that affects their future revenue. 


\subsection{Empirical Results}

This section discusses the results obtained from estimating both SEM frameworks, depicted in Figure 3.1. Table B.5 reports marginal effects for the main variables used in both the business credit framework, Framework A, and the personal credit framework, Framework B.

\subsubsection{Results of SEM for Business Credit}

Starting with exclusion restrictions, the first column of Framework A in Table B.5 shows a significant marginal effect of 1.5 for the survival component in the survival equation. The second column illustrates that a firm's entry-share of tangible assets can effectively identify a high-quality firm selected by a bank. It increases the chances of a high-quality firm to start with business credit by 31.4 percentage points. The marginal effect of the entry-selection component of tangible assets is also positive and significant at 0.005 . The same column exhibits that one percent growth in the per-capita secured loans would escalate the chances of a high-quality SMs firm of obtaining business credit by 2.1 percentage points. This finding confirms the first hypothesis developed in equation 3.4 in section 3.4 .

The significant coefficients of -1.096 for $S U H_{1}$ and -8.072 for $S U H_{2}$ in the third column of Framework A confirm that accounting for both endogeneity bias and sample selection bias are important. The shared factor $S U H_{1}$ may partly account for issues such as adverse selection, moral hazard or a mix of both. Its negative coefficient denotes that banks, even after examining the observable quality factors and collateral, could not completely remove the threat of these issues. Some low-quality and risky start-ups successfully deceived the banks and obtained business credit. That reduces the average performance of the surviving firms in the future.

Even in the presence of asymmetric information, banks appear to be successful in 
selecting high-quality firms in this cohort. The third column in Table B.5 also discloses a significant, positive endogenous treatment effect for granted business credit. On average, SMs firms with higher quality at entrance are more likely to convince banks to grant them business credit. A bank granting business credit to a firm might also decide to audit that firm on a periodic basis. The threat could force a high-quality firm to expend more effort which could result in higher growth (Khalil and Parigi (1998) and Besanko and Kanatas (1993)). Starting with business credit boosts a firm's future revenue by 1.47 percent (see the third column).

\subsubsection{Results of SEM for Personal Credit}

Framework B in Table B.5 displays the results for the structural equation modelling of personal credit. As before, the fourth column reports a positive and significant marginal effect for the survival component, 1.580. In the fifth column, however, the results differ for the exclusion-restrictions of the personal-credit equation. First, the coefficients of both the entry share of tangible assets and the entry-selection component turn out insignificant. So, both the reliability and the entry scale of tangible assets for a typical high-quality firm would not induce it to start with personal credit. Second, the coefficient of secured loans, though significant, turns out negative. One percent growth in the supply of secured loans reduces by 2.7 percentage points the likelihood that a high-quality firm starts with personal credit.

These findings confirm the presence of credit-type or -size rationing, i.e., rationing Type I disscued eariler. A tighter monetary policy, a lower quality of firms, or both can reduce the share of SMs firms starting with business credit while increasing the share of those entering with personal credit in a cohort. Besides, obtaining business credit could be very expensive to a firm since it may lose its collateral if it goes bankrupt. Because of that, firms starting with business credit are likely to invest it efficiently and avoid over-optimistic inspirations, see Ang (1991). Either because of 
their low-quality or because of avoiding the above mentioned costs, firms that start with personal credit are likely to start with lower than their optimal level of capital.

The sixth column reflects the importance of handling both sources of bias. Also, it indicates that starting with personal credit in 2004, on average, decreases the revenue of a firm in 2007. A firm's low quality and its inefficient initial capital probably stay with it and plunge its future revenue growth by 1.65 percent.

\subsubsection{Robustness Check}

As a robustness check, the bottom part of Table B.5 reports four likelihood-ratio (LR) tests for examining over-identification. The first two LR tests relate to dropping all exclusion restrictions reported in the upper part of the table. The second and third refer to dropping additional exclusion restrictions. To account for nonlinearity, various combinations of the squares and polynomials of the exclusion restrictions are added to both empirical frameworks. The findings indicate that the augmented models result in no significant changes in the estimation of the parameters reported in the previous sections. ${ }^{9}$ Thus the second and third LR tests in Table B.5 relate to dropping all of the exclusion restrictions present in one of the augmented models (similar results obtained from other augmented models). All $\tilde{\chi}^{2}$ statistics turn out to be very high and significant. These findings can confirm the robustness of the estimated empirical models (see Skrondal and Rabe-Hesketh (2004)). ${ }^{10}$

\footnotetext{
9 The foucs is on those augmented models that their estimation procedure converged.

${ }^{10}$ Some macroeconomic variables (measured in 2004) and the principle components of a set of them were also used to account for the impact of macroeconomic conditions on the dependent variables. The list of these variables are: the number of establishments at state level (county level and Zip code level) with different employee size (at three digit NAICS), the number of employment at state level (county level and Zip code level), the number of loans based on agriculture and non-agriculture sectors, per-capita commercial and industrial loans at state level, total loans to individuals, total loans and lease. Most of these variables were insignificant and their presence did not change the results and conclusions reported in the thesis.
} 


\subsubsection{The Observable Quality Factors}

Table B.6 depicts the results estimated from both frameworks and explores the roles of other entry conditions (Thompson (2005),Cooper et al. (1992), and Low and MacMil$\operatorname{lan}(1988))$.

\section{The Effect of entry conditions on Survival time}

The results in columns one and four of Table B.6 disclose that if a firm starts with any credit such as business, personal, and/or trade credit, its probability of survival time increases by 5.2 percentage points. A better credit score also improves a firm's chance of surviving longer by 1.9 percentage points. ${ }^{11}$ The survival probability rises if a firm markets both products and services; and if its owner has human capital such as work experience, a college or a graduate degree. However, a small business starting with its owner's equity is less likely to survive till the end of 2007.

\section{The Effect of entry conditions on bank credit at start-up}

Columns two and five investigate the second hypothesis developed in equation 3.5 in section 3.4. They illustrate that a firm with a better credit score has a greater chance of obtaining business credit by 3.4 percentage points, and less likely to start with personal credit alone by 2.6 percentage points (see also Robb et al. (2009)). The chances of getting business credit at start-up increase when a firm has the qualities such as incorporation, owning intellectual property, selling both products and services, and having an owner with previous business experience.

Fairlie et al. (2016) show that black entrepreneurs started with smaller amounts of both outside debt and other sources of financial capital. Their study reveals no evidence of racial bias limiting the injection of outside debt into their business. They

\footnotetext{
11 A firm with a credit score of 1 is an indicator of a high-quality, low-risk firm and a firm with a credit score of 5 represents a very high-risk, low-quality firm.
} 
also argue that black entrepreneurs have lower credit scores compared to white owners, and this factor prevents them to start with outside debt. Their findings confirm the results presented in Table B.6 that the racial characteristics of the owners do not affect the chances of starting with business credit; rather, it is the credit score that either increases or decreases those chances.

Table B.6 indicates that a female entrepreneur has a lesser chance of obtaining business credit and is more likely to start with personal credit only. Coleman and Robb (2009) also reported similar results for the financial status of such firms. After a thorough review of the capital and performance of women-owned firms in the KFS, they conclude that female entrepreneurs depend heavily on their personal equity and personal sources of debt.

\section{The Effect of entry conditions on revenue}

Columns three and six show that, regardless of starting with business or personal credit, the revenue of a firm is positively affected by its corporate status, by its entry scale (measured by its revenue in the first year), by having multiple owners at startup, by devoting more hours to the business, and by its owner's human capital such as pre-entry work experience and the experience of running other businesses in the past.

Though the number of firms owned by women has been growing in recent years, the results in Table B.6 show that being a female owner reduces a venture's revenue by about 4.6 percentage points. This finding confirms previous studies that womenowned businesses are more prone to smaller sales, lower profit, and smaller number of employees (See Coleman and Robb (2009), Rosa et al. (1996); Robb (2002); Watson (2002)).

Overall, the results in Table B.6 show that firms that started with personal credit (but not business credit) are more likely to be categorized as low-quality firms. For 
example, they are more likely to have characteristics such as not being incorporated, not having intellectual property, having low credit scores and less-experienced owners, and likely to have started with money borrowed from friends and family members. Table B.6 also shows that having more than one owner affects a firm's revenue positively, regardless of starting with personal or business credit. Since the majority of the firms in the KFS are solo entrepreneurs, these findings suggest that the owners of those firms who started with personal credit are more likely to be among the least able entrepreneurs.

Åstebro et al. (2011) confirm this finding. They argue that self-employed entrepreneurs are more likely to be drawn from the tails of the ability distribution, and the average of their incomes is less than that of wage workers. This would also indicate that the owner of a small business which started with personal credit (especially a firm with a single entrepreneur) is likely to be of low ability. Also, Åstebro et al. (2011) show that a self-employed entrepreneur is more likely to have a history of spells of unemployment, job switching, and job mismatch. In other words, the work history of such an entrepreneur may also affect the quality of his/her firm. In contrast, the owners of the firms that started with business credit are likely to be high-ability individuals with relevant work experience, even if they might have been unemployed or switched their jobs in the past. The fact that they were able to acquire business credit would indicate that the banks considered their firm(s) to be of high quality and that the owner(s) had high-business abilities.

\subsection{Summary and Conclusion}

Though $72 \%$ of firms in the Kauffman Firm Survey started with bank credit, they were granted heterogeneous types and sizes of credit. To empirically explore the reasons behind this rationing and its influence on the firms' performance, this chapter 
distinguishes between business and personal credit. It uses a structural equation model with two shared, unobserved heterogeneity factors to avoid endogeneity bias and to link the following three equations: one equation for the survival time of firms, one for the type of bank credit they started with in 2004, and one for their revenue in 2007. The results identify firms starting with business credit as high quality. The identification is based on revealing unobservable initial quality using three proxies: the firm's entry share of tangible assets, the entry-selection component of tangible assets, and the per-capita state-level secured loans. Also, start-ups with better human capital, better credit risk, incorporated status, and owners who exert greater effort are more likely to start with business credit. The results reveal a positive endogenous treatment effect on the revenue of firms starting with business credit, whereas, for firms starting with personal credit only, the effect is negative. 


\section{Chapter 4}

\section{Evaluating the Impact of Knowledge} Spillover on Start-ups: Using

\section{Collaboration as a Proxy for Knowledge}

\section{Spillover}

\subsection{Introduction}

Many studies have investigated the impact of knowledge spillovers on economic growth by using proxies for the spillover, such as the share of new firms, R\&D expenditures, and knowledge localization instruments. Studies of large firms show that R\&D can play a significant role in transferring knowledge into their operation. Other related studies demonstrate how universities can affect regional macroeconomic variables such as output, employment, and/or wages.

In contrast, this chapter focuses on Small- and Medium-size (SMs) firms in the Kauffman Firm Survey (2004-2011). To identify the impact of knowledge spillovers on the performance of an SMs venture, this study uses a better proxy for knowledge

\footnotetext{
${ }^{1}$ Data included herein are derived from the Kauffman Firm Survey (KFS). Any opinions, findings, and conclusions or recommendations expressed in this material are those of the author and do not necessarily reflect the views of the Ewing Marion Kauffman Foundation.
} 
spillovers such as a firm's direct teaming with other companies, universities, government labs and research centres, and/or teaming with the sources of patents. With such collaboration, a firm can benefit from innovation, production efficiency, comparative advantage, networking, and social capital. These factors facilitate transferring abstract knowledge into their operation. This chapter empirically investigates this process by examining whether teaming with other institutions has any direct causality effect on the future performance of the small businesses in the KFS data.

For small businesses in the KFS, the principal method of transferring absolute knowledge into comparative advantage relates to teaming with other companies. Nearly $30 \%$ of them acquired their comparative advantage by this method. In contrast, only about $8 \%$ of them increased their comparative advantage by teaming with universities, and $4 \%$ by teaming with government laboratories and research centres. Most of the studies related to knowledge localization, however, rely on the role of universities. These studies and those that use the ratio of new firms as the proxy for commercializing knowledge have focused on the macroeconomic outcomes rather than a firm's performance. Defining a proxy that takes into account all types of teaming together would entail a broader range of the creation of economic knowledge for small businesses.

Audretsch (1995) argues that SMs firms undertake less R\&D expenditures compared with large firms. Also, the collaboration of the SMs firms with research institutions rather than conducting their own R\&D expenditures is more likely to lead to innovation (Audretsch and Vivarelli (1996)). The KFS data also reveal that the experience of teaming is more relevant to the creation of economic knowledge for a firm rather than its R\&D expenditure is. For example, in 2007, about $30 \%$ of the firms obtained their comparative advantage as a result of teaming, and the fraction steadily increases to $36 \%$ in 2011. However, among firms with a comparative advantage, $20 \%$ of them conducted R\&D during the same period (see Table C.1). Moreover, about 
$35 \%$ of the firms with no R\&D employees still had teaming experience during that period.

Similarly, among small businesses with less than or equal to seven employees, a greater percentage of them engaged in teaming compared with those that undertook R\&D. Only after the total number of employees in a small business exceeds six, does the percentages converge, i.e., about the same percentage of firms experienced teaming as the percentage which undertook R\&D (see Table C.3). If comparative advantage is used as a sign of commercializing economic knowledge, a firm's teaming experience appears to be a better proxy than R\&D expenditures for knowledge spillover associated with small businesses.

Though teaming defined as above can be considered as a treatment (in the sense of something administered to experimental units), it would be hard to accept it as a random treatment isolated from a firm's influence. Such non-random influences could result in a biased estimation of the treatment effect. For example, we do not know why SMs firms in the KFS chose different partners for collaboration. One assumption is that their selections were meant to maximize their profit (Leyden and Link (2013)). Alternatively, collaborations might be driven by personal contacts and/or by intellectual curiosity.

To identify the direct effect of this treatment, the analysis not only needs to account for selection bias resulting from a firm's specific characteristics, but it also requires to account for shared unobservable factors such as overall economic shocks and countrywide laws that influence the outcome of all firms.

To address these identification issues, the present empirical analysis implements a combination of matching and difference-in-difference approaches. This method has more power in removing omitted variable bias and selection bias resulting from observable and unobservable heterogeneous factors (see section 4.3). The analysis employs different matching algorithms to better picture a robust causality effect of teaming 
on a firm's performance.

The results of this chapter reveal that firms with teaming treatment experience a higher growth in real revenue, in employment size, and in per-capita real wages.

The next section presents a brief literature review. Section 4.3 discusses the empirical strategy employed in this chapter, and section 4.4 reviews the KFS data. Section 4.5 presents the empirical results, and section 4.6 concludes.

\subsection{Literature Review}

The knowledge spillover theory of entrepreneurship explains how economic knowledge is created and commercialized (Audretsch (1995); Acs et al. (2009), Acs and Sanders (2013), Hayter (2013)). In contrast with traditional growth theory where knowledge accumulation prompts endogenous growth (Romer (1990)), knowledge spillover theory focuses on entrepreneurship. Entrepreneurs overcome the knowledge filter, i.e., they convert intellectual knowledge to economic knowledge (Acs and Plummer (2005) and Acs et al. (2009)). They are the missing link in the growth theory for filtering or commercializing knowledge to bring about new products and services (Acs et al. (2004), Braunerhjelm et al. (2010)).

Entrepreneurs in Schumpeter's creative destruction theory disrupt the equilibrium in the economy and create a new one through innovation (Hayter (2013)). By embracing uncertainty and seeking opportunities for marketable future goods and services, entrepreneurs drive higher economic growth (Carlsson et al. (2013) and Venkataraman (1997), for Economic Co-operation and Development) (1998)). Not all start-ups survive. However, some - which might be termed high-quality - are more productive, survive longer, and boost the economy (González-Pernía and Peña-Legazkue (2015); Wong et al. (2005), Colombelli et al. (2016)). For example, those firms created by 
the employees of existing firms are more likely to come up with innovation in production (Wong et al. (2008)). Some empirical studies use the number or the share of new firms as a proxy to measure the role of knowledge filtering on GDP growth and employment (Acs et al. (2012), Van Stel and Suddle (2008))

Incumbents can also commercialize knowledge and affect the economy of their region through absorptive capacity (Qian and Jung (2017)). Absorptive capacity refers to recognizing and applying new knowledge in a firm's operation (Cohen (1990)). It is possible that (or we speculate that) young firms can also increase their absorptive capacity if during their operation, they are faced with issues or problems pushing them to team up with other firms or research institutions. Collaborations may also develop later, during the follow-up stages after entry. It can be encouraged by legislation such as the Small Business Innovation Research (SBIR) Bill, enacted in the USA in the early 1980s (Audretsch (2003)). Collaboration causes a firm to endogenously grow both by engaging in knowledge filtering and by creating network capital.

Network capital is an effective instrument in accessing sources of knowledge. It improves a firm's quality and induces innovation, technical success, and growth for the firm (Huggins and Thompson (2015), Knoben and Oerlemans (2006), Pavitt (2003), Portes (1998); Putnam (2000)). Innovative network refers to the knowledge resulting from the interaction between producers, suppliers, customers, universities and research institutions (Karlsson and Warda (2014)). In addition to yielding intellectual benefits, collaboration with universities enhances a firm's social capital such as credibility, which can pave the firm's path toward more innovative opportunities (Wang and Shapira (2012)).

While SMs firms may undertake little R\&D themselves, they prompt most innovation (Audretsch (1995)). Compared with large firms, the innovation of small firms relates more to the spillovers from research institutes than from their $R \& D$ expenditures (Audretsch and Vivarelli (1996)). 
Networking and teaming with researchers and advisors facilitate both solving technical issues and knowledge spillover (Cockburn and Henderson (1998), Brüderl and Preisendörfer (1998), Acs et al. (2009), Morgan 2004). Leyden and Link (2013) show that a firm maximizes its profit by choosing to collaborate with different R\&D partners, whether the latter are academic or non-academic. Only about $10 \%$ of the firms in Europe cooperated with universities in 2000 (Veugelers and Cassiman (2005)), while $15 \%$ cooperated in the USA (Hall et al. (2001)). Programs such as interfirm networking, extending the external knowledge network, improving networking in follow-up stages can also improve a firm's innovation and growth (Hayter (2013), Huggins and Johnston (2010), Baum et al. (2000), Partanen et al. (2008), Greve and Salaff (2003), Starr and MacMillan (1990)). ${ }^{2}$

Many recent studies have focused on the macroeconomic impact of localized knowledge spillovers. For example, research institutes, especially universities, can foster the growth of science-based industries around them (Jaffe et al. (1993); Varga (1998); Anselin et al. (2000)); they can prompt the creation of new firms (Bonaccorsi et al. (2013), Fritsch and Aamoucke (2013), Audretsch and Lehmann (2005), Baptista and Mendonça (2010) ); they can lead to the acquisition of more patents (Jaffe et al. (1993), Acs et al. (2002), Piva et al. (2011)); and through R\&D expenditures they can cause the regional wages to increase (Kantor and Whalley (2014)).

Sabetti (2016) examines whether regional knowledge leads to innovation among start-ups in the KFS. He uses the average five-year R\&D expenditures of local Higher Education Sector (1999-2004) as a proxy for the regional R\&D intensity. The regional R\&D intensity increases the probability that a firm spends on R\&D (extensive margins) and also raises the amount of R\&D expenditures (intensive margins) at start-up.

\footnotetext{
${ }^{2}$ As an evidence, universities specialized in nanotechnology and biotechnology collaborate more with industry (Thursby and Thursby (2011)); firms specialized in chemical and pharmaceutical industry more likely engage with research institutes (Veugelers and Cassiman (2005)); and universities specialized in applied sciences and engineering can create more new firms (Bonaccorsi et al. (2013)).
} 
His results, however, show that the effect is significant only for two sub-samples of firms: the sample of medium- or high-tech firms, and the sample of large firms.

Also, Huynh and Rotondi (2009) show that the impact of regional R\&D intensity is three times stronger for the sub-sample of large Italian firms with more than 500 employees. Using the whole sample of the firms, however, the coefficient of the interaction between small firms and regional R\&D intensity variables turns out to be insignificant. They show that regional R\&D intensity increases the probability of investing in R\&D expenditures for large firms. Also, the average of R\&D intensity for the firms cooperating with universities is higher than that of other firms.

Since the majority of the firms in the KFS are small firms with fewer than 10 employees, they are less likely to rely on R\&D expenditures as the main source of knowledge spillover. Also, during 2007 to 2011, around 8\% of surviving firms in the KFS collaborated with universities. These findings suggest that the driving force of regional R\&D intensity may not fully reflect the sources of knowledge spillover for the majority of small businesses in the KFS. Compared with R\&D expenditures, the proxy defined in this chapter (collaboration) would better reflect the sources of knowledge spillover for the small businesses in the KFS.

Recently, few studies have focused on the effect of knowledge spillover on the outcome of SMs firms. Some have examined R\&D subsidies to evaluate the positive effect of knowledge spillovers at the firm-level data (Czarnitzki and Delanote (2015)). Kobayashi (2014) uses R\&D expenditures as a proxy for knowledge spillovers. He shows that Japanese SMs firms receiving R\&D tax credit (treatment group) spent twice as much on R\&D expenditures compared to the control firms. These studies rely on either the Difference-in-Difference approach, or Average Treatment effect on Treated (ATT) based on matching approaches.

Only few studies in this area have focused on the combination of matching approach with Difference-in-Difference approach (CDiD). The latter method is more 
robust in reducing the bias arising from a firm's self-selection into a treatment (see section 4.3). Using CDiD for Finnish SMs firm, Karhunen and Huovari (2015) find that R\&D subsidies increase employment but have no effect on labor productivity. Arnold and Javorcik (2009) implement a similar approach for Indonesian firms. They show that firms with Foreign Direct Investment (treatment group) obtain higher total factor productivity; achieve higher labour productivity; and undertake more import and export compared with control group.

Similarly, this chapter focuses on SMs firms such as those in KFS. It contributes to the above studies by focusing on a firm's direct teaming with other firms, and/or with academic and non-academic institutions to identify the effect of knowledge spillovers on their performance.

The next section reviews the features of CDiD approach employed for empirical analysis in this chapter. It illustrates how this approach can be useful in better identifying the direct causal effect of teaming on a firm's outcome.

\subsection{Empirical Strategy}

When an analysis is based on non-natural experimental samples, identifying the true causality effect of a firm's action on its performance can be challenging. Having a good proxy conveying relevant information about that action might not necessarily be enough. Other disturbances can lead to a biased estimation of the causality effect. The true effect can usually be confounded at least by two sources of bias: selection bias (omitted variable bias) and unobserved elements that may stay with a firm for a long time.

An omitted variable may simultaneously affect both a treatment variable and its resulting consequence. In regression analysis, the issue can lead to correlation between the treatment variable and the error term of the regression. The lack of accounting 
for a firm's heterogeneity can also lead to such a correlation and can induce selection bias.

There are two ways of tackling omitted variable bias (selection bias) to identify the true causality effect of a treatment. The first one depends heavily on the functional form and/or the existence of an instrumental variable (IV) that satisfies two conditions, see Angrist et al. (2009). ${ }^{3}$ First, conditional on observed covariates, the IV should be uncorrelated with the omitted variables affecting both the variable of interest and the outcome variable (or the error term). This feature is called the selection on unobservable. Second, the IV should be correlated solely with the variable of interest. It should play the role of an exclusion restriction, i.e., it should affect the outcome variable such as $Y$ only through the channel of affecting the variable of interest. Finding an IV that satisfies these two conditions can be hard, however.

Another way of handling selection bias could be through removing the heterogeneity effect and creating more homogenous samples of treatment and control groups. Heterogeneity arises since a firm's future development, its interaction with other firms and institutions, and its success can be strongly affected by its owners' decisions at the time of entry. What we observe as a firm's characteristics at start-up may reveal its potential operation and may reflect all thoughts and experiences of its owners. The potential link between a firm's selection into entry (its heterogeneity) and its subsequent behaviour can confound evaluating its current and future actions.

Classifying firms based on their observed heterogeneity can mitigate selection bias. By providing an environment mimicking a random sample where a treatment operates independently from interfering factors, the true causality effect of the treatment can better be identified. The matching approach used in this chapter aims to remove the heterogeneity among the treatment and non-treatment (control) groups. The

\footnotetext{
${ }^{3}$ Methods such as local average treatment effect, limited information maximum likelihood, and two-stage least squares can mitigate the omitted variable bias. Similar to IV method, the reliability of these methods depends heavily on the existence of an instrument.
} 
approach is also less subject to the functional-form restrictions and can strengthen the parallel assumption of a treatment (see section (4.3.4)).

However, having a good measure of a treatment as well as accounting for selection on observables would not necessarily remove unobserved heterogeneity. Some unobserved heterogeneity can stay with a firm for a long time and might interfere with the true effect of a treatment on the performance of the firm. Also, there might be other unobserved factors that can influence the outcomes for both the treatment and control groups.

The next section discusses how Difference in Difference (DiD) approach handles such unobserved heterogeneity. Overall, we would expect that a good measure of a treatment together with a combination of matching and DiD approaches would result in a stronger identification strategy.

\subsubsection{Difference in Difference Approach}

This section discusses how the DiD approach can remove some of the unobserved omitted variables that can affect an outcome such as $Y$ for those in the treatment group, in the control group, or both. The DiD approach assumes parallel trends, i.e., with the absence of treatment, the counter-factual trend for an outcome variable would be similar for both the treatment and control groups. Suppose we have data for at least two periods: the period before implementing treatment $(t=0)$, and the period after that $(t=1)$. If dummy variable $D_{i}$ equals 1 for the objects in the treatment group, and $D_{1 i}$ equals 1 for period $t=1$, then the coefficient $\delta$ in the following regression can identify the causal effect of the treatment:

$$
Y_{t i}=\beta_{0}+\beta_{1} D_{i}+\gamma D_{1 i}+\delta D_{i} D_{1 i}+\epsilon_{i t}
$$

Assuming that the unobserved omitted variables either are common for both 
groups or are heterogeneous characteristics that stay for a long time with a firm, DiD approach removes some of them. The following estimation of the coefficient $\delta$ in equation (4.1) reveals that feature:

$$
\hat{\delta}=\left(\bar{Y}_{0}^{T}-\bar{Y}_{1}^{T}\right)-\left(\bar{Y}_{0}^{C}-\bar{Y}_{1}^{C}\right)=\left(\bar{Y}_{0}^{T}-\bar{Y}_{0}^{C}\right)-\left(\bar{Y}_{1}^{T}-\bar{Y}_{1}^{C}\right)
$$

where $\bar{Y}_{j}^{k}$ denotes the average outcome in period $j(j=0,1)$ for the treatment group $(k=T)$, and for the control group $(k=C)$. In equation $(4.2),\left(\bar{Y}_{0}^{T}-\bar{Y}_{1}^{T}\right)$ and $\left(\bar{Y}_{0}^{C}-\bar{Y}_{1}^{C}\right)$ remove unobserved fixed factors other than a treatment that may also cause a firm's outcome in each group to differ between periods 0 and 1 . On the right-hand side of equation $(4.2),\left(\bar{Y}_{0}^{T}-\bar{Y}_{0}^{C}\right)$ and $\left(\bar{Y}_{1}^{T}-\bar{Y}_{1}^{C}\right)$ also remove common factors affecting both groups in each period, see Wooldridge (2010).

By removing some of the unobserved elements affecting the outcomes, the estimated $\hat{\delta}$ more likely identifies the direct causal effect of a treatment. Equation (4.1) might be augmented with more control variables. Especially, in natural experiment studies, the control variables can improve the chances that the treatment had been randomly assigned to the treatment group.

For a non-natural experimental study such as employee training or a firm's teaming with other institutions, however, the advantages of the DiD approach discussed above may not guarantee the independence of the treatment dummy variable, $D_{i}$, from the error term in equation (4.1). The main concern here is selection bias. Firms' characteristics can influence their participation in a treatment, and thus disturb its randomization. The selection can confound the true treatment effect (Angrist et al. (2009)). To better identify the causality effect of a treatment, the analysis needs more homogeneous treatment and control groups. 


\subsubsection{Treatment Independence and Selection Bias}

In this study, selection bias may arise since firms in the treatment group that collaborated with other institutions, might be very different from those in the control group. Suppose $Y_{1}$ represents a firm's outcome if it collaborates, and $Y_{0}$ shows its outcome with no collaboration. Conditional on a set of observable covariates, $X$, the assumption of weak ignorability of treatment, or ignorability in a conditional mean independence, can eliminate the selection effect. With the conditional mean independence assumption (CIA), i.e. $E\left(Y_{0} \mid\right.$ teaming, $\left.X\right)=E\left(Y_{0} \mid X\right)$ and $E\left(Y_{1} \mid\right.$ teaming, $\left.X\right)=E\left(Y_{1} \mid X\right)$, the error term and treatment variable in a regression would no longer be correlated, see Wooldridge (2010). Augmenting DiD with covariates in equation (4.1) also aims to satisfy this assumption.

As will be discussed in section 4.3.4, CIA allows semi-parametric matching approaches to construct more homogeneous random samples to overcome selection bias. The success of this process, of course, relies on having some firms in both treatment and control groups with similar observables. This feature, known as common support, is required in order to make the comparison between treatment and control groups.

Equation (4.3) below shows how selection bias affects the average treatment effect (ATE) of teaming with an institution:

$$
\underbrace{E(Y \mid \text { team }=1)-E(Y \mid \text { team }=0)}_{\text {ATE }}=\underbrace{E\left(Y_{1}-Y_{0} \mid \text { team }=1\right)}_{\text {ATT }}+\{\underbrace{E\left(Y_{0} \mid \text { team }=1\right)-E\left(Y_{0} \mid \text { team }=0\right)}_{\text {Selection bias }}\}
$$

The term $\left(Y_{0} \mid\right.$ team $\left.=1\right)$ in the selection part of equation (4.3) denotes what the outcome for a firm with teaming experience would have been if it had not undertaken teaming. Depending on which type of firms would select teaming, the selection bias can be positive or negative. If high-quality firms collaborate with institutions, this bias would be positive, and ATE of collaboration would be over-estimated. So, the 
selection term causes bias in ATE and causes it to differ from the average treatment effect of the treated group (ATT), see Wooldridge (2010).

If observable variables such as $X$ influence a firm to be in the treatment group, by conditioning on the observables $X$, their impacts can be removed and the causal effect of treatment would be identified. In other words, based on CIA above, $E\left(Y_{0} \mid\right.$ team $=$ $1, X)=E\left(Y_{0} \mid\right.$ team $\left.=0, X\right)=E\left(Y_{0} \mid X\right)$ and the selection term in equation (4.3) will vanish. This identification on observables, however, cannot remove the dependence of treatment on unobservable variables.

Conditional on accessing data before and after treatment, the argument above suggests that combining the DiD approach represented by equation (4.2) with matching approaches, discussed in section 4.3.4, can substantially alleviate the effect of both observable and unobservable variables on treatment. The term $\hat{\delta}$ in equation (4.2) can remove some of a firm's unobserved heterogeneity as well as the common trend. And matching approaches can reduce further heterogeneity among firms by constructing more homogeneous randomization samples of treatment and control groups.

The next section reviews the Combined Difference in Difference (CDiD) approach.

\subsubsection{Combined Difference in Difference}

The CDiD approach aims to better identify the parameter $\hat{\delta}$ by extending equation (4.2) and providing a semi-parametric estimation of it. Not only does it use matching approaches to improve randomization of treatment based on CIA, but also proposes more flexible ways of calculating the average values of outcomes in equation (4.2). So, the results are less restricted with functional form.

Let us consider a treatment group entailing those firms that had teaming experience with other institutions at least once during the period from 2007 to 2011 . The CDiD approach extends equation (4.2) as follows ( see Arnold and Javorcik (2009); Karhunen and Huovari (2015); Ci et al. (2015)): 


$$
\begin{array}{r}
A T T_{C D I D}=\frac{1}{N_{T}} \sum_{i=1}^{N_{T}}\left[Y_{i 1}^{T}-Y_{i 0}^{T}-\frac{1}{N_{C}} \sum_{i=1}^{N_{C}}\left(f(i, j)\left(Y_{i 1}^{C}-Y_{i 0}^{C}\right)\right)\right] \\
=\frac{1}{N_{T}} \sum_{i=1}^{N_{T}}\left[Y_{i 1}^{T}-\frac{1}{N_{C}} \sum_{i=1}^{N_{C}} f(i, j) Y_{j 1}^{C}\right]-\frac{1}{N_{T}} \sum_{i=1}^{N_{T}}\left[Y_{i 0}^{T}-\frac{1}{N_{C}} \sum_{i=1}^{N_{C}} f(i, j) Y_{j 0}^{C}\right]
\end{array}
$$

Where $N_{T}$ is the number of firms in the treatment group, $Y_{i 0}^{T}$ is the outcome for firm $i$ in the treatment group in period 0 (year 2004), $Y_{j 0}^{C}$ is the same outcome for firm $j$ in the control group (those without teaming experience); $Y_{i 1}^{T}$ represents the outcome for firm $i$ after treatment in period 1 (year 2011) while $Y_{j 1}^{C}$ shows the outcome for firm $j$ in period $1 ;^{4}$ and $f(i, j)$ refers to a weight function defined by a matching algorithm. The resulting weights are used to calculate an average outcome of $N_{C}$ firms in the control group that are matched with firm $i$.

The resulting average value provides a counter-factual outcome for firm $i$ since we do not know what would have been the resulting outcome for the treated firm if it had not undertaken teaming. Based on CIA, the CDiD approach chooses more homogeneous firms from the control group to be compared with each firm in the treatment group. This feature reduces selection bias and improves the power of the DiD approach in identifying the causal effect of teaming with other firms and institutions.

The standard error for $A T T_{C D I D}$ in equation (4.4) is calculated based on a bootstrapping approach. This approach provides valid values for the standard errors, see Wooldridge (2010) and Li and Racine (2007).

\footnotetext{
4 The results need to be viewed with some caution. Some firms may have undertaken teaming with other institutions in 2004, 2005, and /or 2006, but the KFS does not report that information. By focusing on the firms that survived from 2004 to 2011, the analysis mitigates the bias through removing those firms that had teaming experience before 2007 but also exited before 2011.
} 


\subsubsection{Alternative Matching Algorithms}

The empirical analysis relies on two matching measures, namely Mahalanobis Distance and Propensity Score. Mahalanobis Distance (MD) measures how much ob-

servations are close together. It calculates $M D(i, j)=\sqrt{\left(X_{i}-X_{j}\right)^{\prime} \Sigma^{-1}\left(X_{i}-X_{j}\right)}$ where $\Sigma$ is the covariance matrix of $X_{i}$ and $X_{j}$. The MD approach loses its efficiency as the number of variables in vector $X$ rises. On the other hand, Propensity Scores (PS) calculates only one value for each firm. The measure is the estimated probability of teaming for firm $i$ conditional on a vector of covariates, $X_{i}$, i.e., $\operatorname{Pr}\left(\right.$ Teaming $\left._{i}=1 \mid X_{i}\right)$, see Rosenbaum and Rubin (1983).

To better picture the robustness of results, MD and PS measures are fed into different matching algorithms such as the Kernel algorithm and the Nearest-neighbor algorithm.

The Kernel algorithm selects observations within a control group based on a moving window. The kernel matching is sensitive to the width of this window called bandwidth. In previous studies, the value of this bandwidth was pre-selected by the authors of the studies. In this chapter, however, a bandwidth is selected by either the pair-matching approach, see Huber et al. (2015), or the cross-validation approach, see Galdo et al. (2008). The kernel matching algorithm employs the Epanechnikov kernel function for constructing the weights. The kernel function assigns higher weights to those selected observations within the control group whose MDs or PSs are closer to that of their reference in the treatment group. The weighted average of these outcomes provides a proxy for the counter-factual outcome.

The K-nearest neighbour algorithm matches at least K-firms with the closest MDs or PSs measures, and it calculates a simple average of their outcomes as a proxy for the counter-factual outcome. Since there is no criteria to choose $K$, this chapter reports the results for $K=1,2, . ., 5$. The increase of $K$ needs some caution since it 
may result in a matching bias that surpasses reduction in variance (efficiency), see Wooldridge (2010) and Abadie and Imbens (2006).

To evaluate the performance of these matching algorithms, section 4.5.1 examines balance and common support tests. The next section describes the KFS data.

\subsection{Data}

This study uses the confidential version of the longitudinal Kauffman Firm Survey (KFS) for the period 2004-2007. The survey considers a firm as a start-up, in 2004, if its owner(s) established it, bought the firm or bought a franchise. The survey starts with 4,928 start-ups in 2004 and tracks them annually for seven following years until 2011. On average, $10 \%$ of them exited each year for different reasons such as acquisition, merging or stopping operation. For each firm, KFS provides information about the demographics of a firm's owners (at most ten) and their share of ownership, the firm's legal status, its strategy and innovation, its commercial credit score class reported by Dun \& Bradstreet, and its capital structure.

The main firm's financial information contains: trade credit, owner(s)' equity and assets, personal bank loans provided by the owner(s), business bank loans obtained under the title of the firm, other personal and business loans, the maximum credit limit on both lines of credit (personal and business) and credit cards (also personal and business), insiders' debt and equity contributions (such as friends and family members), and outsider-equity providers (such as venture capital and angel investors and government).

Starting from 2007, the firms in the KFS with comparative advantage were asked to answer the following four questions: "Was the competitive advantage [NAME BUSINESS] had in calendar year YYYY related in any way to teaming up with another company? ... with university?... with government lab or research center? 
... with the patents that [NAME BUSINESS] owns, has applied for, or licensed?"

In this chapter, if a firm had answered "Yes" to at least one of these questions in a specific year, that firm is considered to have had teaming experience in that year.

The first column of Table C.1 reports the total number of firms in each year and the number of those with a comparative advantage (in parenthesis). The second column of Table C.1 illustrates that starting in 2004 the annual portion of firms with a comparative advantage is about $65 \%$ until 2006; it then drops to about $58 \%$ in 2007 and 2008. The annual portion decreases further by 10\% during 2009 and 2010 and reaches its lowest amount at $41 \%$ in 2011.

In contrast to these continuous declines, the third column of Table C.1 discloses that among the firms with a comparative advantage, the proportion with teaming experience rises steadily from 30\% in 2007 to $36 \%$ in 2011. This evidence indicates that teaming, on average, has a promising role for comparative advantage or commercializing knowledge among the SMs firms. However, the fourth column reveals that among the firms with comparative advantage, the fraction of firms with $R \& D$ expenditures goes down from $25 \%$ in 2004 to $22 \%$ in 2011 . These fractions always remain at least $10 \%$ below those of teaming in each year.

When all the firms instead of those with comparative advantage are considered, the two percentages reveal diminishing trends. The sixth column of Table C.1 illustrates that the percentage of firms with teaming among all firms increases to $18 \%$ in 2008 and then decreases to $15 \%$ by the end of 2011. Also, the seventh column indicates that the percentage of firms with R\&D expenditures among all firms decreases from $21 \%$ in 2004 to $12 \%$ in 2011. Finally, columns five and eight demonstrate a positive and significant correlation, ranging from 0.17 to 0.28 , between teaming and the dummy variable for firms with R\&D expenditures during 2007 to 2011.

Table C.2 focuses on the distribution of R\&D employees among firms with a comparative advantage. It evaluates the relation between teaming experience as a 
proxy for knowledge spillover and this distribution. Part A in Table C.2 shows that about $40 \%$ of the firms with comparative advantage have no R\&D employees during 2007 to 2011, whereas the ratio is above $45 \%$ among all firms. The first row in Part B denotes that among firms with no R\&D employees, however, about 35\% still have teaming experience. Tracking rows further down in Table C.2 unveils that the percentages of firms experiencing teaming soar as the number of $R \& D$ employees rises.

Table C.3 also reveals similar information based on the distribution of total employees. Among the small firms with a comparative advantage and with less than five employees in 2007, the percentage of those engaging in teaming turns out to be at least $11 \%$ more than that of the firms with $R \& D$ expenditures (compare numbers in parentheses). The gap soars to $15 \%$ in 2011 . Though the two percentages get closer for firms with more employees, in most instances the percentages of teaming experience still remain above those of $\mathrm{R} \& \mathrm{D}$ experience.

The comparisons reveal two features of teaming. First, higher percentages of verysmall businesses had teaming experience rather than $R \& D$ expenditures. The finding is important since these firms form the majority of the firms with comparative advantage. Second, most of the positive correlation between teaming and $R \& D$ experiences reported in Table C.1 relates to bigger firms. These findings suggest that teaming might be a better proxy for representing knowledge spillovers and knowledge filtering for small business in the KFS.

Table C.4 illustrates that among the 2032 firms that survived until the end of 2011, $59 \%$ of them did not experience teaming during the period 2007 to 2011 . Among the rest, $41 \%$ of them experienced teaming once, $25 \%$ of them twice, $17 \%$ three times, $11 \%$ four times, and $6 \%$ of them undertook teaming five times.

Table C. 4 also shows that $46 \%$ of the survivals are either in high-tech or in mediumtech sectors. During this period, $50 \%$ of them experienced teaming at least once. On 
the other hand, only $30 \%$ of the firms in non-tech industries exerted teaming from 2007 to 2011.

Table C.5 reports the percentages for different sources of teaming leading to comparative advantage (some firms obtain their comparative advantage from sources other than teaming). During the period 2007 to 2011, a firm's collaboration with other companies appears to be the main source of knowledge spillovers or commercializing knowledge among the SMs firms. Among firms with a comparative advantage, the percentage of teaming with other companies ranges from $28 \%$ to $31 \%$ during that period. The second main source of teaming is related to patents with the constant portion of $9 \%$. After that, teaming with universities appears about $6 \%$ to $8 \%$ during the period. The lowest percentages turn out to be the collaboration with government labs and research centres ranging from $3 \%$ to $4 \%$.

\subsection{Empirical Results}

This section estimates the Average Treatment Effect of the Treated group (ATT) defined in equation (4.4). The empirical analysis uses the CDiD approach for outcomes such as the logarithm of real revenue, the logarithm of employment, and the logarithm of per-capita real wage measured in 2004 and 2011. The nominal values of revenue and wages in 2011 were deflated by Consumer Price Index using 2004 as the base year. The analysis also checks for the robustness of the results using both MD and PS matching measures. For each matching measure, CDiD employs two different matching algorithms: K-nearest neighbour algorithm, $K=1, \ldots, 5$, and kernel algorithm.

To further examine the robustness of the results, two sets of a firm's characteristics at start-up are fed to the MD and PS methods. The second set entails more dummy variables such as whether a firm is categorized as high- or medium-technical firm, and 
whether a firm started with business credit, personal credit, or trade credit. Table B.1 in the appendix summarizes the definition of all the variables measured in 2004 and used in the analysis.

The first column of Table C.6 reports the marginal effects for an estimated Logit model where its dependent variable is 1 if a firm undertakes teaming with one of the institutes at least once during 2007 to 2011. The PS matching approach is based on the estimated probability of this model.

Using the first set of variables, the first column denotes that a firm's chances of engaging in the teaming increase by 0.3 percentage points if it has an experienced owner; by 0.7 percentage if its owner expends more time for the firm; by 3.7 percentage points if its owner ran other businesses before 2004; by 11.3 percentage points if its owner has a college degree; and the chances of teaming soar by 27.5 percentage points if a firm's owner has a graduate degree. Among firms, those with intellectual property are 17.7 percentage points more likely to collaborate with outside institutions, and firms that supply products have 6.9 percentage points more chance to undertake teaming.

Since the analysis selects those firms that survived until the end of 2011, the second and the third columns check for sample selection bias. The second column estimates a Probit model with dependent variable equal to 1 if a firm survives until 2011, and zero otherwise. For the purpose of identification, it uses a dummy variable as exclusion restriction that takes value of 1 if a firm bought new machinery equipment in 2004 . We can expect that such a firm would likely have a long-term plan for its operation.

The footnote in Table C.6 shows that new machinery equipment has a significant correlation with the survival-dummy variable but no correlation with teaming-dummy variable. To estimate these two correlations, two biprobit models with only an intercept as explanatory variable were estimated. Also, since this variable is determined in 2004 and teaming conducted after 2007, we may expect that it would not have 
correlation with the error term in the teaming equation.

The second column of Table C.6 reports the marginal effects obtained from estimating a Probit model where surviving dummy is its dependent variable. It reports a significant marginal effect for the new machinery dummy: it increases a firm's chances of surviving by 4.3 percentage points. Similar to the estimated Logit model for teaming in the first column, factors such as owners' experience, their devoting time, their engagement with other businesses, and their education degrees positively improve the chances of their venture to survive until the end of 2011. Also, having an Asian owner increases the likelihood of surviving by 12.5 percentage points; having a white owner, by 10.7 percentage points. Age of owners has an inverse U-shape effect on the survival probability of a firm. Firms that started with friends' or family members' equity have 7.9 percentage points less chances of surviving until 2011.

The third column of Table C.6 uses the deviance residual of the survival model as a new explanatory variable. Similar to the first column, the dependent variable for the Probit model in the third column is the teaming dummy variable. The estimated model reports an insignificant marginal effect for the added residual denoting no evidence of sample selection bias to be concerned. As another examination for selection bias, the bottom part of the second column reports the estimated $\rho$ from estimating Heckman probit model using the variables of this column. The estimated $\rho$ appears insignificant confirming the previous finding (the footnote in Table C.6 shows that new machinery equipment used in the selection part of the Heckman probit model is statistically significant).

The forth column of Table C.6 reports marginal effects for a Logit model that uses the second set of explanatory variables. In addition to the similar results as of the first column, operating in a high-tech sector increases the probability of teaming by 19.6 percentage points; operating in a medium-tech sector raises the probability by 17.5 percentage points. However, none of the added capital financing variables such as 
business, personal, and trade credit significantly affect the probability of undertaking teaming.

The matching algorithm in the next section will use the propensity scores calculated by the models in the first and the fourth columns of Table C.6.

\subsubsection{Balancing tests}

This section presents balance tests for matching algorithms that use both MD and PS measures. After matching, we expect the difference between the means of each variable in the treatment and control groups to approach 0 , and the ratio of corresponding variances to approach 1 . This section focuses only on the balance tests obtained from the kernel algorithm with cross-validation. The results of this algorithm seem more reliable because of its flexibility in allowing a choice of both bandwidth and the number of matched observations in the control group. The results of the balance tests for other matching algorithms lie somewhere between those of MD and PS measures used by the kernel algorithm, so they are not presented. Tables C.7 and C.8 focus on using the first set of explanatory variables. In Table C.7, the kernel algorithm uses MD measure; in Table C.8, it uses PS measure.

Using MD measure for the matching algorithm, Table C.7 shows that the standardized mean-differences are close to zero, and the variance ratios are close to 1 for most of the variables. Using PS measure for the matching algorithm, Table C.8 reports significant reduction in the numbers. The absolute values of all standardized mean-differences now plunge below 0.07 , and the variance ratios are much closer to one than those in the previous table. Figure C.1a depicts the optimal bandwidth used in the kernel matching as 0.075 . Figure C.1b illustrates the density balancing for propensity scores before and after matching. Overall, both tables and figures confirm the success of the kernel algorithm in matching the firms in the treatment group with those in the control groups. 
The balance tests for the second set of variables were unsatisfactory for MD measure used in the kernel algorithm and hence are not presented here. This outcome denotes the curse of dimensionality. Table C.9 illustrates the balance test for the kernel algorithm that uses PS measure and the second set of variables. In contrast to MD measure, the results denote that adding new variables still leaves the standardized mean-differences close to zero for all variables. The variance ratios also get very close to 1 with the exception of two variables, namely service with a value of 1.14 and insider debt with a value of 1.20. Figure C.1c depicts the optimal bandwidth for the kernel algorithm as 0.087. Figure C.1d illustrates the density balancing for propensity scores before and after matching. The results satisfy the criteria for a reasonable matching.

In the next section, the three groups of matched samples discussed above are used to show how the results of the CDiD approach would change by moving from one group to another

\subsubsection{Combined Difference in Difference for Teaming}

This section discusses the results for the estimated ATT based on the CDiD approach. Each of Tables C.10 to C.12 has three sections of results: the first section is based on the first-set of variables and the samples matched using MD measure; the second section is also based on the first-set of variables but samples matched using PS measure, and the third section of results is based on the second-set of variables and PS measure.

Each section of results is obtained by inputting the MD and PS measures to three matching algorithms such as the nearest-neighbour matching (nn(1) to nn(5)), the kernel pair-matching $(\mathrm{KM}(\mathrm{pm}))$, and the kernel cross-validation matching $(\mathrm{KM}(\mathrm{cv}))$ in order to calculate ATT in equation (4.4). The empirical analysis uses a bootstrapping method with 100 iterations to calculate the standard errors and the significance 
levels reported in the tables.

Table C.10 illustrates the effect of a firm's teaming experience on its real revenue growth between 2004 and 2011. Using the first-set of variables and MD measure, only the pair-matching algorithm reports a significant impact of teaming on revenue at 0.629. Using the same set but PS measure, the estimated ATT are larger for all algorithms except for the pair-matching algorithm. The ATT reported by nn(4) algorithm is significant at 0.662 , and by $\mathrm{KM}(\mathrm{cv})$ at 0.622 . The last part of Table C.10, which is based on the second set of variables and PS measure, also reports a significant treatment effect of teaming on real revenue ranging from 0.662 to 0.955 for $\mathrm{nn}(1)$ to $\mathrm{nn}(4)$ as well as for $\mathrm{KM}(\mathrm{cv})$. The teaming effect is not significant for both nn(5) and the kernel pair-matching algorithms.

Table C.11 indicates that teaming causes a positive growth in a firm's employment. Both MD and PS matching measures report a significant and positive direct effect from the teaming treatment on employment for almost all matching algorithms. On average, the causality effects obtained from PS measure are higher than those from MD measure, except for the pair-matching algorithms. The causality effects under MD measure for different algorithms range from 0.103 for $\mathrm{nn}(1)$ to 0.179 for pair matching. The estimated causality effects based on PS measure for the first set of variables range from 0.129 for pair matching to 0.188 for $\mathrm{nn}(5)$; for the second set, they range from 0.108 for pair matching to 0.175 for $\mathrm{nn}(1)$.

Table C.12 reports positive causal effects arising from teaming on the growth of per-capita real wages in a firm. By focusing on the results for PS measure, all matching algorithms report significant causality effects when the first set of variables are employed. Using the second sets of variables, causality effects, though, remain positive, but only the one for $\mathrm{KM}(\mathrm{cv})$ appears significant.

Overall, the results from all algorithms show that teaming has a positive effect on the different measures of a firm's performance. Also, the estimated ATT turns out 
to be always statistically significant in two cases: first, for MD measures when the CDiD uses the kernel algorithm with a bandwidth selected by pair-matching; second, for PS measure when the CDiD approach employs kernel algorithm with a bandwidth chosen by cross validation.

\subsection{Conclusion}

This chapter quantitatively illustrates that the Small- and Medium-size firms in the Kauffman Firm Survey (2004-2011) benefited from teaming with academic and nonacademic institutions. Teaming facilitates knowledge spillovers, and young firms can use the knowledge to improve production efficiency and/or to innovate. To identify this causal effect, this study uses teaming as a proxy for knowledge spillovers for small businesses. The results show that firms undertaking teaming are successful in commercializing the abstract knowledge. Compared with the control group, firms engaged in teaming obtain higher growth in real revenue, in employment size, and in per-capita real wages. The results rely on implementing a combined difference in difference matching method to improve identification. To check for robustness, it employs the nearest-neighbour and kernel algorithms for both multivariate distance and propensity score matching measures. 


\section{Bibliography}

Alberto Abadie and Guido W Imbens. Large sample properties of matching estimators for average treatment effects. Econometrica, 74(1):235-267, 2006.

Jakob Harmannus Abbring, Jeffrey R Campbell, et al. A firm's first year. Technical report, Tinbergen Institute, 2005.

Alan C Acock. Discovering Structural Equation Modeling Using Stata: Revised Edition. Stata Press, 2013.

Zoltan J Acs and Lawrence A Plummer. Penetrating the "knowledge filter"in regional economies. The Annals of Regional Science, 39(3):439-456, 2005.

Zoltan J Acs and Mark WJL Sanders. Knowledge spillover entrepreneurship in an endogenous growth model. Small Business Economics, 41(4):775-795, 2013.

Zoltan J Acs, Luc Anselin, and Attila Varga. Patents and innovation counts as measures of regional production of new knowledge. Research policy, 31(7):1069$1085,2002$.

Zoltan J Acs, David B Audretsch, Pontus Braunerhjelm, and Bo Carlsson. The missing link: The knowledge filter and entrepreneurship in endogenous growth. 2004.

Zoltan J Acs, Pontus Braunerhjelm, David B Audretsch, and Bo Carlsson. The 
knowledge spillover theory of entrepreneurship. Small business economics, 32(1): 15-30, 2009.

Zoltan J Acs, David B Audretsch, Pontus Braunerhjelm, and Bo Carlsson. Growth and entrepreneurship. Small Business Economics, 39(2):289-300, 2012.

James S Ang. Small business uniqueness and the theory of financial management. The Journal of Entrepreneurial Finance, 1(1):1, 1991.

Joshua David Angrist, Jörn-Steffen Pischke, and Jörn-Steffen Pischke. Mostly harmless econometrics: an empiricists companion. Cram101 Publishing, 2009.

Luc Anselin, Attila Varga, and Zoltan Acs. Geographical spillovers and university research: A spatial econometricperspective. Growth and change, 31(4):501-515, 2000.

Jens Matthias Arnold and Beata S Javorcik. Gifted kids or pushy parents? foreign direct investment and plant productivity in indonesia. Journal of International Economics, 79(1):42-53, 2009.

Thomas Åstebro, Jing Chen, and Peter Thompson. Stars and misfits: Selfemployment and labor market frictions. Management Science, 57(11):1999-2017, 2011.

David B Audretsch. Innovation, growth and survival. International Journal of Industrial Organization, 13(4):441-457, 1995.

David B Audretsch. Standing on the shoulders of midgets: The us small business innovation research program (sbir). Small Business Economics, 20(2):129-135, 2003.

David B Audretsch and Erik E Lehmann. Does the knowledge spillover theory of entrepreneurship hold for regions? Research Policy, 34(8):1191-1202, 2005. 
David B Audretsch and Marco Vivarelli. Firms size and r\&d spillovers: Evidence from italy. Small Business Economics, 8(3):249-258, 1996.

Rui Baptista and Joana Mendonça. Proximity to knowledge sources and the location of knowledge-based start-ups. The Annals of Regional Science, 45(1):5-29, 2010.

Joel AC Baum, Tony Calabrese, and Brian S Silverman. Don't go it alone: Alliance network composition and startups' performance in canadian biotechnology. Strategic management journal, pages 267-294, 2000.

Allen N Berger and Gregory F Udell. Some evidence on the empirical significance of credit rationing. Journal of Political Economy, 100(5):1047-1077, 1992.

Allen N Berger and Gregory F Udell. The economics of small business finance: The roles of private equity and debt markets in the financial growth cycle. Journal of banking \& finance, 22(6-8):613-673, 1998.

David Besanko and George Kanatas. Credit market equilibrium with bank monitoring and moral hazard. Review of Financial studies, 6(1):213-232, 1993.

Helmut Bester. Screening vs. rationing in credit markets with imperfect information. The American Economic Review, 75(4):850-855, 1985.

NIALL Bolger. Data analysis in social psychology. Handbook of social psychology, 1: 233-65, 1998.

Andrea Bonaccorsi, Massimo G Colombo, Massimiliano Guerini, and Cristina RossiLamastra. University specialization and new firm creation across industries. Small Business Economics, 41(4):837-863, 2013.

Pontus Braunerhjelm, Zoltan J Acs, David B Audretsch, and Bo Carlsson. The missing link: knowledge diffusion and entrepreneurship in endogenous growth. Small Business Economics, 34(2):105-125, 2010. 
Josef Brüderl and Peter Preisendörfer. Network support and the success of newly founded business. Small business economics, 10(3):213-225, 1998.

Luis Cabral and Jose Mata. On the evolution of the firm size distribution: Facts and theory. The American Economic Review, 93(4):1075-1090, 2003.

A Colin Cameron and Pravin K Trivedi. Microeconometrics: methods and applications. Cambridge university press, 2005.

Bo Carlsson, Pontus Braunerhjelm, Maureen McKelvey, Christer Olofsson, Lars Persson, and Håkan Ylinenpää. The evolving domain of entrepreneurship research. Small Business Economics, 41(4):913-930, 2013.

Xiaohong Chen, David T. Jacho-Chávez, and Oliver Linton. Averaging Of An Increasing Number Of Moment Condition Estimators. Econometric Theory, 32(01): 30-70, February 2016.

Wen Ci, Jose Galdo, Marcel Voia, and Christopher Worswick. Wage returns to midcareer investments in job training through employer supported course enrollment: evidence for canada. IZA Journal of Labor Policy, 2015.

Mario Cleves, William Gould, William W Gould, Roberto Gutierrez, and Yulia Marchenko. An introduction to survival analysis using Stata. Stata press, 2008.

Iain M Cockburn and Rebecca M Henderson. Absorptive capacity, coauthoring behavior, and the organization of research in drug discovery. The Journal of Industrial Economics, 46(2):157-182, 1998.

DA Cohen. Levintha1. Absorptive capacity: a new perspective on learning and innovation. Administrative Science Quarterly, 3:128-152, 1990.

Rebel A Cole and Tatyana Sokolyk. Debt financing, survival, and growth of start-up firms. Journal of Corporate Finance, 50:609-625, 2018. 
Susan Coleman and Alicia Robb. A comparison of new firm financing by gender: evidence from the kauffman firm survey data. Small Business Economics, 33(4): $397,2009$.

Alessandra Colombelli, Jackie Krafft, and Marco Vivarelli. To be born is not enough: the key role of innovative start-ups. Small Business Economics, 47(2):277-291, 2016.

Thomas F Cooley and Vincenzo Quadrini. Financial markets and firm dynamics. American Economic Review, 91(5):1286-1310, 2001.

Arnold C Cooper, Tim Folta, Javier Gimeno-Gascon, and Carolyn Y Woo. Entrepreneurs'exit decisions: The role of threshold expectations. In Academy of Management Proceedings, volume 1992, pages 75-79. Academy of Management, 1992.

Dirk Czarnitzki and Julie Delanote. R\&d policies for young smes: input and output effects. Small Business Economics, 45(3):465-485, 2015.

Douglas W Diamond. Financial intermediation and delegated monitoring. The review of economic studies, 51(3):393-414, 1984.

Timothy Dunne, Mark J Roberts, and Larry Samuelson. The growth and failure of us manufacturing plants. The Quarterly Journal of Economics, pages 671-698, 1989.

Chris Elbers and Geert Ridder. True and spurious duration dependence: The identifiability of the proportional hazard model. The Review of Economic Studies, 49 (3):403-409, 1982.

David S Evans. Tests of alternative theories of firm growth. journal of Political Economy, 95(4):657-674, 1987. 
Robert Fairlie, Alicia Robb, and David T Robinson. Black and white: Access to capital among minority-owned startups. Stanford Institute for Economic Policy Research discussion paper, pages 17-03, 2016.

OECD (Organisation for Economic Co-operation and Development). Fostering entrepreneurship, 1998.

Xavier Freixas and Jean-Jacques Laffont. Optimal banking contracts. Essays in honor of Edmond Malinvaud, 2, 1990.

Xavier Freixas and Jean-Charles Rochet. Microeconomics of banking. MIT press, 2008.

Michael Fritsch and Ronney Aamoucke. Regional public research, higher education, and innovative start-ups: An empirical investigation. Small Business Economics, 41(4):865-885, 2013.

Jose C Galdo, Jeffrey Smith, and Dan Black. Bandwidth selection and the estimation of treatment effects with unbalanced data. Annales d'Économie et de Statistique, pages 189-216, 2008.

Douglas Gale and Martin Hellwig. Incentive-compatible debt contracts: The oneperiod problem. The Review of Economic Studies, 52(4):647-663, 1985.

José L González-Pernía and Iñaki Peña-Legazkue. Export-oriented entrepreneurship and regional economic growth. Small Business Economics, 45(3):505-522, 2015.

Jo Anna Gray and Ying Wu. On equilibrium credit rationing and interest rates. Journal of Macroeconomics, 17(3):405-420, 1995.

Arent Greve and Janet W Salaff. Social networks and entrepreneurship. Entrepreneurship theory and practice, 28(1):1-22, 2003. 
Bronwyn H Hall. The relationship between firm size and firm growth in the us manufacturing sector. Journal of Industrial Organization, 35(4):538-606, 1987.

Bronwyn H Hall, Albert N Link, and John T Scott. Barriers inhibiting industry from partnering with universities: evidence from the advanced technology program. The Journal of Technology Transfer, 26(1-2):87-98, 2001.

Jason Harkins and Nancy Forster-Holt. Resource dependence and the exits of young firms. Entrepreneurship Research Journal, 4(4):323-349, 2014.

Christopher S Hayter. Conceptualizing knowledge-based entrepreneurship networks: Perspectives from the literature. Small Business Economics, 41(4):899-911, 2013.

James Heckman and Burton Singer. A method for minimizing the impact of distributional assumptions in econometric models for duration data. Econometrica, pages 271-320, 1984 .

Keith M Hmieleski and Robert A Baron. Entrepreneurs' optimism and new venture performance: A social cognitive perspective. Academy of management Journal, 52 (3):473-488, 2009.

Hugo A Hopenhayn. Entry, exit, and firm dynamics in long run equilibrium. Econometrica, 60(5):1127-1150, 1992.

Martin Huber, Michael Lechner, and Andreas Steinmayr. Radius matching on the propensity score with bias adjustment: tuning parameters and finite sample behaviour. Empirical Economics, 49(1):1-31, 2015.

Robert Huggins and Andrew Johnston. Knowledge flow and inter-firm networks: The influence of network resources, spatial proximity and firm size. Entrepreneurship E regional development, 22(5):457-484, 2010. 
Robert Huggins and Piers Thompson. Entrepreneurship, innovation and regional growth: a network theory. Small Business Economics, 45(1):103-128, 2015.

Kim Huynh and Marcel Voia. Mixed proportional hazard models with continuous finite mixture unobserved heterogeneity: an application to canadian firm survival. Applied Stochastic Models in Business and Industry, 33(1):81-94, 2017.

Kim P Huynh and Zeno Rotondi. R\&d spending and knowledge spillovers. 2009.

Kim P Huynh and Marcel C Voia. Mixed proportional hazard models with finite mixture unobserved heterogeneity. Applied Stochastic Models in Business and Industry, 2016.

Kim P Huynh, Robert J Petrunia, and Marcel Voia. The impact of initial financial state on firm duration across entry cohorts. The Journal of Industrial Economics, 58(3):661-689, 2010.

Kim P Huynh, Robert J Petrunia, and Marcel Voia. Duration of new firms: The role of startup financial conditions, industry and aggregate factors. Structural Change and Economic Dynamics, 23(4):354-362, 2012a.

Kim P Huynh, Robert J Petrunia, and Marcel Voia. Initial financial conditions, unobserved heterogeneity and the survival of nascent canadian manufacturing firms. Managerial and Decision Economics, 33(2):109-125, 2012b.

Robert D Innes. Limited liability and incentive contracting with ex-ante action choices. Journal of Economic Theory, 52(1):45-67, 1990.

Adam B Jaffe, Manuel Trajtenberg, and Rebecca Henderson. Geographic localization of knowledge spillovers as evidenced by patent citations. the Quarterly journal of Economics, 108(3):577-598, 1993. 
Boyan Jovanovic. Selection and the evolution of industry. Econometrica, pages 649$670,1982$.

Shawn Kantor and Alexander Whalley. Knowledge spillovers from research universities: evidence from endowment value shocks. Review of Economics and Statistics, 96(1):171-188, 2014.

Hannu Karhunen and Janne Huovari. R\&d subsidies and productivity in smes. Small business economics, 45(4):805-823, 2015.

Charlie Karlsson and Peter Warda. Entrepreneurship and innovation networks. Small Business Economics, 43(2):393-398, 2014.

William R Keeton. Equilibrium credit rationing. PhD thesis, Massachusetts Institute of Technology, 1976.

Fahad Khalil and Bruno M Parigi. Loan size as a commitment device. International Economic Review, 39(1):135-150, 1998.

Steven Klepper and Peter Thompson. Submarkets and the evolution of market structure. The RAND Journal of Economics, 37(4):861-886, 2006.

Rex B Kline. Principles and practice of structural equation modeling. Guilford publications, 2011.

Joris Knoben and Leon AG Oerlemans. Proximity and inter-organizational collaboration: A literature review. International Journal of Management Reviews, 8(2): 71-89, 2006.

Yohei Kobayashi. Effect of r\&d tax credits for smes in japan: a microeconometric analysis focused on liquidity constraints. Small Business Economics, 42(2):311-327, 2014. 
Erkki Koskela. Credit rationing and non-price loan terms: A re-examination. Journal of Banking $\&$ Finance, 7(3):405-416, 1983.

Jean-Jacques Laffont and David Martimort. The theory of incentives: the principalagent model. Princeton university press, 2009.

Dennis Patrick Leyden and Albert N Link. Knowledge spillovers, collective entrepreneurship, and economic growth: The role of universities. Small Business Economics, 41(4):797-817, 2013.

Qi Li and Jeffrey Scott Racine. Nonparametric econometrics: theory and practice. Princeton University Press, 2007.

Murray B Low and Ian C MacMillan. Entrepreneurship: Past research and future challenges. Journal of Management, 14(2):139-161, 1988.

Robert E Lucas. On the size distribution of business firms. The Bell Journal of Economics, 9(2):508-523, 1978.

Edwin Mansfield. Entry, gibrat's law, innovation, and the growth of firms. The American Economic Review, 52(5):1023-1051, 1962.

Geoffrey McLachlan and David Peel. Finite Mixture Models, pages 238-256, 2000.

Richard R Nelson and Sidney G Winter. An evolutionary theory of economic change. Harvard University Press, 2009.

G Steven Olley and Ariel Pakes. The dynamics of productivity in the telecommunications equipment industry. Technical report, National Bureau of Economic Research, 1992.

Simon C Parker. The Economics of Entrepreneurship. Cambridge University Press, 2009 
Simon C Parker and C Mirjam Van Praag. Schooling, capital constraints, and entrepreneurial performance: The endogenous triangle. Journal of Business $\&$ Economic Statistics, 24(4):416-431, 2006.

Jukka Partanen, Kristian Möller, Mika Westerlund, Risto Rajala, and Arto Rajala. Social capital in the growth of science-and-technology-based smes. Industrial Marketing Management, 37(5):513-522, 2008.

Keith Pavitt. Academic research, technical change and government policy. Companion to Science in the Twentieth Century, page 143, 2003.

Eugénio Pinto. Firm dynamics with infrequent adjustment and learning. Finance and Economics Discussion Series, 2008.

Evila Piva, Luca Grilli, and Cristina Rossi-Lamastra. The creation of high-tech entrepreneurial ventures at the local level: the role of local competences and communication infrastructures. Industry and Innovation, 18(6):563-580, 2011.

Alejandro Portes. Social capital: Its origins and applications in modern sociology. Annual Review of Sociology, 24(1):1-24, 1998.

Ross L Prentice and Lynn A Gloeckler's. Regression analysis of grouped survival data with application to breast cancer data. Biometrics, pages 57-67, 1978.

Robert D Putnam. Bowling alone: America's declining social capital. In Culture and politics, pages 223-234. Springer, 2000.

Haifeng Qian and Hyejin Jung. Solving the knowledge filter puzzle: absorptive capacity, entrepreneurship and regional development. Small Business Economics, 48 (1):99-114, 2017. 
Alicia Robb, Janice Ballou, David DesRoches, Frank Potter, Zhanyun Zhao, and EJ Reedy. An overview of the kauffman firm survey: Results from the 2004-2007 data. 2009.

Alicia M Robb. Entrepreneurial performance by women and minorities: The case of new firms. Journal of Developmental Entrepreneurship, 7(4):383, 2002.

Alicia M Robb and David T Robinson. The capital structure decisions of new firms. The Review of Financial Studies, 27(1):153-179, 2014.

Richard Roll, On Incdvidual Loans Pricing Credit Rationing, Avner Kalay, Ramon Rabinovitch, Capital Gain, John T Bart, NASDAQ Stocks, Hans R Stoll, Interest Rate Differentials, Timothy Q Cook, et al. The journal of finance. 1978.

Paul M Romer. Endogenous technological change. Journal of Political Economy, 98 (5, Part 2):S71-S102, 1990.

Peter Rosa, Sara Carter, and Daphne Hamilton. Gender as a determinant of small business performance: Insights from a british study. Small business economics, 8 (6):463-478, 1996.

Paul R Rosenbaum and Donald B Rubin. The central role of the propensity score in observational studies for causal effects. Biometrika, 70(1):41-55, 1983.

Leonard Sabetti. University knowledge spillovers and innovative startup firms. In Productivity and Efficiency Analysis, pages 203-209. Springer, 2016.

Herbert A Simon and Charles P Bonini. The size distribution of business firms. The American Economic Review, 48(4):607-617, 1958.

Anders Skrondal and Sophia Rabe-Hesketh. Generalized latent variable modeling: Multilevel, longitudinal, and structural equation models. Crc Press, 2004. 
Jennifer A Starr and Ian C MacMillan. Resource cooptation via social contracting: Resource acquisition strategies for new ventures. Strategic Management Journal, pages 79-92, 1990 .

Joseph E Stiglitz and Andrew Weiss. Credit rationing in markets with imperfect information. The American Economic Review, 71(3):393-410, 1981.

Maks Tajnikar, Petra Došenovič Bonča, and Lidija Zajec. Harvesting in high growth firms. In The life cycle of entrepreneurial ventures, pages 535-582. Springer, 2006.

Lester G Telser. Cutthroat competition and the long purse. The Journal of Law $\&$ Economics, 9:259-277, 1966.

Peter Thompson. Selection and firm survival: evidence from the shipbuilding industry, 1825-1914. Review of Economics and Statistics, 87(1):26-36, 2005.

Peter Thompson. The iron and steel shipbuilding data set, 1825-1914: Sources, coverage, and coding decisions. 2008.

Jerry Thursby and Marie Thursby. University-industry linkages in nanotechnology and biotechnology: evidence on collaborative patterns for new methods of inventing. The Journal of Technology Transfer, 36(6):605-623, 2011.

André Van Stel and Kashifa Suddle. The impact of new firm formation on regional development in the netherlands. Small Business Economics, 30(1):31-47, 2008.

Attila Varga. University research and regional innovation: a spatial econometric analysis of academic technology transfers, volume 13. Springer Science \& Business Media, 1998.

Sankaran Venkataraman. The distinctive domain of entrepreneurship research. Advances in entrepreneurship, firm emergence and growth, 3(1):119-138, 1997. 
Reinhilde Veugelers and Bruno Cassiman. R\&d cooperation between firms and universities. some empirical evidence from belgian manufacturing. International Journal of Industrial Organization, 23(5-6):355-379, 2005.

Jue Wang and Philip Shapira. Partnering with universities: a good choice for nanotechnology start-up firms? Small Business Economics, 38(2):197-215, 2012.

John Watson. Comparing the performance of male-and female-controlled businesses: relating outputs to inputs. Entrepreneurship theory and practice, 26(3):91-100, 2002.

David C Webb. Long-term financial contracts can mitigate the adverse selection problem in project financing. International Economic Review, 32(2):305-320, 1991.

Stephen D Williamson. Costly monitoring, loan contracts, and equilibrium credit rationing. The Quarterly Journal of Economics, 102(1):135-145, 1987.

Poh Kam Wong, Yuen Ping Ho, and Erkko Autio. Entrepreneurship, innovation and economic growth: Evidence from gem data. Small business economics, 24(3): 335-350, 2005.

Poh Kam Wong, Lena Lee, and Maw Der Foo. Occupational choice: The influence of product vs. process innovation. Small Business Economics, 30(3):267-281, 2008.

Jeffrey M Wooldridge. Econometric analysis of cross section and panel data. MIT press, 2010.

Douglas H Wrenn, H Allen Klaiber, and David A Newburn. Confronting price endogeneity in a duration model of residential subdivision development. Journal of Applied Econometrics, 32(3):661-682, 2017.

Luigi Zingales. Survival of the fittest or the fattest? exit and financing in the trucking industry. The Journal of Finance, 53(3):905-938, 1998. 


\section{Appendix A}

\section{Appendices for Chapter 1}

\section{A.1 Tables and Figures}

Table A.1: Survival Rate, Exit Rate, and Exclusion Restrictions

\begin{tabular}{lcclllll}
\hline A: & Pre-Exp & No Pre-Exp & & & & \\
\hline Survival after first year & $60 \%$ & $40 \%$ & & & & \\
Exit in the first year & $27 \%$ & $73 \%$ & & & & \\
B: & Pre-Exp & No Pre-Exp & Diff & $\mathbf{S} \mid \mathbf{t}=\mathbf{1}$ & $\mathbf{S} \mid \mathbf{t}=\mathbf{2}$ & $\mathbf{S} \mid \mathbf{t}=\mathbf{3}$ \\
Entry production share (tons) & 0.314 & 0.203 & $0.111^{* *}$ & $0.220^{* *}$ & 0.018 & -0.098 \\
Entry production share (\#) & 0.287 & 0.237 & $0.050^{*}$ & $0.107^{*}$ & -0.008 & -0.115 \\
Entry-selection component & 0.174 & 0.038 & $0.136^{* *}$ & $0.273^{* *}$ & 0.044 & 0.07 \\
\hline
\end{tabular}

Note: Authors' calculation based on data from Thompson (2005). Pre-Exp: refers to the firms whose owners had a background in shipbuilding or engine manufacturing. $\mathbf{S} \mid \mathbf{t}=\mathbf{1}$ : this column refers to the correlation between each of the exclusion restrictions with a dummy variable equal to 1 for those firms that pass the first year. Column $\mathbf{S} \mid \mathbf{t}=\mathbf{2}$ represents the same correlation for survivals in the second period, while column $\mathbf{S} \mid \mathbf{t}=\mathbf{3}$ shows survivals in the third period. Diff: this column tests the null hypothesis: whether the mean of each exclusion restriction is equal for the firms with pre-entry experience and for those with no pre-entry experience. ${ }^{*} p<0.10,{ }^{* *} p<0.05$. 
Table A.2: Estimated Hazard Ratios - Different Model Specifications

\begin{tabular}{|c|c|c|c|c|c|c|}
\hline & Weibull & DFM1 & DFM2 & TS-DFM1 & TS-DFM2 & Final TS-DFM \\
\hline \multicolumn{7}{|l|}{ Time-Invariant: } \\
\hline Scale of plant & $\begin{array}{c}0.722^{* *} \\
(0.063)\end{array}$ & $\begin{array}{c}0.898 \\
(0.069)\end{array}$ & $\begin{array}{c}0.979 \\
(0.079)\end{array}$ & $\begin{array}{c}0.981 \\
(0.086)\end{array}$ & $\begin{array}{c}1.006 \\
(0.084)\end{array}$ & $\begin{array}{c}0.957 \\
(0.091)\end{array}$ \\
\hline Current market share & $\begin{array}{l}1.017^{* *} \\
(0.005)\end{array}$ & $\begin{array}{l}1.025^{* *} \\
(0.008)\end{array}$ & $\begin{array}{c}0.998 \\
(0.007)\end{array}$ & $\begin{array}{l}1.024^{* *} \\
(0.010)\end{array}$ & $\begin{array}{l}1.023^{* *} \\
(0.008)\end{array}$ & $\begin{array}{l}1.016^{*} \\
(0.009)\end{array}$ \\
\hline Industry output & $\begin{array}{c}1.003 \\
(0.002)\end{array}$ & $\begin{array}{l}1.008^{* *} \\
(0.002)\end{array}$ & $\begin{array}{c}0.997^{* *} \\
(0.001)\end{array}$ & $\begin{array}{l}1.005^{* *} \\
(0.002)\end{array}$ & $\begin{array}{l}1.006^{* *} \\
(0.002)\end{array}$ & $\begin{array}{l}1.006^{* *} \\
(0.002)\end{array}$ \\
\hline \multicolumn{7}{|c|}{ Pre-entry Experience: } \\
\hline In shipbuilding & $\begin{array}{c}0.630^{* *} \\
(0.139)\end{array}$ & - & $\begin{array}{c}0.320^{* *} \\
(0.067)\end{array}$ & $\begin{array}{c}1.027 \\
(0.360)\end{array}$ & $\begin{array}{c}0.526^{* *} \\
(0.122)\end{array}$ & - \\
\hline In engine building & $\begin{array}{c}0.524^{* *} \\
(0.122)\end{array}$ & - & $\begin{array}{c}0.280^{* *} \\
(0.078)\end{array}$ & $\begin{array}{c}0.763 \\
(0.253)\end{array}$ & $\begin{array}{c}0.550^{* *} \\
(0.152)\end{array}$ & - \\
\hline Miscellaneous & $\begin{array}{c}0.788 \\
(0.202)\end{array}$ & - & $\begin{array}{c}0.380^{* *} \\
(0.112)\end{array}$ & $\begin{array}{c}0.815 \\
(0.346)\end{array}$ & $\begin{array}{c}0.802 \\
(0.258)\end{array}$ & - \\
\hline Unknown & $\begin{array}{c}1.756^{* *} \\
(0.412)\end{array}$ & - & $\begin{array}{c}0.955 \\
(0.188)\end{array}$ & $\begin{array}{c}2.758^{* *} \\
(0.989)\end{array}$ & $\begin{array}{c}2.059^{* *} \\
(0.568)\end{array}$ & - \\
\hline Age & $\begin{array}{l}0.929^{*} \\
(0.038)\end{array}$ & $\begin{array}{c}0.903 \\
(0.109)\end{array}$ & $\begin{array}{c}0.515^{* *} \\
(0.057)\end{array}$ & $\begin{array}{c}1.013 \\
(0.203)\end{array}$ & - & - \\
\hline \multicolumn{7}{|l|}{ Selection } \\
\hline $\mathrm{d} 1$ & & - & - & - & $\begin{array}{c}4.045^{* *} \\
(0.911)\end{array}$ & $\begin{array}{l}3.344^{* *} \\
(1.176)\end{array}$ \\
\hline $\operatorname{Pr}($ Survive $>1$ year $)$ & & - & - & $\begin{array}{c}0.021^{* *} \\
(0.018)\end{array}$ & $\begin{array}{c}0.008^{* *} \\
(0.008)\end{array}$ & $\begin{array}{c}0.020^{* *} \\
(0.007)\end{array}$ \\
\hline \multicolumn{7}{|l|}{ Mixture Parameters: } \\
\hline Mass point 2 & & $0.034^{* *}$ & $25.127^{* *}$ & $27.270^{* *}$ & $7.476^{* *}$ & $6.915^{* *}$ \\
\hline Probability $($ class $=1)$ & & $\begin{array}{c}0.386^{* *} \\
(0.040)\end{array}$ & $\begin{array}{c}0.856^{* *} \\
(0.077)\end{array}$ & $\begin{array}{c}0.599 * * \\
(0.069)\end{array}$ & $\begin{array}{c}0.173 \\
(0.120)\end{array}$ & $\begin{array}{c}0.596^{* *} \\
(0.099)\end{array}$ \\
\hline Probability $($ class $=2)$ & & $\begin{array}{c}0.614^{* *} \\
(0.040)\end{array}$ & $\begin{array}{l}0.144^{*} \\
(0.077)\end{array}$ & $\begin{array}{c}0.401^{* *} \\
(0.069)\end{array}$ & $\begin{array}{c}0.827^{* *} \\
(0.120)\end{array}$ & $\begin{array}{c}0.404^{* *} \\
(0.099)\end{array}$ \\
\hline Observations & 2084 & 2084 & 2084 & 2027 & 2027 & 2027 \\
\hline Log lik. & -421.060 & -589.740 & -606.055 & -562.751 & -551.151 & -567.564 \\
\hline AIC & 866.120 & 1197.479 & 1236.110 & 1153.501 & 1130.302 & 1155.128 \\
\hline BIC & 933.824 & 1248.258 & 1303.814 & 1232.101 & 1208.902 & 1211.271 \\
\hline
\end{tabular}

Notes: We report hazard ratios or the exponential of coefficients, standard errors are in parentheses with the marginal significance level of ${ }^{*} p<0.10,{ }^{* *} p<0.05$. Weibull: is the replicated Weibull estimates from Thompson (2005),

DFM1: Discrete Finite Mixture Model with missing pre-entry experience information, DFM2: Discrete Finite Mixture Model with pre-entry experience variables included, and excluded location-dummy variables, TS-DFM1: Two-Stage Discrete Finite Mixture Model with pre-entry experience variables included, TS-DFM2: Two-Stage Discrete Finite Mixture Model with first-year dummy and pre-entry experience variables included, Final TS-DFM: Two-Stage Discrete Finite Mixture Model with missing pre-entry experience information. Mass point $\mathbf{1}$ is normalized to 0 . The exclusion-restriction vector contains entry-production shares (in terms of number and weight) and the entry-selection component by Pinto (2008). Their coefficients are significant and positive, with the values of $1.676^{* *}$ (0.778), 1.235** (0.500), and 2.864** (0.630), respectively. Their Marginal Effects are also significant and positive, with the values of $0.181^{* *}(0.080), 0.133^{* *}(0.055), 0.309^{* *}(0.071)$, respectively. 
Figure A.1: Empirical, TS-DFM: Two-Stage Discrete Finite Mixture (Average, Class 1, and Class 2), and Weibull Hazards

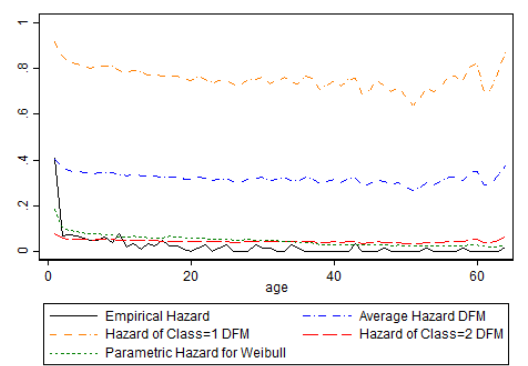

(a) Empirical,Weibull, and DFM Haz-(b) ards

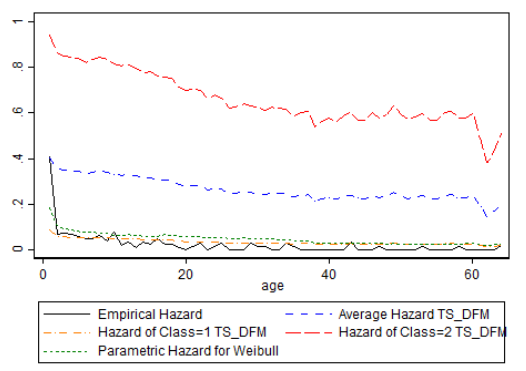

(c) TS-DFM Hazard with $\ln ($ age $)$

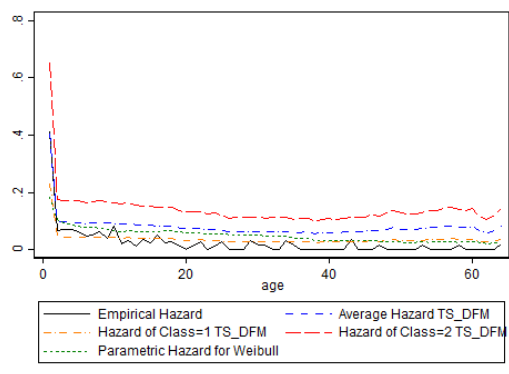

(e) TS-DFM Hazard with $d 1$

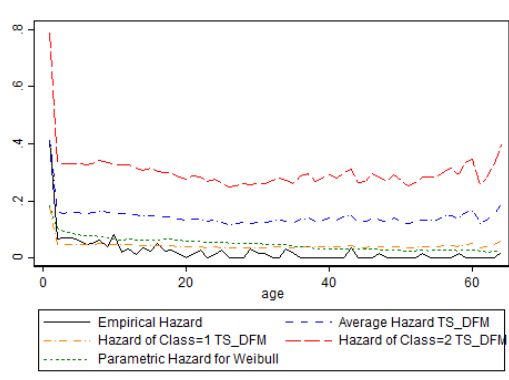

(g) Final TS-DFM Hazard

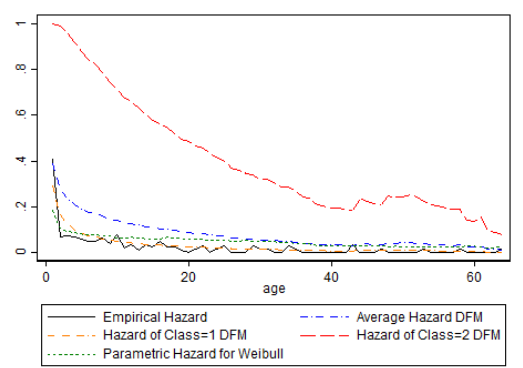

(b) Empirical,Weibull, and DFM Hazards

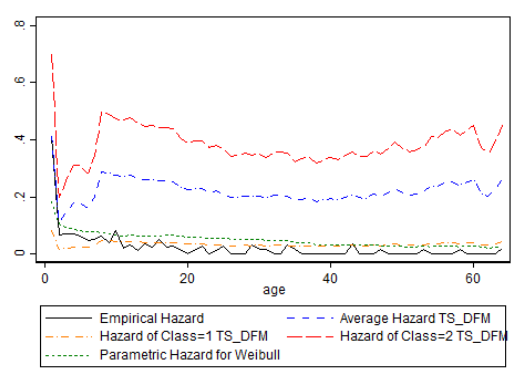

(d) TS-DFM Hazard with $d 1, \ldots, d 7$

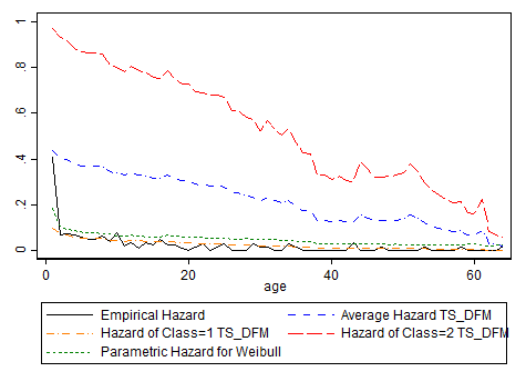

(f) DFM with $d 1$

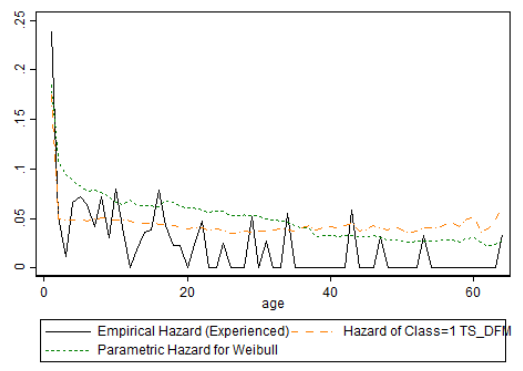

(h) Empirical for Expe'd Firm, TSDFM (Class 1), and Weibull Hazards 


\section{A.2 Selection Effect and Hazard Rates}

As outlined before, to handle more parts of unobserved heterogeneity and to properly explain a firm's dynamics, the selection effect needs to be taken into account. This section modifies Olley and Pakes (1992) to account for exit time selection. Olley and Pakes (1992) connect unobserved productivity to the factors of production in the following manner:

$$
A_{t}=T\left(K_{t}, i_{t}, a_{t}\right)=T\left(K_{t}, a_{t}\right)
$$

where $K_{t}$ is capital, $i_{t}$ investment, and $a_{t}$ the age of the firm at period $t$. The second equality in equation (A.1) implies that investment depends on the stock of capital. In the shipbuilding industry, the entry conditions such as entry scale of a plant and other selected-entry conditions can describe the major sources of irreversible-production technology. This leads to rewriting equation (A.1) as below:

$$
A_{t}=T\left(K_{t}, i_{t}, a_{t}\right)=T_{t}\left(K_{0}, a_{t}\right)
$$

Where $K_{0}$ comprises all factors that determine the firm's entry-scale decision. $T_{t}\left(K_{0}, a_{t}\right)$ in equation (A.2) can denote a firm's initial-selected technology that specifies its efficiency, its post-entry performance, and its survival time. As will be discussed in section A.3, time-dummy variables can be used for discrete hazard models to manage the irregularities of duration dependence such as piecewise regions or discontinuities. Equation (A.3) incorporates this idea:

$$
A_{t}=T\left(K_{t}, i_{t}, a_{t}\right)=T_{t}\left(K_{0}, D\right)
$$


where $D$ is a matrix of time-dummy variables. Now, consider the following cloglog hazard function ${ }^{1}$ :

$$
\log \left[-\log \left(1-h\left(t_{i}\right)\right)\right]=y\left(t_{i}\right)
$$

The right hand side of equation (A.3) can specify part of missing information in the error term of the above hazard function. Defining $y\left(t_{i}\right)=v_{k}+\beta^{\prime} X_{t i}+T_{t}\left(K_{0}, D\right)$, the hazard function is specified as:

$$
\log \left[-\log \left(1-h\left(t_{i} \mid v_{k}, x\right)\right)\right]=v_{k}+\beta^{\prime} X_{t i}+T_{t}\left(K_{0}, D\right)+\epsilon_{t i}
$$

To account for exit decision after the first year, the hazard model should be enriched with a firm's founder decision about her firm's technology, $K_{0}$, in equation (A.3). In other words, it should be connected to the entry-condition information. Following Olley and Pakes (1992), a firm exits from the market when its productivity goes below a threshold. Defining the threshold as $\underline{\mathrm{A}}$, the decision (probability) of operating more than one year in the industry can be defined as follows:

$$
\operatorname{Pr}(\text { Survive }>1 \text { year })=\operatorname{Pr}(S=1)=\operatorname{Pr}\left(A_{t}>\underline{A}\right)=1-\Phi\left(\underline{A}\left(K_{0}, D\right)\right)=P
$$

where, $\Phi$ is a cumulative Normal distribution, and $S$ equals 1 if the firm survives beyond the first year and zero otherwise. Inverting equation (A.5) specifies $\underline{A}$ as a function of survival probability:

$$
\underline{A}=L(P)
$$

To account for the selection effect in equation (A.4), take expectation from both sides of the equation at time $t$ :

$$
E\left\{\log \left[-\log \left(1-h\left(t_{i} \mid v_{k}, x, S=1\right)\right)\right]\right\}=v_{k}+\beta^{\prime} X_{t i}+E\left\{T_{t}\left(K_{0}, D\right) \mid S=1\right\}
$$

\footnotetext{
${ }^{1}$ Section A.3 provides details about this function (see equation (A.13)).
} 
$E\left\{T_{t}\left(K_{0}, D\right) \mid S=1\right\}$ means that the firm's technology at time $t$ depends on passing the first year. As equation (A.5) indicates, the decision about staying more than one year in the industry, $S=1$, depends on $\underline{A}$. Thus equation (A.7) can be summarised as:

$$
E\left\{\log \left[-\log \left(1-h\left(t_{i} \mid v_{k}, x, S=1\right)\right)\right]\right\}=v_{k}+\beta^{\prime} X_{t i}+g(\underline{A})
$$

By using equation (A.6) in equation (A.8):

$$
E\left\{\log \left[-\log \left(1-h\left(t_{i} \mid v_{k}, x, S=1\right)\right)\right]\right\}=v_{k}+\beta^{\prime} X_{t i}+g(L(P))
$$

In other words:

$$
\log \left[-\log \left(1-h\left(t_{i} \mid v_{k}, x, S=1\right)\right)\right]=v_{k}+\beta^{\prime} X_{t i}+g(P)+\epsilon_{t i}
$$

For simplicity, consider $g(P)=\eta P$. Therefore, the hazard function (A.10) becomes:

$$
h\left(t_{i} \mid v_{k}, x, S=1\right)=1-\exp \left[-\exp \left(v_{k}+\beta^{\prime} X_{t i}+\eta P+\epsilon_{t i}\right)\right],
$$

\section{A.3 Discrete Hazard Model}

This section describes complementary log-log (cloglog) hazard function as an example of discrete hazard models. An extension of this model, namely a discrete finite mixture hazard model, will be specified in section A.4. The model is employed to analyze the duration of shipbuilding firms discussed through the chapter.

As Jenkins ${ }^{2}$ discusses, the complementary log-log discrete hazard model approximates proportional hazard models such as the Weibull model. To estimate these types of discrete models in Stata, the data set should be organized like an unbalanced

\footnotetext{
${ }^{2}$ Seehttps://www.iser.essex.ac.uk/teaching/stephenj/ec968/index.php, espcially'Lesson7'.
} 
panel data. With such a data set, the dependent variable for the cloglog hazard function is a dummy variable equal to 0 for all years that the firm has been operating except the last year. For the last year, if a firm exits the discrete variable takes value 1; otherwise, it is a censored observation and equals zero. Equation (A.12) below defines the hazard rate or the probability of failure condition on a firm's surviving until time $t, \mathrm{~h}(\mathrm{t})$, as:

$$
h\left(t_{i}\right)=1-\exp \left(-\exp \left[b(t)+\beta^{\prime} X_{t i}\right]\right)
$$

Let's define $y\left(t_{i}\right)=b(t)+\beta^{\prime} X_{t i}$. Equation (A.12) becomes:

$$
\begin{gathered}
\log \left[-\log \left(1-h\left(t_{i}\right)\right)\right]=y\left(t_{i}\right) \\
h\left(t_{i}\right)=1-\exp \left\{-\exp \left(y\left(t_{i}\right)\right)\right\}
\end{gathered}
$$

$y\left(t_{i}\right)=b(t)+\beta^{\prime} X_{t i}$ for any firm at time $t$ contains two parts: $b(t)$ represents the baseline hazard function and $\beta^{\prime} X_{t i}$ that contains an intercept and involves both the firm's specific characteristics as well as its related industry features.

Following Jenkins, by defining the baseline hazard as $b(t)=(q-1) \times \ln (t) ; q>0$, the hazard rate is summarized as $h\left(t_{i}\right)=p\left(t_{i}\right)=1-\exp \left[-\exp \left(\beta^{\prime} X_{t i}\right) \times t^{q-1}\right]$. The coefficient $(q-1)$ estimates almost the equivalence value for duration dependence as the one provided by $(\alpha-1)$ in the Weibull hazard model, $h\left(t_{i}\right)=\alpha \exp \left(\beta^{\prime} X_{t i}\right) t^{\alpha-1}$.

Klepper and Thompson (2006) argue that some industries have irregular firm dynamics which make them different from the mainstream markets. The non-parametric feature of the discrete hazard functions might capture some of those irregularities. For example, in some industries hazard rates might follow a piecewise pattern or be zero in some years. In these circumstances, we might not gain a lot by specifying the baseline $b(t)$ as a function of age of a firm, $t$, and we might need to impose $q=1$ to make 
the cloglog function independent of time. Instead, we can specify a non-parametric baseline by employing some time-dummy variables or interval-dummy variables.

Finally, the survival function for a firm that survives until period $t$ is calculated as:

$$
S(t)=[1-p(1)][1-p(2)] \ldots . .[1-p(t)]
$$

which is equivalent to ${ }^{3}$ :

$$
S(t)=\exp \left[\sum_{s=1}^{t} \ln [1-p(s)]\right]
$$

\section{A.4 Unobserved heterogeneity}

For a continuous hazard function, the unobserved heterogeneity, $v$, is usually defined by multiplicative scale such as:

$$
h\left(t_{i} \mid v, x\right)=v b(t) \exp \left\{\beta^{\prime} X_{i t}\right\}
$$

where in standard duration models such as the Weibull hazard and the Cox proportional hazard models, $v$ follows a Gamma or an Inverse Gaussian distribution. ${ }^{4}$ Mis-specifying the functional form of UH, however, will induce spurious state dependence and create bias in the baseline hazard, see Elbers and Ridder (1982). Therefore, non-parametric UH models can be considered as an alternative to the parametric UH models.

On the other hand, Discrete Finite Mixture (DFM) models can avoid the shortcomings of the parametric models in identifying UH among agents, see McLachlan and Peel (2000). Heckman and Singer (1984) propose a hazard model that assumes

\footnotetext{
${ }^{3}$ The command to calculate the survival probability, $S(t)$, in Stata is: bysort id $(j)$ : gen $\mathrm{s}=\exp (\operatorname{sum}(\ln (1-\mathrm{h}))$

${ }^{4}$ The difference is that the Weibull has a parametric baseline hazard while Cox utilizes a nonparametric baseline.
} 
that each observation may belong to one of several latent classes, with each latent class having its own distribution which collapses to a discrete mass point.

\section{A.4.1 Discrete Finite Mixture Hazard Model}

Jenkin's method in Stata estimates a discrete hazard model by using the maximum likelihood method. To account for unobserved heterogeneity suggested by Heckman and Singer (1984), Jenkins' method incorporates a discrete finite mixture distribution in Prentice and Gloeckler's (1978) model. ${ }^{5}$ The discrete finite mixture model used in this chapter employs the discrete proportional hazard cloglog model discussed above.

Suppose that the cloglog hazard function assigns different intercepts for each class of firms. These differences among hazard functions can identify some of the missing information, or part of the unobserved heterogeneity among firms. For example, suppose that the baseline hazard is independent of time. We can adjust Equation (A.12) by assuming $b(t)=0$ and adding some time-dummy variables into vector $X_{t i}$ to encompass the non-parametric duration dependence in the model.

This procedure adds the unobserved heterogeneity as another parameter, such as intercept, to the hazard function of firm $i$ as below:

$$
h(t \mid v, x)=1-\exp \left[-\exp \left(v+\beta^{\prime} X_{t i}\right)\right]
$$

Now, consider $K$ different classes of firms. Each class has its own distribution. The method summarizes those distributions to unobservable mass points. Since we already do not know which firm is in which of the $K$ classes, each firm can be assigned to those classes with a probability coming from a multinomial distribution. Let's assume that the $\mathrm{UH}, v$, has $K$ discrete mass points $v=\left\{v_{1}, v_{2}, \ldots, v_{K}\right\}$ with probabilities $p=\left\{p_{1}, p_{2}, p_{3} \ldots, p_{K}\right\}$, where $p_{1}=\left(1-p_{2}-p_{3}-\ldots-p_{K}\right)$. Usually, $v_{1}$ is normalized

\footnotetext{
${ }^{5}$ Search for hshaz in Stata using the help command.
} 
to 0 .

In addition to the parameters in the $\beta$ vector, the method estimates $v_{1}, v_{2}, \ldots, v_{K}$ as well as $p_{1}, p_{2}, p_{3} \ldots, p_{K}$. So, the method estimates $K$ hazard functions - one for each latent class. For example, for the first class, the hazard function is:

$$
\hat{h}\left(t_{i} \mid \hat{v}_{1}, x\right)=1-\exp \left[-\exp \left(\hat{v}_{1}+\hat{\beta}_{0}+\hat{\beta}^{\prime} X_{i t}\right)\right]
$$

This specification leads to the following average hazard function for firm $i$ in period $t:$

$$
E\left[h\left(t_{i} \mid v, x\right)\right]=\sum_{k=1}^{K}\left[p_{k} h\left(t_{i} \mid v_{k}, x\right)\right]
$$

With $S\left(t_{i}\right)$ denoting the survival probability of firm $i$ operating in the market until time $t$ (see equation (A.16)), the contribution of this firm at time $t$ to the sample likelihood function is:

$$
f\left(t_{i} \mid v_{k}, x\right)=S\left(t_{i} \mid v_{k}, x\right)\left\{h\left(t_{i} \mid v_{k}, x\right) /\left(1-h\left(t_{i} \mid v_{k}, x\right)\right)\right\}^{d_{i}}
$$

where $d_{i}$ represents a censoring indicator; it equals 1 for censored observations, and zero otherwise. Since firm $i$ at each time can be categorized in class $k=1,2, \ldots, K$ with probability $p_{k}$, its contribution to DFM likelihood function at time $t$ is:

$$
L\left(t_{i}\right)=\sum_{k=1}^{K} p_{k} f\left(t_{i} \mid v_{k}, x\right)=\sum_{k=1}^{K}\left[p_{k} S\left(t_{i} \mid v_{k}, x\right)\left\{\frac{h\left(t_{i} \mid v_{k}, x\right)}{\left(1-h\left(t_{i} \mid v_{k}, x\right)\right)}\right\}^{d_{i}}\right]
$$

If we have panel data and firm $i$ survives up to period $T_{i}$, we can rewrite the above contribution of firm $i$ to the sample DFM likelihood function as bellow:

$$
L(i)=\sum_{k=1}^{K} p_{k} \prod_{t_{i}=1}^{T_{i}} f\left(t_{i} \mid v_{k}, x\right)
$$


With Equation (A.23), the following equation calculates the logarithm of the likelihood function for all $n$ firms in the industry:

$$
\ln (L(\theta))=\sum_{i=1}^{n} \ln L(i)
$$

Using Equation (A.23) for $L(i)$ in Equation (A.24):

$$
\ln (L(\theta))=\sum_{i=1}^{n} \ln \left[\sum_{k=1}^{K} p_{k} \prod_{t_{i}=1}^{T_{i}} f\left(t_{i} \mid v_{k}, x\right)\right]
$$

The expansion of Equation (A.25) after using the definition of $f\left(t_{i} \mid v_{k}, x\right)$ from Equation (A.21) takes the following form:

$$
\ln (L(\theta))=\sum_{i=1}^{n} \ln \left[\sum_{k=1}^{K} p_{k} \prod_{t_{i}=1}^{T_{i}} S\left(t_{i} \mid v_{k}, x\right)\left\{\frac{h\left(t_{i} \mid v_{k}, x\right)}{\left(1-h\left(t_{i} \mid v_{k}, x\right)\right)}\right\}^{d_{i}}\right]
$$

where, firm $i$ survives from $t_{i}=1,2, \ldots, T_{i}$. Different survival time for each firm leads to an unbalanced panel data.

The joint likelihood estimates the parameters of interest $\theta=$ $\left\{p_{1}, p_{2}, \ldots, p_{K}, v_{1}, v_{2}, \ldots, v_{K}, \beta_{0}, \beta, \lambda, K\right\}$. To determine the number of mixtures classes, $K$, the Bayesian Information Criterion (BIC) is used, $B I C_{k}=-2 \log l(\theta, p \mid t ; x)+d_{k} \log (N)$, where $d_{k}$ is equal to the dimension of the model and acts as a penalty term for overparameterizing the model and $N$ is the number of observations.

After estimating $\hat{\theta}, v_{k}+\hat{\beta}^{\prime} \bar{X}_{t}$ is calculated for each of the $k=1,2,3, \ldots, K$ classes, where $\bar{X}_{t}=\sum_{i=1}^{n} X_{t i}$. This result leads to calculating the hazard function for each type of firm at periods $t=1, \ldots, \max \left(T_{i}\right)$ by using Equation (A.19) as follows:

$$
\hat{h}\left(t \mid \hat{v}_{k}, x\right)=1-\exp \left[-\exp \left(\hat{v}_{k}+\hat{\beta}_{0}+\hat{\beta}^{\prime} \bar{X}_{t}\right)\right]
$$


Having estimated the probabilities of $\hat{p}_{1}, \hat{p}_{2}, \ldots, \hat{p}_{K}$, we can estimate the DFM hazard function by using (A.31) as below:

$$
E[h(t \mid v, x)]=\sum_{k=1}^{K}\left[\hat{p}_{k} \hat{h}\left(t \mid \hat{v}_{k}, x\right)\right]
$$

\section{A.5 The TS-DFM Model}

\section{A.5.1 The First Stage}

The first stage of the TS-DFM model estimates the following survival probability, $\hat{P}_{t i}$, where $z_{t i}$ serves as a vector of the exclusion restrictions, and $\Phi($.$) represents cdf of a$ Normal distribution:

$$
\operatorname{Pr}\left(t_{i}>1 \mid X_{t i}, z_{t i}\right)=\Phi\left(\delta^{\prime} X_{t i}+\gamma^{\prime} z_{t i}\right)
$$

\section{A.5.2 The Second Stage}

The second stage relies on the Stata code by Jenkins ${ }^{6}$ that employs the maximum likelihood method to estimate a discrete proportional hazard model for firm $i$ based on the following cloglog hazard:

$$
h\left(t_{i} \mid v, X_{t i}, \hat{\operatorname{Pr}}\left(t_{i}>1 \mid X_{t i}, z_{t i}\right)\right)=1-\exp \left[-\exp \left(v+\beta^{\prime} X_{t i}+\eta \hat{P}_{t i}+\epsilon_{t i}\right)\right]
$$

Where $\hat{P}_{t i}$ represents the estimated survival probability from the first stage. The vector $X_{t i}$ contains firm $i$ 's characteristics at time $t$. It also encompasses some timedummy variables to capture the non-parametric duration dependence in the model.

Parameter $v$ accounts for the unobserved heterogeneity suggested by Heckman

\footnotetext{
${ }^{6}$ Search for hshaz in Stata using the help command, or download it at:https://econpapers . repec.org/software/bocbocode/s444601.htm
} 
and Singer (1984). Now, consider $K$ different classes of firms. Each class has its own distribution. The method summarizes those distributions to unobservable mass points such as $v$. Since we already do not know which firm is in which of the $K$ classes, each firm can be assigned to those classes with a probability coming from a multinomial distribution. Let's assume that the unobserved heterogeneity, $v$, has $K$ discrete mass points $v=\left\{v_{1}, v_{2}, \ldots, v_{K}\right\}$ with probabilities $p=\left\{p_{1}, p_{2}, p_{3} \ldots, p_{K}\right\}$, where $p_{1}=\left(1-p_{2}-p_{3}-\ldots-p_{K}\right)$. Usually, $v_{1}$ is normalized to 0 .

A joint likelihood estimates the parameters of $\theta=$ $\left\{p_{1}, p_{2}, \ldots, p_{K}, v_{1}, v_{2}, \ldots, v_{K}, \beta, K\right\}$. To determine the number of mixtures classes, $K$, the Bayesian Information Criterion (BIC) is used, $B I C_{k}=$ $-2 \log l(\theta, p \mid t ; x)+d_{k} \log (N)$, where $d_{k}$ is equal to the dimension of the model and acts as a penalty term for overparameterizing the model and $N$ is the number of observations.

The estimation of $\hat{\theta}$ results in the calculation of $v_{k}+\hat{\beta}^{\prime} \bar{X}_{t}+\eta \overline{\hat{P}}_{t}$ for each of the $k=1,2,3, \ldots, K$ classes, where $\bar{X}_{t}=\frac{1}{n} \sum_{i=1}^{n} X_{t i}$ and $\overline{\hat{P}}_{t}=\frac{1}{n} \sum_{i=1}^{n} \hat{P}_{t i}$. Then, the hazard function for each type of the firms at periods $t=1, \ldots, \max \left(T_{i}\right)$ obtains as follows:

$$
\hat{h}\left(t \mid \hat{v}_{k}\right)=1-\exp \left[-\exp \left(\hat{v}_{k}+\hat{\beta}_{0}+\hat{\beta}^{\prime} \bar{X}_{t}\right)+\eta \overline{\hat{P}}_{t}\right] ; k=1,2,3, \ldots, K
$$

Having estimated the probabilities of $\hat{p}_{1}, \hat{p}_{2}, \ldots, \hat{p}_{K}$, the average DFM hazard function determines as:

$$
E[h(t \mid v)]=\sum_{k=1}^{K}\left[\hat{p}_{k} \hat{h}\left(t \mid \hat{v}_{k}\right)\right]
$$




\section{Appendix B}

\section{Appendix for Chapter 2}

\section{B.1 Tables}

Table B.1: Definition of Variables

\section{Credit Variables}

Any Credit

Business Credit

Personal Credit
Dummy variable, equals 1 if firm reports that it used either business credit, personal credit, or trade credit.

Dummy variable, equals 1 if firm reports that it used line, business credit. Business credit includes any of the following categories: business bank loan, business credit, business loan from non-bank institutions, business credit card, business credit card issued on owner's name, business loan from the government, business loan from other businesses, business loan from other sources. Dummy variable, equals 1 if firm reports that it used owner, personal credit. Personal credit includes any of the following categories: personal bank loan by the 
primary personal bank loan by other owners, the primary owner's personal credit card used for business purposes, and the other owners' personal credit cards used for business purposes.

Trade Credit Dummy variable, equals 1 if firm reports that it used trade credit.

\section{Other Sources of}

\section{Capital:}

Insider Equity

Insider Debt

Outsider Equity
Dummy variable, equals 1 if either spouse or parent provided equity financing.

Dummy variable, equals 1 if either family, employee, or any firm owner loaned money to the firm, primary owner, or other owners.

Dummy variable, equals 1 if informal investors (i.e., angel investors), businesses, government, venture capitalists, or other entities provided equity financing.

\section{Firm Characteristics:}

Revenue

Revenue growth

Tangible Assets

Credit Risk
Annual revenue from sales of product or service.

Growth rate of revenue between revenue in 2004 and revenue in 2007.

Sum of equipment, land/building, vehicles, other business property, and other assets such as intangibles.

Categorical variable (1 to 5 ) based on the credit score of 
the firm derived from Dunn and Bradstreet U.S. Ratings and Scores. A firm with a credit risk of 1 has the highest credit quality; a firm with a credit risk of 5 has the lowest credit quality.

Corporate

Non-Corp

Multiown

Intell Property

Comparative Advantage

Product

Product \& Service

Owner Characteristics:

Primary Owner

Ownership

Owner Age

Female

Asian

Black

Hispanic

White

High School
Firm is organized as an S-corporation, C-corporation, or Limited Liability Company/Partnership (LLC/LLP). Firm is organized as a Sole-proprietorship or Partnership. Firm has more than one owner.

Dummy variable, equals 1 if firm reports that it has trademarks, patents, or copyrights.

Dummy variable, equals 1 if firm reports that it has a comparative advantage.

Dummy variable, equals 1 if firm only sells product.

Dummy variable, equals 1 if firm sells product and service.

Owner with the highest percentage of firm ownership. Firm ownership (in \%) by primary owner.

Age of primary owner (in years).

Primary owner is female.

Primary owner is Asian.

Primary owner is Black.

Primary owner is Hispanic.

Primary owner is White.

Primary owner is either a high school graduate, 
has some high school education but no diploma, or has less than ninth-grade education.

College Education Primary owner has either attended some college, has a bachelor's degree, or may have attended a graduate school but has no graduate degree.

Graduate Degree

Work Experience

Other businesses

Hours worked
Primary owner has a graduate degree.

Prior work experience (in years) of the primary owner in the same industry.

Number of prior business start-ups by the primary owner. Number of hours worked per week by the primary owner.

Notes: The author borrows most of the variables' definition from Cole and Sokolyk (2018). 
Table B.2: Initial Conditions and Their Correlations with Survival Time and Revenue Groups

\begin{tabular}{|c|c|c|c|c|}
\hline & 2004 & Survivals (2007) & \multicolumn{2}{|c|}{ Correlation } \\
\hline \multirow[t]{2}{*}{ Initial conditions } & $\mathrm{N}(\%$ of total) & $\mathrm{N}(\%$ of 2004$)$ & \multicolumn{2}{|c|}{ Survival $\ln ($ revenue) } \\
\hline & & & $(2007)$ & $(2007)$ \\
\hline \multicolumn{5}{|l|}{ Credit variables } \\
\hline Any credit & $3338(76)$ & $2188(65)$ & 0.039 & 0.136 \\
\hline Business, personal, or both credits & $3168(72)$ & $2072(65)$ & 0.023 & 0.104 \\
\hline Business credit & $1960(45)$ & $1298(66)$ & 0.041 & 0.142 \\
\hline Business but not personal credit & $772(17)$ & $525(68)$ & 0.031 & 0.111 \\
\hline Only business credit & $574(13)$ & $395(69)$ & 0.039 & 0.055 \\
\hline Personal credit & $2396(55)$ & $1547(65)$ & -0.003 & 0.007 \\
\hline Personal but not business credit & $1208(28)$ & $774(64)$ & -0.023 & -0.056 \\
\hline Only personal credit & $968(22)$ & $618(66)$ & -0.018 & -0.09 \\
\hline
\end{tabular}

\section{Other variables}

Females

Black

Asian

White

Corporation

Multiple owners

Work $\exp >0$ year

Other busin $>0$ year
1114(31)

321(9)

149(4)

3561(81)

2744(60)

1708(38)

4015(94)

1909(45)
688(62)

188(59)

91(61)

2338(66)

1753(64)

1083(63)

2604(65)

1254(66)
$-0.055$

$-0.133$

$-0.006 \quad-0.123$

$0.012 \quad-0.025$

$0.039 \quad 0.126$

$-0.003$

0.177

$0.004 \quad 0.109$

$0.098 \quad 0.056$

$0.044 \quad 0.056$ 


\begin{tabular}{lcccc} 
Intellectual property & $925(19)$ & $603(65)$ & 0.043 & 0.033 \\
Comparative advantage & $2790(62)$ & $1830(66)$ & 0.027 & 0.142 \\
Product & $2249(51)$ & $1443(64)$ & 0.011 & 0.085 \\
College degree & $2860(47)$ & $1833(64)$ & 0.019 & -0.026 \\
Graduate degree & $926(18)$ & $628(68)$ & 0.04 & 0.038 \\
Insider debt & $518(13)$ & $304(59)$ & -0.039 & 0.056 \\
Insider equity & $157(4)$ & $93(60)$ & -0.036 & -0.01 \\
Outside equity & $226(5)$ & $130(58)$ & -0.028 & 0.086 \\
\hline
\end{tabular}

Notes:

Source: Confidential Kauffman Firm Survey (KFS). Survey weights are applied.

Any credit: Refers to those firms that initially use at least one type of credit such as business credit, personal credit, and/or trade credit.

Business credit: Refers to those firms that business credit constitutes part of their financing resources in the first year. Some of them may also use personal credit.

Personal credit: Refers to those firms that personal credit constitutes part of their financing resources in the first year. Some of them may also use business credit.

Business but not personal credit: Refers to those firms that business credit constitutes part of their financing resources in the first year. They do not use personal credit, however, some of them may also rely on trade credit.

Personal but not Business credit: Refers to those firms that personal credit constitutes part of their financing resources in the first year. They do not use business credit, however, some of them may also rely on trade credit.

Only business credit: Refers to those firms that start with only business credit to financing their businesses in 2004 . Only personal credit: Refers to those firms that start with only personal credit to financing their businesses in 2004 . Survivals: Refers to a dummy variable with the value of 1 if a firm survives until the end of 2007 .

Calculated by the author. 
Table B.3: Pre-entry quality revealed by the entry share of Tangible Assets (TA)

\begin{tabular}{|c|c|c|c|}
\hline \multirow[b]{2}{*}{ A: } & \multicolumn{3}{|c|}{ Average Entry-Share of TA } \\
\hline & if Yes & if No & Diff \\
\hline Business credit & 0.01 & 0.004 & $0.006^{* *}$ \\
\hline Personal credit & 0.003 & 0.006 & $-0.003^{*}$ \\
\hline Number of employees $>=2$ & 0.007 & 0.003 & $0.004^{* *}$ \\
\hline Other businesses $>1$ & 0.01 & 0.004 & $0.006^{* *}$ \\
\hline Graduate degree & 0.007 & 0.005 & $0.002^{*}$ \\
\hline Intellectual property & 0.008 & 0.004 & $0.004^{* *}$ \\
\hline Comparative Adva & 0.006 & 0.004 & $0.002^{*}$ \\
\hline Incorporated & \multicolumn{3}{|c|}{ correlation } \\
\hline B: & \multicolumn{3}{|c|}{ Business credit Personal credit $\ln ($ revenue 2007) } \\
\hline Entry-share of TA & $0.055^{* *}$ & $-0.024^{* *}$ & 0.026 \\
\hline
\end{tabular}

Table B.4: Other Exclusion Restrictions

Correlation

A:

Selection component Per-capita secured loans

$\begin{array}{lcc}\text { Tangible Assets } \mid \text { BusCrd=1 } & 0.081^{* *} & 0.231^{* *} \\ \text { Tangible Assets|PersCrd=1 } & 0.023 & 0.03 \\ \text { Ln(Revenue2007) } & 0.012 & 0.088^{* *}\end{array}$

B:

Correlation

Survive Survival Component

Ln(Revenue2007) 0.012

Notes: Author's calculation based on Kauffman Firm Survey data. Tangible Assets|BusCrd=1: tangible assets for those firms that started with only business credit in 2004. Tangible Assets|PersCrd=1: tangible assets for those firms that started with only personal credit in 2004. Selection component: is the selection component of tangible assets calculated based on the formula in Pinto (2008), separately for agricultural and non-agricultural sectors, for the firms that passed the first year. Survival Component is the average of survival components for revenue calculated based on the formula in Pinto (2008) (averaged on a firm's survival time). Survive: a dummy variable equal to 1 if a firm survives until the end of $2007 .{ }^{*} p<0.10,{ }^{* *} p<0.05$. 
Table B.5: Structural Equation Modelling for Business Credit (Framework A) and Personal Credit (Framework B)

Framework A

$(1)$

(3)

$(4)$

(5)

(6)

Framework B

Survive Business Revenue Survive Personal Revenue

\section{Excl. restrictions:}

Survival comp.

$1.584^{* *}$

(0.088)
Entry share of TA

Entry-selection comp.

Per-capita secured loan

Sources of bias

Endogeneity (SUH1)

Surviving (SUH2)

1

$$
\begin{array}{cc}
1 & -1.096^{* *} \\
- & (0.265)
\end{array}
$$$$
1.580^{* *}
$$

$0.314^{* *}$

$0.005^{*}$

(0.003)

$0.021^{* *}$

(0.006)
$-0.077$

0.203

0.002

(0.003)

$-0.027^{* *}$

(0.008)

$\begin{array}{lll}- & (0.265) \quad-\quad(0.176)\end{array}$

Endog. treatment:

Business credits

Personal credits 
$(0.219)$

\begin{tabular}{|c|c|c|c|c|c|}
\hline \multirow[t]{4}{*}{3282} & 3272 & 1966 & 3282 & 3272 & 1966 \\
\hline & \multicolumn{2}{|c|}{16583.44} & \multicolumn{3}{|c|}{17328.560} \\
\hline & \multicolumn{2}{|c|}{17083.33} & \multicolumn{3}{|c|}{17828.45} \\
\hline & \multicolumn{2}{|c|}{-8209.721} & \multicolumn{3}{|c|}{-8582.280} \\
\hline \multicolumn{3}{|c|}{$\tilde{\chi}^{2}=908.21^{* *}$} & \multicolumn{3}{|c|}{$\tilde{\chi}^{2}=877.83^{* *}$} \\
\hline \multicolumn{3}{|c|}{$\tilde{\chi}^{2}=921.44^{* *}$} & \multicolumn{3}{|c|}{$\tilde{\chi}^{2}=883.43^{* *}$} \\
\hline
\end{tabular}

Notes: Coefficients represent Marginal Effects, Standard errors in parentheses, ${ }^{*} p<0.10,{ }^{* *} p<0.05$.

Excl. restrictions: Exclusion restrictions.

Endog. treatment: Endogenous treatment.

Framework A: A structural equation modelling where latent variable $S U H_{1}$ with normal distribution links the Business credit equation and the Revenue equation, and controls for endogeneity bias in the two equations. Latent variable $\mathrm{SUH}_{2}$ with normal distribution binds the Survival equation and the Revenue equation and controls for surviving selection bias.

Framework B: A structural equation modelling where latent variable $S U H_{2}$, similar to Framework A, links the Personal credit equation and the Revenue equation, and controls for endogeneity bias in the two equations. Latent variable $\mathrm{SU} \mathrm{H}_{2}$ binds the Survival equation and the Revenue equation, and controls for surviving selection bias.

The SEM frameworks uses a Probit model for the Business credit equation, for the Personal credit equation, for the Survival equation. They employ a linear regression model for the Revenue equations.

Business credit: Refers to a dummy variable that gets the value of one if an owner starts with business credits, but not personal credit, as part of financing the capital in the first year, 2004. Personal credit: Refers to a dummy variable that gets the value of one if an owner runs its business by using the personal credit, but not business credit, as part of financing the capital in the first year, 2004. $\mathbf{L n}($ revenue+1): The dependent variable in the revenue equation is equal to the natural logarithm of revenue in 2007 plus one (to avoid the issue related to the logarithm of zero).

LR test: is the Likelihood Ratio Test for testing the hypothesis that the coefficients of Survival comp., Entry share of TA, Entry-selection comp., and Per-capita secured loan are equal to 0 .

LR test (with sq. and poly.): is the Likelihood Ratio Test for testing the hypothesis that the coefficients of exclusion restrictions, and a combination of their squares and polynomials are all equal to zero.

The Stata assumes that exogenous variables are freely correlated, see Acock (2013), page 81.

Calculated by the author. 
Table B.6: Entry conditions, survival probability, start-up bank credit, and a firm's performance

\begin{tabular}{|c|c|c|c|c|c|c|}
\hline & \multicolumn{3}{|c|}{ SEM(Business Credit) } & \multicolumn{3}{|c|}{ SEM (Personal Credit) } \\
\hline & Surviving & Bus Crd & Revenue & Surviving & Pers Crd & Revenue \\
\hline \multirow[t]{2}{*}{ Any credit } & $0.052^{* *}$ & - & - & $0.050^{* *}$ & - & - \\
\hline & $(0.022)$ & & & $(0.022)$ & & \\
\hline \multirow[t]{2}{*}{ Credit_score } & $-0.019^{*}$ & $-0.034^{* *}$ & $-0.171^{* *}$ & $-0.020^{*}$ & $0.026^{* *}$ & $-0.184^{* *}$ \\
\hline & $(0.012)$ & $(0.009)$ & $(0.057)$ & $(0.012)$ & $(0.013)$ & $(0.056)$ \\
\hline \multirow[t]{2}{*}{$\ln (1+$ revenue2004) } & 0.003 & $0.006^{* *}$ & $0.047^{* *}$ & 0.003 & -0.002 & $0.053^{* *}$ \\
\hline & $(0.002)$ & $(0.001)$ & $(0.008)$ & $(0.002)$ & $(0.002)$ & $(0.008)$ \\
\hline \multirow[t]{2}{*}{ Corporate } & -0.008 & $0.045^{* *}$ & $0.570^{* *}$ & -0.007 & -0.061 & $0.557^{* *}$ \\
\hline & $(0.020)$ & $(0.014)$ & $(0.098)$ & $(0.020)$ & $(0.023)$ & $(0.096)$ \\
\hline \multirow[t]{2}{*}{ Multiowner } & 0.019 & 0.017 & $0.442^{* *}$ & 0.016 & -0.069 & $0.408^{* *}$ \\
\hline & $(0.020)$ & $(0.015)$ & $(0.097)$ & $(0.020)$ & $(0.021)$ & $(0.096)$ \\
\hline \multirow[t]{2}{*}{$\ln$ (hours) } & 0.008 & 0.010 & $0.498^{* *}$ & 0.008 & -0.016 & $0.474^{* *}$ \\
\hline & $(0.010)$ & $(0.008)$ & $(0.045)$ & $(0.010)$ & $(0.010)$ & $(0.046)$ \\
\hline \multirow[t]{2}{*}{ Female } & -0.030 & $-0.024^{*}$ & $-0.462^{* *}$ & -0.030 & $0.047^{* *}$ & $-0.424^{* *}$ \\
\hline & $(0.020)$ & $(0.014)$ & $(0.095)$ & $(0.020)$ & $(0.022)$ & $(0.093)$ \\
\hline \multirow[t]{2}{*}{ Intellectual Property } & 0.002 & -0.006 & -0.028 & 0.002 & $-0.042^{*}$ & -0.077 \\
\hline & $(0.020)$ & $(0.016)$ & $(0.099)$ & $(0.020)$ & $(0.022)$ & $(0.100)$ \\
\hline \multirow[t]{2}{*}{ Comparative adv } & 0.017 & 0.021 & -0.004 & 0.018 & $0.039 * *$ & 0.085 \\
\hline & $(0.018)$ & $(0.013)$ & $(0.085)$ & $(0.018)$ & $(0.019)$ & $(0.085)$ \\
\hline Product & -0.029 & 0.008 & $0.195^{* *}$ & -0.029 & 0.016 & $0.225^{* *}$ \\
\hline
\end{tabular}




$$
\begin{array}{lllll}
(0.025) \quad(0.020) \quad(0.125) \quad(0.025) \quad(0.028) \quad(0.126)
\end{array}
$$

$\begin{array}{lllllll}\text { product_service } & 0.055^{* *} & -005 & -0.053 & 0.055^{* *} & -0.046^{*} & -0.143\end{array}$

$\begin{array}{lllllll} & (0.025) & (0.20) & (0.126) & (0.024) & (0.027) & (0.128) \\ \text { Work experience } & 0.002^{*} & 0.001^{*} & 0.013^{* *} & 0.002^{*} & -0.002^{* *} & 0.011^{* *} \\ & (0.001) & (0.0007) & (0.004) & (0.001) & (0.001) & (0.004)\end{array}$

$\begin{array}{lllllll}\text { Other businesses } & 0.007 & -0.008 & 0.075^{* *} & 0.007 & 0.009 & 0.080^{* *}\end{array}$ $\begin{array}{lllll}(0.007) & (0.005) & (0.032) & (0.007) & (0.008)\end{array} \quad(0.033)$

$\begin{array}{lllllll}\text { College degree } & 0.078^{* *} & 0.001 & -0.058 & 0.078^{* *} & 0.016 & -0.042\end{array}$ $\begin{array}{lllll}(0.026) & (0.020) & (0.130) & (0.026) & (0.028)\end{array} \quad(0.129)$

$\begin{array}{lllllll}\text { Graduate degree } & 0.113^{* *} & 0.024 & 0.009 & 0.113^{* *} & 0.037 & 0.095\end{array}$

$$
\begin{array}{lllll}
(0.025) & (0.026) & (0.150) \quad(0.025) \quad(0.036) & (0.151)
\end{array}
$$

$\begin{array}{lllllll}\text { Outside equity } & -0.060 & 0.010 & 0.370^{* *} & -0.061 & -0.019 & 0.331\end{array}$

$$
\begin{array}{lllll}
(0.043) & (0.027) \quad(0.191) \quad(0.043) \quad(0.044) \quad(0.201)
\end{array}
$$

$\begin{array}{lllllll}\text { Insider equity } & -0.037 & 0.005 & -0.278 & -0.038 & 0.055 & -0.181\end{array}$

$$
\begin{array}{lllll}
(0.043) & (0.034) & (0.221) & (0.047) \quad(0.055) & (0.227)
\end{array}
$$

$\begin{array}{lllllll}\text { Insider debt } & 0.011 & -0.053^{* *} & 0.117 & 0.011 & 0.033 & 0.079\end{array}$

$\begin{array}{lcccccc} & (0.026) & (0.015) & (0.129) & (0.026) & (0.030) & (0.128) \\ \ln (1+\text { owner's equity }) & -0.005^{* *} & -0.002 & 0.027^{* *} & -0.005^{* *} & 0.000 & 0.024^{* *} \\ & (0.002) & (0.002) & (0.011) & (0.002) & (0.002) & (0.011) \\ \ln (\text { owner's age }) & 0.6 & 0.013 & 8.318^{* *} & 0.613 & -1.158 & 6.731^{*} \\ & (0.769) & (0.609) & (3.780) & (0.768) & (0.838) & (3.833) \\ \ln (\text { owner's age })^{2} & -0.075 & -0.005 & -1.173^{* *} & -0.077 & 0.158 & -0.963^{*} \\ & (0.130) & (0.81) & (0.504) & (0.103) & (0.112) & (0.511) \\ & 0.024 & 0.020 & 0.276 & 0.023 & -0.070^{*} & 0.180\end{array}$




\begin{tabular}{lcccccc} 
& $(0.051)$ & $(0.049)$ & $(0.264)$ & $(0.051)$ & $(0.048)$ & $(0.271)$ \\
Black & $0.068^{*}$ & -0.003 & 0.053 & $0.068^{*}$ & $-0.092^{* *}$ & -0.092 \\
& $(0.038)$ & $(0.038)$ & $(0.222)$ & $(0.037)$ & $(0.037)$ & $(0.224)$ \\
White & $0.112^{* *}$ & 0.021 & $0.298^{*}$ & $0.112^{* *}$ & -0.020 & $0.286^{*}$ \\
& $(0.037)$ & $(0.025)$ & $(0.170)$ & $(0.037)$ & $(0.039)$ & $(0.173)$ \\
\hline
\end{tabular}

Notes: Standard errors in parentheses, ${ }^{*} p<0.10,{ }^{* *} p<0.05$.

Any credit: Refers to those firms that initially use at least one type of credit such as business credit, personal credit, and/or trade credit.

$\ln (\text { owner's age })^{2}:$ is the the natural logarithm of an owner's age in power two.

Calculated by the author. 


\section{B.2 Optimal Debt Contract}

Following Freixas and Laffont (1990), consider an entrepreneur with an initial asset, A. The initial asset, however, is less than the investment, $I$, required to start a venture. So, the entrepreneur needs to borrow the amount $l=I-A$ from a bank to run the business. The firm has the following production function:

$$
\tilde{y}=\tilde{s} \theta f(l) ; \quad f^{\prime}(l)>0, f^{\prime \prime}(l)<0, \quad \lim _{x \rightarrow 0} f^{\prime}(l)=\infty, \lim _{x \rightarrow \infty} f^{\prime}(l)=0
$$

where $\tilde{y}$ denotes output. For a small business we may assume $A=0$, so the amount of business credit, $l$, represents the firm's investment. The stochastic variable $\tilde{s}$ represents uncertainty about the firm's production (uncertainty about the economic environment). It follows a uniform distribution on the interval $[0,1]$. The parameter $\theta$ specifies the firm's productivity as well as everything related to its quality or its type.

Also, with the assumption of limited liability, a firm receives zero output in a bad state. In an environment with both the bank and firm risk neutral, and with auditing cost $c$ for observing $y$, a debt contract with repayment $R(l, \theta, y)=\operatorname{Min}(R(l, \theta), y)$ for $l$ turns out optimal. As Freixas and Laffont (1990), let's define a failure rate, $\psi(\theta)$, as follows:

$$
\psi(\theta)=\frac{R(\theta)}{\theta f(l)}
$$

For a firm with quality $\theta$, its expected output is calculated by integrating over $\tilde{s} \in[0,1]$. With $0<\psi(\theta)<1$, let's suppose that $s^{*}=\psi(\theta)$ is the threshold of $\tilde{s}$ that results in an expected profit larger or equal to the firm's reservation profit. For $\tilde{s} \geq s^{*}$

the firm's expected output can be defined as $\theta f(l) \int_{\psi}^{1} s d s=\theta f(l) \frac{1-\psi^{2}}{2}$. For values of $\tilde{s} \leq s^{*}$, however, the firm's expected profit would be less or equal to the reservation level, and the firm goes bankrupt. The expected output in the bankruptcy case is 
equal to $\theta f(l) \int_{0}^{\psi} s d s=\theta f(l) \frac{\psi^{2}}{2}$. In the bankruptcy situation, the banks receives all the output and the firm gets zero. If a firm's quality is very high, regardless of economic uncertainty, the firm's expected profit will be bigger than its reservation level. Therefore, $s^{*}=\psi(\theta)=0$, and the expected output is equal to $\theta f(l) \int_{\psi=0}^{1} s d s$.

With $\psi(\theta)=\frac{R(\theta)}{\theta f(l)}$, the elements of a credit contract can be specified as $(l, \psi(\theta))$ instead of $(l, R(\theta))$. Suppose $\psi(\theta)$ denotes a firm's probability of bankruptcy when the bank also knows its $\theta$. This specification leads to the following expected profit for the firm:

$$
\begin{array}{r}
U=\underbrace{\int_{\psi(\theta)}^{1} \theta f(l) s d s}_{\text {Firm's income when no bankruptcy }}-\underbrace{R(\theta) \int_{\psi(\theta)}^{1} d s}_{\text {Firm's payment to the bank when no bankruptcy }} \\
=\theta f(l)\left(\frac{1}{2}-\frac{\psi^{2}(\theta)}{2}\right)-R(1-\psi(\theta))
\end{array}
$$

which can be written as:

$$
U=\theta f(l)\left\{\left(\frac{1}{2}-\frac{\psi^{2}(\theta)}{2}\right)-\psi(\theta)+\psi^{2}(\theta)\right\}=\frac{1}{2} \theta f(l)(1-\psi(\theta))^{2}
$$

Similarly, the bank obtains the following expected income:

$$
\begin{aligned}
& V=\underbrace{R(\theta) \int_{\psi(\theta)}^{1} d s}_{\text {Firm's payment to the bank when no bankruptcy }}+\underbrace{\int_{0}^{\psi(\theta)} \theta f(l) s d s}_{\text {Bank's income when bankruptcy }} \\
& -\underbrace{c \int_{0}^{\psi(\theta)} d s}_{\text {audit cost when bankruptcy }}-(1+r)(I-A)
\end{aligned}
$$


Equation B.5 can be rewritten as:

$$
\begin{array}{r}
V=\theta f(l)\left\{\frac{R(\theta)}{\theta f(l)} \int_{\psi(\theta)}^{1} d s+\int_{0}^{\psi(\theta)} s d s\right\}-c \psi(\theta)-(1+r)(I-A) \\
=\theta f(l)\left\{\psi(\theta)[1-\psi(\theta)]+\left[\frac{\psi^{2}(\theta)}{2}\right]\right\}-c \psi(\theta)-(1+r)(I-A) \\
=\theta f(l)\left\{\psi(\theta)-\frac{\psi^{2}(\theta)}{2}\right\}-c \psi(\theta)-(1+r)(I-A)
\end{array}
$$

\section{B.2.1 Adverse Selection and Moral Hazard}

In contrast to the model with continuous types in Freixas and Laffont (1990), this paper focuses on two types of firms: a high-quality (or efficient) firm with parameter

$\bar{\theta}$ accessing to bank credit $\bar{l}$, and a low-quality (or inefficient) firm with parameter $\underline{\theta}$ accessing to bank credit $\underline{l}$. Now, assume that the bank can recognize the efficient firm only with probability $v$ at the time of contract, namely adverse selection issue. Also, the bank needs to satisfy a firm's incentive constraint for convincing it to exert effort, namely moral hazard issue. Exerting effort, however, raises the costs for the firm by $B$. With exerting effort, the good state occurs more likely with probability $p_{1}$; without exerting effort, it occurs with $p_{0}<p_{1}$. Suppose that the bank maximizes its profit subject to incentive and participation constraints associated with both types of firms, see Laffont and Martimort (2009). For the high- and the low-quality firms, this specification leads to the following incentive (IC) and participation (PC) constraints related to both moral hazard $(\mathrm{MH})$ and adverse selection $(\mathrm{AD})$ issues:

ICs for the high quality firm:

$$
\begin{gathered}
\overline{I C}^{A D}: \bar{U}=\frac{1}{2} p_{1} \bar{\theta} f(\bar{l})(1-\bar{\psi})^{2}-B \geq \frac{1}{2} p_{1} \bar{\theta} f(\underline{l})(1-\underline{\psi})^{2}-B \\
\overline{I C}^{M H}: \frac{1}{2} \Delta p \bar{\theta} f(\bar{l})(1-\bar{\psi})^{2}-B \geq 0 \quad ; \quad \Delta p=p_{1}-p_{0}
\end{gathered}
$$


ICs for the low quality firm:

$$
\begin{gathered}
\underline{I C}^{A D}: \underline{U}=\frac{1}{2} p_{1} \underline{\theta} f(\underline{l})(1-\underline{\psi})^{2}-B \geq \frac{1}{2} p_{1} \underline{\theta} f(\bar{l})(1-\bar{\psi})^{2}-B \\
\underline{I C}^{M H}: \frac{1}{2} \Delta p \underline{\theta} f(\underline{l})(1-\underline{\psi})^{2}-B \geq 0 \quad ; \quad \Delta p=p_{1}-p_{0}
\end{gathered}
$$

PCs:

$$
\begin{gathered}
\bar{U} \geq 0 \\
\underline{U} \geq 0
\end{gathered}
$$

The bank prefers to bind moral hazard (incentive) constraints B.8 and B.10, leading to the following equality:

$$
\frac{1}{2} \bar{\theta} f(\bar{l})(1-\bar{\psi})^{2}=\frac{B}{\Delta p}=\frac{1}{2} \underline{\theta} f(\underline{l})(1-\underline{\psi})^{2}
$$

The LHS of restriction B.13 represents the difference between the expected output in the good state and zero output in the bad state for a high-quality firm. The RHS denotes the same value for a low-quality firm. These differences should be the same for both types (see also Laffont and Martimort (2009)).

Following Laffont and Martimort (2009), restriction B.7 becomes:

$$
\begin{array}{r}
\bar{U} \geq \frac{1}{2} p_{1} \bar{\theta} f(\underline{l})(1-\underline{\psi})^{2}-\frac{1}{2} p_{1} \underline{\theta} f(\underline{l})(1-\underline{\psi})^{2}+\frac{1}{2} p_{1} \underline{\theta} f(\underline{l})(1-\underline{\psi})^{2} \\
\bar{U} \geq \frac{1}{2} \Delta \theta f(\underline{l})(1-\underline{\psi})^{2}+\underline{U} \quad ; \Delta \theta=\bar{\theta}-\underline{\theta}
\end{array}
$$

Similarly, restriction B.9 becomes:

$$
\underline{U} \geq \bar{U}-\frac{1}{2} \Delta \theta f(\bar{l})(1-\bar{\psi})^{2}
$$

As usual, we bind the participation constraint B.12 for the low-quality firm. By using 
the definition of $\underline{\mathrm{U}}$ and inserting the right hand side of B.13 in it, we can write:

$$
\underline{U}=\frac{1}{2} p_{1} \underline{\theta} f(\underline{l})(1-\underline{\psi})^{2}-B=p_{1} \frac{B}{\Delta p}-B=\frac{p_{0} B}{\Delta p}>0
$$

Using the moral hazard rent B.16, the bank also prefers to bind the incentive constraint related to adverse selection for the high-quality firm (B.14) to get:

$$
\bar{U}=\frac{1}{2} p_{1} \Delta \theta f(\underline{l})(1-\underline{\psi})^{2}+\frac{p_{0} B}{\Delta p}
$$

In equation B.16, $\underline{U}>0$ reflects the limited liability constraint. The term $\frac{p_{0} B}{\Delta p}$ refers to the rent that the bank has to pay to the low-quality firm to encourage it for exerting effort. The bank, however, rewards more the high-quality firm. The extra reward depends on the firm's efficiency in equation B.17. The higher is the gap between the quality of the two firms, $\Delta \theta$, the bigger is the reward to the high-quality firm. The feature of the low-quality firm also affects the extra reward. When the low-quality firm has a higher failure rate or obtains smaller bank credit, $\underline{l}$, the bank offers less additional reward to the high-quality firm. This reward can be reflected in the terms and conditions of a credit contract. For example, the bank may ask the high-quality firm to repay the business credit with a lower repayment rate or a smaller amount of reimbursement. Thus the heterogeneity in the quality of the firms leads to heterogeneity in the terms of credit contracts.

The way a cohort enters in a market may also influence the amount of bank credit granted to its firms. Consider firms of a cohort that start operating in a harsh economic environment. Most firms have to rely on less efficient tangible and intangible assets. They select less efficient scales, i.e., lower productivity, $\theta$. Overall, this situation directly and indirectly affects bank credit granted to the firms of this 
cohort. Low-quality firms would start with more restricted bank credit, and highquality firms would receive smaller extra reward or lower reimbursement discounts.

\section{The Bank's Optimization Problem}

This section reviews the bank's optimization problem. It presents the optimal amount of loans that the bank grants to a low- and high-quality firms.

If a high-quality firm exerts effort, its utility based on equation B.3 becomes:

$$
\bar{U}=p_{1} \bar{\theta} f(\bar{l})\left(\frac{1}{2}-\frac{\bar{\psi}^{2}}{2}\right)-p_{1} R(1-\bar{\psi})-B
$$

Equation B.18 gives the firm's reimbursement to the bank as:

$$
p_{1} \bar{R}(1-\bar{\psi})=-\bar{U}+p_{1} \bar{\theta} f(\bar{l})\left(\frac{1}{2}-\frac{\bar{\psi}^{2}}{2}\right)-B
$$

When the high-quality firm exerts effort, equation B.5 presents the bank's profit as:

$$
\bar{V}=p_{1} R(1-\bar{\psi})+\left(1-p_{1}\right) \bar{\theta} f(\bar{l}) \frac{\bar{\psi}^{2}}{2}-\left(1-p_{1}\right) c \bar{\psi}-(1+r)(\bar{l}-A)
$$

Using equation B.19 to substitute for the first term in the RHS of equation B.20 results in:

$$
\bar{V}=-\bar{U}+p_{1} \bar{\theta} f(\bar{l})\left(\frac{1}{2}-\frac{\bar{\psi}^{2}}{2}\right)-B+(1-p) \bar{\theta} f(\bar{l}) \frac{\bar{\psi}^{2}}{2}-\left(1-p_{1}\right) c \bar{\psi}-(1+r) \bar{l}
$$

Similarly, for the low quality firm the bank's expected profit becomes:

$$
\underline{V}=-\underline{U}+p_{1} \underline{\theta} f(\underline{l})\left(\frac{1}{2}-\frac{\underline{\psi}^{2}}{2}\right)-B+(1-p) \underline{\theta} f(\underline{l}) \frac{\underline{\psi}^{2}}{2}-\left(1-p_{1}\right) \underline{c} \underline{\psi}-(1+r) \underline{l}
$$


The above specification summarizes the bank's maximization problem as below:

$$
\begin{aligned}
& \max _{(\bar{l}, \bar{\psi}),(\underline{l}, \underline{\psi})}\left\{v\left\{-\bar{U}+p_{1} \bar{\theta} f(\bar{l})\left(\frac{1}{2}-\frac{\bar{\psi}^{2}}{2}\right)-B+\left(1-p_{1}\right) \bar{\theta} f(\bar{l}) \frac{\bar{\psi}^{2}}{2}-\left(1-p_{1}\right) c \bar{\psi}-(1+r) \bar{l}\right\}\right. \\
& \left.+(1-v)\left\{-\underline{U}+p_{1} \underline{\theta} f(\underline{l})\left(\frac{1}{2}-\frac{\underline{\psi}^{2}}{2}\right)-B+\left(1-p_{1}\right) \underline{\theta} f(\underline{l}) \frac{\psi^{2}}{2}-\left(1-p_{1}\right) c \underline{\psi}-(1+r) \underline{l}\right\}\right\}
\end{aligned}
$$

subject to

$\operatorname{Equation}(B .17): \quad \bar{U}=\frac{1}{2} p_{1} \Delta \theta f(\bar{l})(1-\bar{\psi})^{2}+\underline{U}$

$\operatorname{Equation}(B .16): \quad \underline{U}=\frac{p_{0} B}{\Delta p}$

$$
\bar{\psi} \geq 0 \quad ; \quad \mu \bar{\psi}=0
$$

The last restriction ensures that the bank gets positive reimbursements from both types. After substituting both restrictions B.16 and B.17 into the maximization problem, it becomes:

$$
\begin{aligned}
H= & \max _{(\bar{l}, \bar{\psi}),(\underline{l}, \underline{\underline{ }})}\left\{v \left\{-\frac{1}{2} p_{1} \Delta \theta f(\underline{l})(1-\underline{\psi})^{2}-\frac{p_{0} B}{\Delta p}+p_{1} \bar{\theta} f(\bar{l})\left(\frac{1}{2}-\frac{\bar{\psi}^{2}}{2}\right)-B+\left(1-p_{1}\right) \bar{\theta} f(\bar{l})\right.\right. \\
& \left.\frac{\bar{\psi}^{2}}{2}-\left(1-p_{1}\right) c \bar{\psi}-(1+r) \bar{l}+\mu \bar{\psi}\right\}+(1-v)\left\{-\frac{p_{0} B}{\Delta p}+p_{1} \underline{\theta} f(\underline{l})\left(\frac{1}{2}-\frac{\underline{\psi}^{2}}{2}\right)-B\right. \\
& \left.\left.+\left(1-p_{1}\right) \underline{\theta} f(\underline{l}) \frac{\psi^{2}}{2}-\left(1-p_{1}\right) c \underline{\psi}-(1+r) \underline{l}\right\}\right\}
\end{aligned}
$$

First order conditions:

$$
\begin{aligned}
& \frac{\partial H}{\partial \bar{l}}=v\left\{p_{1} \bar{\theta} f^{\prime}(\bar{l})\left(\frac{1}{2}-\frac{\bar{\psi}^{2}}{2}\right)+\left(1-p_{1}\right) \bar{\theta} f^{\prime}(\bar{l}) \frac{\bar{\psi}^{2}}{2}-(1+r)\right\}=0 \\
& \frac{\partial H}{\partial \bar{\psi}}=v\left\{p_{1} \bar{\theta} f(\bar{l})(-\bar{\psi})+\left(1-p_{1}\right) \bar{\theta} f(\bar{l}) \bar{\psi}-\left(1-p_{1}\right) c+\mu\right\}=0
\end{aligned}
$$




$$
\frac{\partial H}{\partial \underline{l}}=v\left\{-\frac{1}{2} p_{1} \Delta \theta f^{\prime}(\underline{l})(1-\underline{\psi})^{2}\right\}+(1-v)\left\{p_{1} \underline{\theta} f^{\prime}(\underline{l})\left(\frac{1}{2}-\frac{\underline{\psi}^{2}}{2}\right)+\left(1-p_{1}\right) \underline{\theta} f^{\prime}(\underline{l}) \frac{\psi^{2}}{2}-(1+r)\right\}=0
$$

$$
\frac{\partial H}{\partial \underline{\psi}}=v\left\{-p_{1} \Delta \theta f(\underline{l})(-1)(1-\underline{\psi})\right\}+(1-v)\left\{p_{1} \underline{\theta} f(\underline{l})(-\underline{\psi})+\left(1-p_{1}\right) \underline{\theta} f(\underline{l}) \underline{\psi}-\left(1-p_{1}\right) c\right\}=0
$$

Equation B.23 results in the F.O.C for the amount of loan to the high-quality firm:

$$
p_{1} \bar{\theta} f^{\prime}(\bar{l})\left(\frac{1}{2}-\frac{\bar{\psi}^{2}}{2}\right)+\left(1-p_{1}\right) \bar{\theta} f^{\prime}(\bar{l}) \frac{\bar{\psi}^{2}}{2}=(1+r)
$$

The LHS denotes the expected marginal product of loan if the high-quality firm exerts effort with probability $p_{1}$. It is equal to the marginal opportunity cost of the bank, $(1+r)$. Thus, the high quality firm faces no distortion.

On the other hand, equation B.25 leads to the following F.O.C for the amount of loan to the low-quality firm, $\underline{l}$ :

$$
p_{1} \underline{\theta} f^{\prime}(\underline{l})\left(\frac{1}{2}-\frac{\underline{\psi}^{2}}{2}\right)+\left(1-p_{1}\right) \underline{\theta} f^{\prime}(\underline{l}) \frac{\underline{\psi}^{2}}{2}=(1+r)+\frac{v}{2(1-v)} p_{1} \Delta \theta f^{\prime}(\underline{l})(1-\underline{\psi})^{2}
$$

Comparing with equation (B.27), a new positive term appears on the RHS of equation (B.28). It represents the size of distortion and reduces the optimal amount of loan granted to the low-quality firm. Substituting $\frac{1}{2}(1-\underline{\psi})^{2}=\frac{B}{\underline{\theta} \Delta p f(\underline{l})}$ from Equation (B.13) into equation (B.28) the F.O.C becomes:

$$
p_{1} \underline{\theta} f^{\prime}(\underline{l})\left(\frac{1}{2}-\frac{\underline{\psi}^{2}}{2}\right)+\left(1-p_{1}\right) \underline{\theta} f^{\prime}(\underline{l}) \frac{\psi^{2}}{2}=(1+r)+\frac{v}{(1-v)} \frac{p_{1}}{\Delta p} \frac{\Delta \theta}{\underline{\theta}} \frac{f^{\prime}(\underline{l})}{f(\underline{l})} B
$$


Now, the distortion term provides more information. It rises with a bigger percentage of gap in the quality of firms, $\frac{\Delta \theta}{\underline{\theta}}$, or with a higher cost of exerting effort, $B$, or both. Either case induces a smaller bank credit for the low-quality firm. If the bank could recognize the type of the firms, $v=1$, the distortion term converges to infinity, and the bank shuts down granting business credit to the low-quality firm.

Equation (B.24) leads to:

$$
\left(1-2 p_{1}\right) \bar{\psi}-\frac{\left(1-p_{1}\right) c}{\bar{\theta} f(\bar{l})}+\mu=0
$$

To ensure that the low-risk firm exerts effort (i.e. $p_{1}>\frac{1}{2}$ ) the optimal $\bar{\psi}$ should be zero. This result turns out in two cases.

First, if $\mu>0$, equation (B.30) implies:

$$
\bar{\psi}<\frac{\left(1-p_{1}\right) c}{\left(1-2 p_{1}\right) \bar{\theta} f(\bar{l})}
$$

For $p>\frac{1}{2}$, equation (B.31) becomes negative. Since, $\mu \bar{\psi}=0$, this equality needs $\bar{\psi}=0$. So, $\mu=\frac{\left(1-p_{1}\right) c}{\bar{\theta} f(\bar{l})}$.

Second, if $\mu=0$, the maximization requires $\bar{\psi} \geq 0$. With $\mu=0$ equation (B.30) implies:

$$
\bar{\psi}=\frac{\left(1-p_{1}\right) c}{\left(1-2 p_{1}\right) \bar{\theta} f(\bar{l})}
$$

For $p>\frac{1}{2}$ equation (B.32) also gives $\bar{\psi}<0$. Since maximization requires $\frac{\partial H}{\partial \bar{\psi}} \bar{\psi}=0$, thus $\bar{\psi}^{\star}=0$.

By inserting $\bar{\psi}^{\star}=0$ in equation (B.27), the optimal amount of loan granted to the high-quality firm can be summarized as below:

$$
\frac{1}{2} p_{1} \bar{\theta} f^{\prime}(\bar{l})=(1+r)
$$


Equation (B.33) indicates that the high-quality firm will have incentive to exert the highest effort, since the optimal loan increases with $p_{1}$. The outcome leads to a higher output for the high-quality firm.

Now turning to equation (B.26), it reduces to:

$$
\frac{v}{(1-v)} p_{1} \Delta \theta=\frac{(1-p) c}{f(\underline{l})(1-\underline{\psi})}-\left(1-2 p_{1}\right) \frac{\underline{\psi} \underline{\theta}}{(1-\underline{\psi})}
$$

Substituting (B.34) into equation (B.28) results:

$$
\frac{1}{2} \underline{\theta} f^{\prime}(\underline{l})\left\{p_{1}+\left(1-2 p_{1}\right) \underline{\psi}^{2}\right\}=1+r+\frac{1}{2}\left\{\frac{(1-p) c}{f(\underline{l})(1-\underline{\psi})}-\left(1-2 p_{1}\right) \frac{\underline{\psi} \underline{\theta}}{(1-\underline{\psi})}\right\} f^{\prime}(l)(1-\underline{\psi})^{2}
$$

Equation (B.35) gives:

$$
\frac{p_{1}}{2} \underline{\theta} f^{\prime}(\underline{l})=(1+r)+\frac{1}{2} \frac{\left(1-p_{1}\right) c f^{\prime}(\underline{l})}{f(\underline{l})}(1-\underline{\psi})-\frac{1}{2} \underline{\theta} f^{\prime}(\underline{l})\left(1-2 p_{1}\right)\left\{\underline{\psi}-\underline{\psi}^{2}+\underline{\psi}^{2}\right\}
$$

Finally, the optimal amount of loan granted to the low-quality firm is summarized as below:

$$
\frac{p_{1}}{2} \underline{\theta} f^{\prime}(\underline{l})=(1+r)+\frac{1}{2} \frac{\left(1-p_{1}\right) c f^{\prime}(\underline{l})}{f(\underline{l})}(1-\underline{\psi})+\frac{1}{2} \underline{\theta} f^{\prime}(\underline{l})\left(2 p_{1}-1\right) \underline{\psi}
$$

Comparing equation (B.37) with equation (B.33), two additional terms show up on the RHS. The second term on the RHS indicates the way that auditing cost reduces the optimal loan for the low-quality firm. The term $\frac{f^{\prime}(\underline{l})}{f(\underline{l})}(1-\underline{\psi})$ reflects the resulting rise in the failure rate through granting one unit more $\underline{l}$, see also Freixas and Laffont (1990). A higher $p_{1}$, however, mitigates this effect. With $p_{1}>\frac{1}{2}$, the third term is also positive. This term comprises factors related to adverse selection issue, moral hazard issue, and the failure rate. Together, they escalate the total distortion for the low-quality firm. 
Thus, the bank optimally grants different sizes of business credit to the firms because of heterogeneity in their quality and their potential effort. This optimal credit-size rationing makes firms heterogeneous in their start-up capital. High-quality firms have more chance to start with business credit or get a larger amount. They can achieve greater outcomes in the future by starting with more efficient initial capital.

\section{B.2.2 No Loan to Low-Quality Firm}

A bank will grant a loan to a low-quality firm as long as $\underline{l}=0$ is not its optimal decision. It means that the expected value of the bank's profit when it grants loans to both firms should be higher than the corresponding value when the high-quality firm only receives a loan. The outcome of this comparison results in the following inequality:

$$
\begin{gathered}
(1-v)\left\{p_{1} \underline{\theta} f(\underline{l})\left(\frac{1}{2}-\frac{\underline{\psi}^{2}}{2}\right)+\left(1-p_{1}\right) \underline{\theta} f(\underline{l}) \frac{\underline{\psi}^{2}}{2}-\left(1-p_{1}\right) c \underline{\psi}-(1+r) \underline{l}-B\right\} \\
-(1-v)\left(\frac{p_{0} B}{\Delta p}\right)-v\left(\frac{1}{2} p_{1} \Delta \theta f(\underline{l})(1-\underline{\psi})^{2}\right)>0
\end{gathered}
$$

If this inequality becomes negative, the bank shuts down granting loan to the low-quality firm. The inequality denotes that the higher is the difference between the quality of two firms, i.e., the bigger is $\Delta \theta$, the smaller will be the LHS. This reduction leads to a lower chance of granting loan to the low-quality firm. A similar result arises with a higher cost of exerting effort, $B$. Also, a higher probability of bankruptcy for a low-quality firm, $\underline{\psi}$, has two effects. It definitely reduces the reward to the high-quality firm through reducing $(1-\underline{\psi})^{2}$ in the last term. But, it also has an ambiguous effect on the terms in the big bracket. The value of the bracket is reduced through the first and the third term while it is increased by the second term. A higher probability of success through effort $p_{1}$, however, mitigates the magnitude 
of all these terms, except of the one related to the first term in the big bracket. In total, if the reducing effects outweigh the raising effect, the bank more likely rejects lending business credit to the low-quality firm.

\section{B.2.3 Comparative Statics Analysis}

This Appendix discusses the way that adverse selection and moral hazard issues can affect loan-size rationing at the optimal point.

For simplicity suppose that $p_{1}$ is constant. The total differentiation of equation B.33 can be written as:

$$
\frac{1}{2} p_{1} \bar{\theta} f^{\prime \prime}(\bar{l}) d \bar{l}+\frac{1}{2} p_{1} f^{\prime}(\bar{l}) d \bar{\theta}=d r
$$

And, the total differentiation of equation B.37 can be written as:

$$
\begin{aligned}
\frac{p_{1}}{2} \underline{\theta} f^{\prime \prime}(\underline{l}) d \underline{l}+\frac{p_{1}}{2} f^{\prime}(\underline{l}) d \underline{\theta}=d r & \\
& +\frac{1}{2} \frac{\left(1-p_{1}\right) f^{\prime}(\underline{l})}{f(\underline{l})}(1-\underline{\psi}) d c \\
& +\frac{1}{2} \frac{\left(1-p_{1}\right) c f^{\prime}(\underline{l})}{f(\underline{l})}(-d \underline{\psi}) \\
& +\frac{1}{2}\left(1-p_{1}\right) c \frac{f^{\prime \prime}(\underline{l}) f^{\prime}(\underline{l})-f^{\prime}(\underline{l})^{2}}{f(\underline{l})^{2}}(1-\underline{\psi}) d \underline{l} \\
& +\frac{1}{2} f^{\prime}(\underline{l})\left(2 p_{1}-1\right) \underline{\psi} d \underline{\theta} \\
& +\frac{1}{2} \underline{\theta} f^{\prime}(\underline{l})\left(2 p_{1}-1\right) d \underline{\psi} \\
& +\frac{1}{2} \underline{\theta} f^{\prime \prime}(\underline{l})\left(2 p_{1}-1\right) \underline{\psi} d \underline{l}
\end{aligned}
$$

For simplicity, let also assume that the bankruptcy rate of a low-quality firm stays 
constant at its optimal level $(d \underline{\psi}=0)$. Equation B.40 can be summarized as:

$$
\begin{aligned}
\frac{p_{1}}{2} \underline{\theta} f^{\prime \prime}(\underline{l}) d \underline{l}+\frac{p_{1}}{2} f^{\prime}(\underline{l}) d \underline{\theta}=d r & \\
& +\frac{1}{2} \frac{\left(1-p_{1}\right) f^{\prime}(\underline{l})}{f(\underline{l})}(1-\underline{\psi}) d c \\
& +\frac{1}{2}\left(1-p_{1}\right) c \frac{f^{\prime \prime}(\underline{l}) f^{\prime}(\underline{l})-f^{\prime}(\underline{l})^{2}}{f(\underline{l})^{2}}(1-\underline{\psi}) d \underline{l} \\
& +\frac{1}{2} f^{\prime}(\underline{l})\left(2 p_{1}-1\right) \underline{\psi} d \underline{\theta} \\
& +\frac{1}{2} \underline{\theta} f^{\prime \prime}(\underline{l})\left(2 p_{1}-1\right) \underline{\psi} d \underline{l}
\end{aligned}
$$

Or,

$$
\begin{aligned}
& \left\{\frac{p_{1}}{2} \underline{\theta} f^{\prime \prime}(\underline{l})-\frac{1}{2} \underline{\theta} f^{\prime \prime}(\underline{l})\left(2 p_{1}-1\right) \underline{\psi}-\frac{1}{2}\left(1-p_{1}\right) c \frac{f^{\prime \prime}(\underline{l}) f^{\prime}(\underline{l})-f^{\prime}(\underline{l})^{2}}{f(\underline{l})^{2}}(1-\underline{\psi})\right\} d \underline{l}= \\
& d r+\left\{\frac{1}{2} f^{\prime}(\underline{l})\left(2 p_{1}-1\right) \underline{\psi}-\frac{p_{1}}{2} f^{\prime}(\underline{l})\right\} d \underline{\theta}+\frac{1}{2} \frac{\left(1-p_{1}\right) f^{\prime}(\underline{l})}{f(\underline{l})}(1-\underline{\psi}) d c
\end{aligned}
$$

The partial derivatives of equations (B.39) and (B.42) w.r.t the interest rate, $r$ become:

$$
\begin{aligned}
& \frac{\partial \bar{l}}{\partial r}=\frac{1}{\frac{1}{2} p_{1} \bar{\theta} f^{\prime \prime}(\bar{l})}<0
\end{aligned}
$$

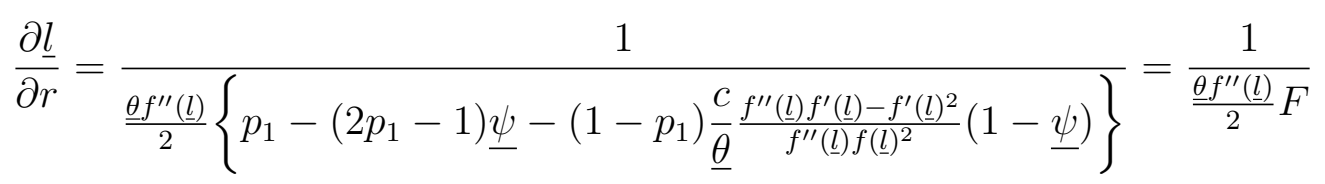

Let $M$ represents the monetary balance. Then $\frac{\partial \bar{l}}{\partial M}=\frac{\partial \bar{l}}{\partial r} \frac{\partial \bar{r}}{\partial M}$, where we can assume 
$\frac{\partial r}{\partial M}<0$. Using (B.43) for $\frac{\partial \bar{l}}{\partial M}$ results in:

$$
\frac{\partial \bar{l}}{\partial M}>0
$$

With the assumption that $p_{1}>\frac{1}{2}$, the sum of the first two terms in expression $F,\left\{p_{1}-\left(2 p_{1}-1\right) \underline{\psi}\right\}$, is positive. In other words, $p_{1}-\left(2 p_{1}-1\right) \underline{\psi}>0$ leads to the following expression that turns out to be always correct:

$$
\frac{1}{\underline{\psi}}>1-\left(2-\frac{1}{p_{1}}\right) ; \quad\left(\text { since } \quad 0<\underline{\psi}<1 \quad \text { and } \quad p_{1}>\frac{1}{2}\right)
$$

However, the last term in expression $F,\left\{-\frac{c}{\underline{\theta}} \frac{f^{\prime \prime}(\underline{l}) f^{\prime}(\underline{l})-f^{\prime}(\underline{l})^{2}}{f^{\prime \prime}(\underline{l}) f(\underline{l})^{2}}(1-\underline{\psi})\right\}$, is negative. Therefore, the sign of $F$ can be negative, zero, or positive.

At the optimal point, inequality (B.45) implies that with an expansionary monetary policy, banks would be willing to grant bigger sizes of loans to the high-quality firms. The discussion above, however, illustrates that if the presence of auditing cost as well as adverse selection and moral hazard issues in equation (B.44) induces a negative sign for expression $F$, the denominator of this equation can become positive. Such situation reduces the chances of low-quality firms to acquire bigger amount of business credit with an expansionary monetary policy, resulting in:

$$
\frac{\partial \underline{l}}{\partial M}<0
$$

The partial derivative of equation (B.39) w.r.t $\bar{\theta}$ becomes:

$$
\frac{\partial \bar{l}}{\partial \bar{\theta}}=-\frac{f^{\prime}(\bar{l})}{f^{\prime \prime}(\bar{l})}>0
$$


And, the partial derivative of equation (B.42) w.r.t $\underline{\theta}$ results in:

$$
\frac{\partial \underline{l}}{\partial \underline{\theta}}=\frac{\frac{1}{2} f^{\prime}(\underline{l})\left\{\left(2 p_{1}-1\right) \underline{\psi}-p_{1}\right\}}{\frac{\theta f^{\prime \prime}(\underline{l})}{2}\left\{p_{1}-\left(2 p_{1}-1\right) \underline{\psi}-\left(1-p_{1}\right) \frac{c}{\underline{\theta}} \frac{f^{\prime \prime}(\underline{l}) f^{\prime}(\underline{l})-f^{\prime}(\underline{l})^{2}}{f^{\prime \prime}(\underline{l}) f(\underline{l})^{2}}(1-\underline{\psi})\right\}}
$$

Or,

$$
\begin{aligned}
& \frac{\partial \underline{l}}{\partial \underline{\theta}}=-\frac{\frac{1}{2} f^{\prime}(\underline{l})\left\{p_{1}-\left(2 p_{1}-1\right) \underline{\psi}\right\}}{\frac{\underline{\theta} f^{\prime \prime}(\underline{l})}{2}\left\{p_{1}-\left(2 p_{1}-1\right) \underline{\psi}-\left(1-p_{1}\right) \frac{c}{\underline{\theta}} \frac{f^{\prime \prime}(\underline{l}) f^{\prime}(\underline{l})-f^{\prime}(\underline{l})^{2}}{f^{\prime \prime}(\underline{l}) f(\underline{l})^{2}}(1-\underline{\psi})\right\}} \\
& =\frac{\frac{1}{2} f^{\prime}(\underline{l})\left\{p_{1}-\left(2 p_{1}-1\right) \underline{\psi}\right\}}{-\frac{\theta f^{\prime \prime}(\underline{l})}{2} F}
\end{aligned}
$$

Based on inequality (B.48), an increase in the proportion of high-quality firms, $\bar{\theta}$, increases the optimal sizes of business loans that banks grant to them. However, the effect of an increase in the portion of low-quality firms, $\underline{\theta}$, on optimal loan size can be ambiguous. If adverse-selection and moral-hazard parameters result in a negative sign for expression $F$ in equation (B.50), the sign of the equation would also become negative. As a result, the banks would cut the sizes of business loans that they supply to low-quality firms. So, the grant of heterogeneous amounts of business credit to different firms cannot be random. The argument can support credit rationing Type I.

\section{B.3 Technical Note for Identification}

The model follows identification rules for a mixed indicator such as revenue (see Kline (2011), p.140-141; and Bolger (1998)). 


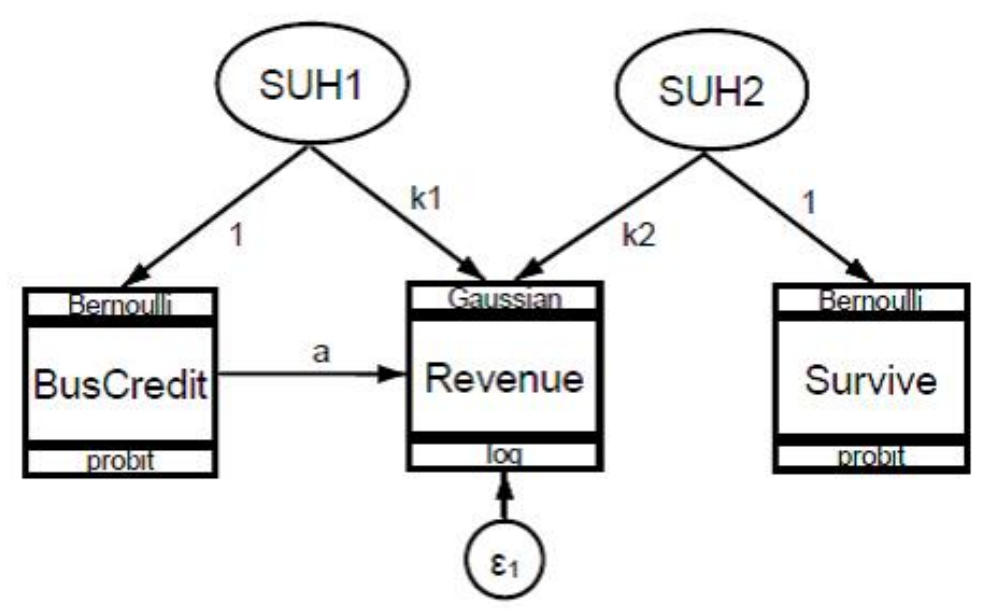

Figure B.1: The GSEM framework

Rule 1: Each latent factor must be connected to at least two indicators whose errors are independent: $S U H 1$ is connected to the revenue variable (in 2007) and the business credit variable (in 2004), while SUH2 is connected to the revenue and the survival variables.

Rule 2: The error terms of the revenue and the business credit equations are independent of the error term of the survival equation. Similarly, the error terms of the revenue and the survival equations must be independent of the error term of the credit equation (these assumptions are satisfied when applying maximum likelihood method for estimating the model).

Rule 3: The error term of business credit equation in 2004 that is connected to latent variable $S U H 1$ and the error term of the survival equation connected to latent variable $S U H 2$ are both independent of each there.

Moreover, the system section of the model is recursive since only business credit in 2004 has causality effect on revenue in 2007. Because a recursive model is also identified, altogether, the model is identified. Adding more independent variables to the model would not change the identification since the number of extra parameters to be estimated will be equal to the number of added variances and co-variances (see 
Acock (2013), page 83).

The identification can also be verified based on "degree of freedom" (d.f), which is the difference between the number of variance and co-variance terms of the observable variables in the model and the number of parameters to be estimated. If the d.f is equal to zero, the model is just identified, and if it is bigger than zero, the model would be over-identified. This is known as the "t-rule".

The model used in this analysis has three observable variables: revenue, business credit, and survival. The number of variances and co-variances in the $\mathrm{V}-\mathrm{C}$ matrix of the observable variables is $3(3+1) / 2=6$. Thus the number of equations for identifying the structural parameters is equal to six. The number of the parameters to be estimated is also six. Since there are two Probit functions, their variances of error terms are already restricted to 1 . So, there would be six other parameters to be estimated: the variance of the error term in the revenue equation, two latent factor variances, two latent factor coefficients $(k 1$ and $k 2$ ), and one direct causality effect, $a$. Based on the t-rule the degree of freedom is equal to zero $(6-6=0)$ and the model is just identified. The model satisfies this necessary condition.

\section{B.4 The Survival and Selection Componants}

For each cohort, the Pinto method takes the gap between the average revenue of firms in period $\tau$ and its corresponding value in the entry year, and breaks it up into survival and selection components:

$$
\begin{array}{r}
\underbrace{\frac{1}{N\left(S_{\tau}\right)} \sum_{i \in S_{\tau}} Y_{i, \tau}-\frac{1}{N\left(S_{1}\right)} \sum_{i \in S_{1}} Y_{i, 1}}_{\text {Overall average gap }}=\underbrace{\frac{1}{N\left(S_{\tau}\right)} \sum_{i \in S_{\tau}} Y_{i, \tau}-\frac{1}{N\left(S_{\tau}\right)} \sum_{i \in S_{\tau}} Y_{i, 1}}_{\text {Survival component }} \\
+\underbrace{\frac{N\left(E_{\tau}\right)}{N\left(S_{\tau}\right)}\left(\frac{1}{N\left(S_{\tau}\right)} \sum_{i \in S_{\tau}} Y_{i, 1}-\frac{1}{N\left(E_{\tau}\right)} \sum_{i \in E_{\tau}} Y_{i, 1}\right)}_{\text {Selection component }}
\end{array}
$$


where $N\left(S_{\tau}\right)$ and $N\left(E_{\tau}\right)$, respectively, refer to the number of survived and exited firms at time $\tau$, and $Y_{i, \tau}$ represents revenue of firm $i$ at time $\tau$.

\section{B.5 Endogenous Treatment Effect}

This section follows Skrondal and Rabe-Hesketh (2004) and represents the system of equation demonstrated in Figure 3.1. Consider the following latent response model for access to business credit:

$$
\operatorname{BusCrd}_{i}^{*}=X_{1 i}^{\prime} \beta_{1}+\epsilon_{1 i}
$$

where $\epsilon_{1} i$ has a $N(0,1)$. Equation B.52 for a treatment such as $B u s C r d_{i}$ becomes:

$$
\text { BusCrd }_{i}= \begin{cases}1 & \text { if BusCrd } \\ 0 & \text { otherwise. }\end{cases}
$$

Now, define the following latent model to describe a firm's survival period until 2007 $(\operatorname{Surv07})_{i}$ :

$$
\operatorname{Surv} 07_{i}^{*}=X_{2 i}^{\prime} \gamma+\epsilon_{2 i}
$$

It can be written as:

$$
\operatorname{Surv} 07_{i}= \begin{cases}1 & \text { if } \operatorname{Surv} 07_{i}^{*}>0 \\ 0 & \text { otherwise. }\end{cases}
$$

If equation $\mathrm{BusCrd}_{i}$ has a shared unobserved heterogeneity $S U H_{1 i}$ with revenue equation and $S u r v 07_{i}$ has a shared-unobserved heterogeneity $S U H_{2 i}$ with revenue equation, we can write the system as: 


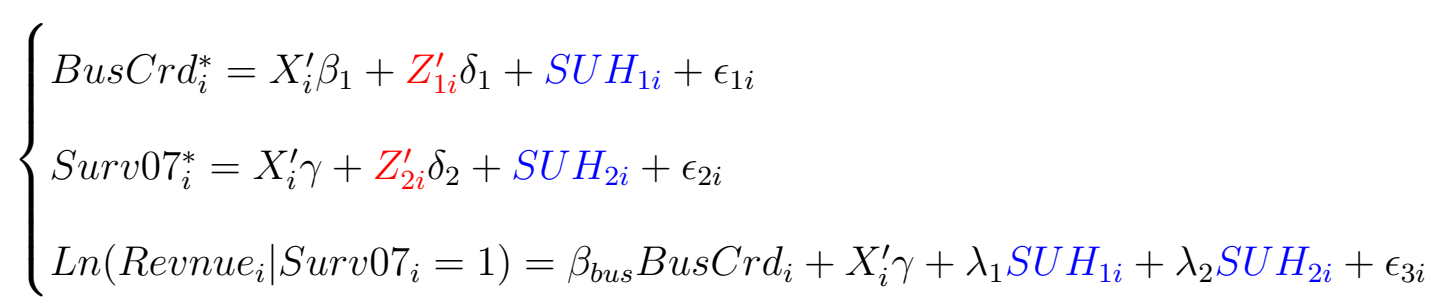

where $S U H_{1 i}$ and $S U H_{2 i}$ each has a $N(0, \psi)$. Also, $\epsilon_{j i}$ is iid and has $N\left(0, \theta_{j}\right)$ with $\operatorname{cov}\left(S U H_{j i}, \epsilon_{j i}\right)=0$ for all $i$ and $j$. Both $Z_{1 i}$ and $Z_{2 i}$ exhibit the vectors of exclusion restrictions. Latent factor $S U H_{1 i}$, for example, captures the dependence between business credit equation and the revenue equation. Coefficient $\lambda_{1}$ captures endogeneity bias to allow the system to provide an unbiased estimate of $\alpha$, the treatment effect. In other words, $\operatorname{Cov}\left(\operatorname{BusCrd}_{i}^{*}, \operatorname{Ln}\left(\right.\right.$ Revenue $\left.\left._{i}\right) \mid X_{i}, Z_{1 i}\right)=\lambda_{1} \psi$. If either $\lambda_{1}=0$ or $\psi=0$ the two equations would be independent and can be estimated separately. Similar analysis is applied to $\lambda_{2}$ that captures surviving bias. The above system can be rewritten as below $\left(\operatorname{Var}\left(\epsilon_{1 i}\right)=1\right.$ and $\left.\operatorname{Var}\left(\epsilon_{2 i}\right)=1\right)$ :

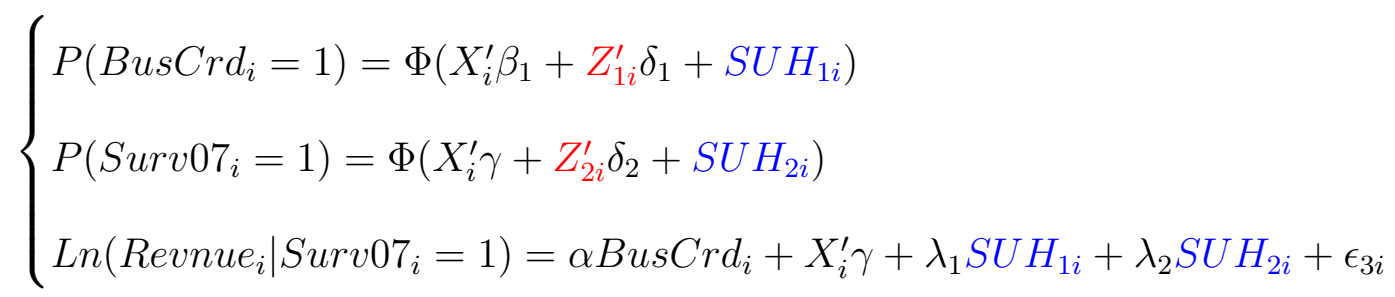




\section{Appendix $\mathrm{C}$}

Appendix for Chapter 3

C.1 Tables and Figures 
Table C.1: Comparison Between Teaming and R\&D

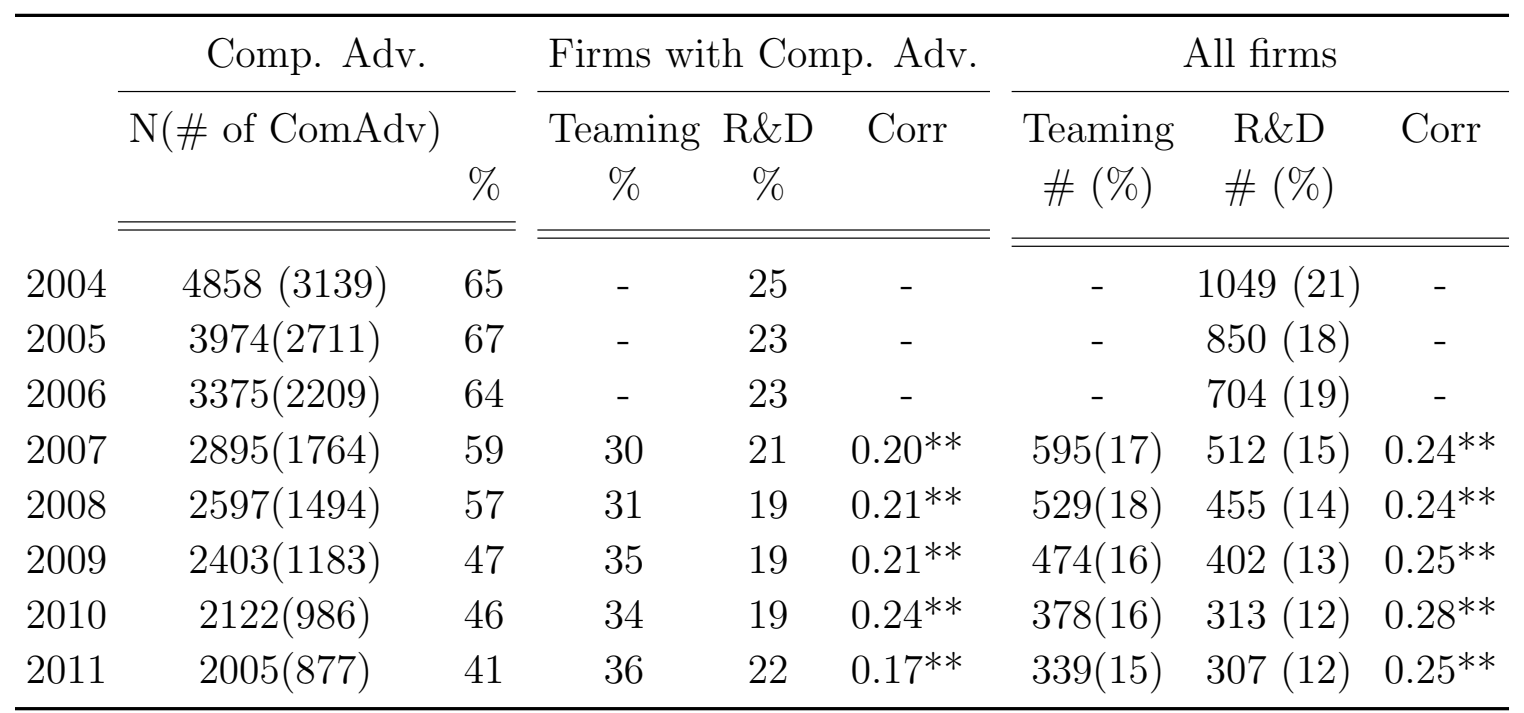

Notes: Survey weights are applied for calculating the shares. ${ }^{*} p<0.10,{ }^{* *} p<0.05$.

Teaming is a dummy variable equal to 1 if during the period of 2007 to 2011 a firm experiences teaming with other companies, universities, government labs and research centres, and/or teaming with the sources of patents. Comp. Adv.: Firms with a comparative advantage.

Corr: Correlation

Calculated by the author. 
Table C.2: The distribution of R\&D employees, the number of firms with comparative advantage, and fraction of them with teaming experience

\begin{tabular}{lccccc}
\hline A: & \multicolumn{5}{c}{ Among firms with comparative advantage $\%$} \\
\cline { 2 - 6 } & 2007 & 2008 & 2009 & 2010 & 2011 \\
Number of R\&D employee $=0$ & 39 & 39 & 38 & 39 & 40
\end{tabular}

B: \# of firms with a comp. Adv. (teaming \%)

Number of R\&D employees

$20072008 \quad 2009 \quad 2010 \quad 2011$

\begin{tabular}{|c|c|c|c|c|c|}
\hline 0 & $499(31)$ & $424(33)$ & $319(37)$ & $271(35)$ & $249(33)$ \\
\hline 1 & $484(39)$ & $403(37)$ & $326(38)$ & $265(43)$ & $232(39)$ \\
\hline 2 & $202(36)$ & $178(36)$ & $122(42)$ & $99(44)$ & $81(44)$ \\
\hline 3 & $49(49)$ & $39(49)$ & $40(63)$ & $28(46)$ & $26(54)$ \\
\hline 4 & $23(48)$ & $14(64)$ & $10(80)$ & $15(73)$ & $10(40)$ \\
\hline 5 & $12(42)$ & $6(86)$ & 10(70) & $5(80)$ & $7(86)$ \\
\hline 6 & $6(83)$ & $3(67)$ & $7(86)$ & $3(100)$ & $2(100)$ \\
\hline 7 & - & 1(100) & - & $4(25)$ & $5(80)$ \\
\hline 8 & $5(60)$ & $3(100)$ & $2(100)$ & $3(100)$ & $4(75)$ \\
\hline 9 & $1(100)$ & $2(100)$ & - & - & $1(100)$ \\
\hline 10 & $2(50)$ & $2(100)$ & $2(50)$ & $1(100)$ & $1(100)$ \\
\hline 11 & 1(100) & - & $2(50)$ & $1(0)$ & - \\
\hline 12 & - & $2(100)$ & $2(0)$ & - & - \\
\hline 13 & - & $1(0)$ & 1(100) & - & - \\
\hline 15 & - & $2(50)$ & 1(100) & - & - \\
\hline 16 & - & - & $2(100)$ & - & - \\
\hline 18 & - & - & - & - & $1(100)$ \\
\hline 20 & $1(100)$ & - & - & - & - \\
\hline 21 & - & 1(100) & - & - & $1(0)$ \\
\hline 22 & - & $1(100)$ & $1(100)$ & $1(0)$ & - \\
\hline 25 & $2(50)$ & - & $1(100)$ & $1(0)$ & $1(100)$ \\
\hline 30 & 1(100) & - & - & - & - \\
\hline 31 & - & - & $1(100)$ & - & - \\
\hline 33 & - & - & - & - & $1(0)$ \\
\hline 35 & - & - & - & $1(0)$ & - \\
\hline 40 & - & 1(100) & - & - & - \\
\hline 45 & - & - & - & - & $1(100)$ \\
\hline 50 & $1(100)$ & - & - & - & $1(0)$ \\
\hline
\end{tabular}

Teaming is a dummy variable equal to 1 if during the period of 2007 to 2011 a firm experiences teaming with other companies, universities, government labs and research centres, and/or teaming with the sources of patents.

Calculated by the author. 
Table C.3: The distribution of total employees, the number of firms with a comparative advantage, fraction of them with teaming experience, and fraction of them with $R \& D$ expenditure

\begin{tabular}{|c|c|c|c|c|c|c|c|c|c|c|}
\hline \multirow[t]{2}{*}{$\mathrm{N}$} & \multicolumn{2}{|c|}{2007} & \multicolumn{2}{|c|}{2008} & \multicolumn{2}{|c|}{2009} & \multicolumn{2}{|c|}{2010} & \multicolumn{2}{|c|}{2011} \\
\hline & Teaming & $R \& D$ & Teaming & $\mathrm{R} \& \mathrm{D}$ & Teaming & $R \& D$ & Teaming & $\mathrm{R} \& \mathrm{D}$ & Teaming & $\mathrm{R} \& \mathrm{D}$ \\
\hline 0 & $359(30)$ & $359(19)$ & $303(28)$ & $303(17)$ & $254(35)$ & $254(18)$ & $214(33)$ & $214(16)$ & $188(34)$ & $188(20)$ \\
\hline 1 & $346(30)$ & $346(19)$ & $302(32)$ & $302(15)$ & $219(41)$ & $219(16)$ & $177(28)$ & $177(12)$ & $154(36)$ & $154(17)$ \\
\hline 2 & $262(33)$ & $262(21)$ & $226(43)$ & $226(20)$ & $168(38)$ & $168(23)$ & $116(43)$ & $116(16)$ & $122(30)$ & $122(16)$ \\
\hline 3 & $164(34)$ & $164(22)$ & $126(43)$ & $126(19)$ & $93(40)$ & $93(31)$ & $97(41)$ & $97(24)$ & $69(45)$ & $69(20)$ \\
\hline 4 & $128(36)$ & $128(22)$ & $97(49)$ & $97(20)$ & $78(39)$ & $78(23)$ & $74(43)$ & $74(34)$ & $52(31)$ & $52(14)$ \\
\hline 5 & $81(47)$ & $81(24)$ & $82(35)$ & $82(33)$ & $68(40)$ & $68(22)$ & $52(50)$ & $52(27)$ & $39(51)$ & $39(38)$ \\
\hline 6 & $62(42)$ & $62(19)$ & $46(35)$ & $46(37)$ & $42(50)$ & $42(29)$ & $33(36)$ & $33(18)$ & $41(44)$ & $41(39)$ \\
\hline 7 & $45(31)$ & $45(31)$ & $45(27)$ & $45(33)$ & $27(33)$ & $27(41)$ & $28(29)$ & $28(36)$ & $17(47)$ & $17(29)$ \\
\hline 8 & $37(43)$ & $37(43)$ & $30(30)$ & $30(20)$ & $30(43)$ & $30(27)$ & $19(26)$ & $19(16)$ & $29(38)$ & $29(31)$ \\
\hline 9 & $27(30)$ & $27(26)$ & $27(33)$ & $27(30)$ & $22(46)$ & $22(18)$ & $19(47)$ & $19(47)$ & $19(47)$ & $19(21)$ \\
\hline 10 & $28(43)$ & $28(25)$ & $29(55)$ & $29(35)$ & $15(53)$ & $15(47)$ & $15(33)$ & $15(27)$ & $12(42)$ & $12(41)$ \\
\hline 11 & $21(43)$ & $21(43)$ & $16(38)$ & $16(31)$ & $21(48)$ & $21(38)$ & $15(47)$ & $15(40)$ & $17(53)$ & $17(29)$ \\
\hline 12 & $20(40)$ & $20(30)$ & $9(33)$ & $9(11)$ & $9(33)$ & $9(33)$ & $11(36)$ & $11(27)$ & $10(60)$ & $10(30)$ \\
\hline 13 & $17(30)$ & $17(41)$ & $11(55)$ & $11(36)$ & $12(50)$ & $12(50)$ & $7(71)$ & $7(57)$ & $8(50)$ & $8(75)$ \\
\hline 14 & $13(46)$ & $13(46)$ & $14(21)$ & $14(50)$ & $11(36)$ & $11(36)$ & $4(75)$ & $4(75)$ & $9(56)$ & $9(45)$ \\
\hline 15 & $11(36)$ & $11(18)$ & $13(62)$ & $13(78)$ & $7(29)$ & $7(43)$ & $7(14)$ & $7(14)$ & $6(33)$ & $6(67)$ \\
\hline 16 & $8(80)$ & $8(50)$ & $10(40)$ & $10(50)$ & $6(33)$ & $6(83)$ & $17(59)$ & $17(29)$ & $8(13)$ & $8(25)$ \\
\hline 17 & $9(22)$ & $9(44)$ & $5(20)$ & $5(0)$ & $9(67)$ & $9(44)$ & $2(50)$ & $2(100)$ & $6(67)$ & $6(67)$ \\
\hline 18 & $7(29)$ & $7(27)$ & $5(20)$ & $5(40)$ & $3(0)$ & $3(33)$ & $5(60)$ & $5(40)$ & $3(33)$ & $3(67)$ \\
\hline 19 & $6(33)$ & $6(33)$ & $6(0)$ & $6(67)$ & $3(33)$ & $3(33)$ & $6(50)$ & $6(50)$ & $3(67)$ & $3(67)$ \\
\hline 20 & $4(25)$ & $4(25)$ & $4(20)$ & $4(25)$ & $7(57)$ & $7(57)$ & $4(75)$ & $4(50)$ & $6(33)$ & $6(50)$ \\
\hline 21 & $8(25)$ & $8(50)$ & $8(25)$ & $8(38)$ & $4(75)$ & $4(50)$ & $5(80)$ & $5(60)$ & $3(100)$ & $3(67)$ \\
\hline 22 & $4(0)$ & $4(25)$ & $3(33)$ & $3(33)$ & $4(75)$ & $4(75)$ & $4(50)$ & $4(50)$ & $2(50)$ & $2(50)$ \\
\hline 23 & $3(67)$ & $3(67)$ & $4(50)$ & $4(50)$ & $1(100)$ & $1(100)$ & $5(40)$ & $5(40)$ & $3(0)$ & $3(67)$ \\
\hline 24 & $2(50)$ & $2(50)$ & $3(67)$ & $3(75)$ & $2(0)$ & $2(50)$ & $2(0)$ & $2(100)$ & - & - \\
\hline 25 & $5(50)$ & $5(75)$ & $3(33)$ & $3(67)$ & $1(0)$ & $1(0)$ & $2(0)$ & $2(100)$ & $2(0)$ & $2(0)$ \\
\hline 26 & $5(40)$ & $5(20)$ & $9(33)$ & $9(22)$ & $8(50)$ & $8(50)$ & $2(50)$ & $2(50)$ & $4(50)$ & $4(50)$ \\
\hline 27 & $4(50)$ & $4(75)$ & $4(50)$ & $4(50)$ & $6(33)$ & $6(50)$ & $2(50)$ & $2(50)$ & $2(50)$ & $2(0)$ \\
\hline 28 & $2(50)$ & $2(50)$ & $3(0)$ & $3(66)$ & $3(67)$ & $3(67)$ & - & - & $2(100)$ & $2(50)$ \\
\hline 29 & $2(50)$ & $2(50)$ & - & - & - & - & - & - & $3(63)$ & $3(100)$ \\
\hline 30 & $2(0)$ & $2(50)$ & $4(50)$ & $4(50)$ & $4(25)$ & $4(50)$ & $2(0)$ & $2(0)$ & - & - \\
\hline
\end{tabular}

$\mathbf{N}$ : Total number of employees.

Teaming is a dummy variable equal to 1 if during the period of 2007 to 2011 a firm experiences teaming with other companies, universities, government labs and research centres, and/or teaming with the sources of patents. Calculated by the author. 
Table C.4: The number and share of teaming for the survivals (2004-2011)

\begin{tabular}{lc}
\hline A: & Survival firms $(2004-2011): \#(\%)$ \\
\hline Teaming $(2007-2011)=1$ & $830(41)$ \\
Teaming $(2007-2011)=0$ & $202(59)$ \\
Total & Among survivals $(2004-2011)$ \\
& with teaming: \# (\%) \\
B: & $340(41)$ \\
& $208(25)$ \\
One time teaming & $139(17)$ \\
Two times teaming & $90(11)$ \\
Three times teaming & $53(6)$ \\
Four times teaming & \\
Five times teaming & $933(46)$ \\
& $1099(54)$ \\
C: & $2032(100)$ \\
High and medium tech & Survival firms $(2004-2011): \#(\%)$ With teaming \# (\%) \\
Non tech & $470(50)$ \\
Total & $830(32)$ \\
\hline
\end{tabular}

Teaming is a dummy variable equal to 1 if during the period of 2007 to 2011 a firm experiences teaming with other companies, universities, government labs and research centres, and/or teaming with the sources of patents.

Calculated by the author.

Table C.5: The types of teaming among all firms with comparative advantage: \# (\%)

\begin{tabular}{ccccc}
\hline & \multicolumn{4}{c}{ Other companies Patnents University Gov. recearch center } \\
\cline { 2 - 5 } 2007 & $433(26)$ & $152(9)$ & $123(7)$ & $49(3)$ \\
2008 & $408(28)$ & $120(8)$ & $88(6)$ & $41(3)$ \\
2009 & $364(31)$ & $103(9)$ & $94(8)$ & $41(4)$ \\
2010 & $282(29)$ & $83(9)$ & $78(8)$ & $37(4)$ \\
2011 & $252(29)$ & $79(9)$ & $69(8)$ & $32(4)$ \\
\hline
\end{tabular}

Calculated by the author. 
Table C.6: Estimated Models

\begin{tabular}{|c|c|c|c|c|}
\hline & \multicolumn{3}{|c|}{ Variable Set 1} & \multirow{2}{*}{$\frac{\text { Variable Set } 2}{\text { Logit }}$} \\
\hline & Logit & Probit & Probit & \\
\hline & \multicolumn{3}{|c|}{ (teaming) (Surviving) (teaming $\mid \mathrm{S}=1$ ) } & (teaming) \\
\hline \multirow[t]{2}{*}{ Corporate } & 0.053 & -0.011 & 0.045 & 0.022 \\
\hline & $(0.034)$ & $(0.021)$ & $(0.034)$ & $(0.035)$ \\
\hline \multirow[t]{2}{*}{ Multiowner } & 0.015 & -0.015 & 0.005 & 0.033 \\
\hline & $(0.034)$ & $(0.021)$ & $(0.036)$ & $(0.035)$ \\
\hline \multirow[t]{2}{*}{ Credit_score } & 0.001 & $-0.032^{* *}$ & -0.016 & 0.000 \\
\hline & $(0.020)$ & $(0.013)$ & $(0.030)$ & $(0.021)$ \\
\hline \multirow[t]{2}{*}{ Lnhours } & $0.070^{* *}$ & 0.004 & $0.073^{* *}$ & $0.072^{* *}$ \\
\hline & $(0.017)$ & $(0.010)$ & $(0.018)$ & $(0.018)$ \\
\hline \multirow[t]{2}{*}{ Female } & 0.012 & -0.023 & -0.004 & 0.028 \\
\hline & $(0.034)$ & $(0.021)$ & $(0.038)$ & $(0.035)$ \\
\hline \multirow[t]{2}{*}{ Intell_property } & $0.177^{* *}$ & $0.046^{* *}$ & $0.202^{* *}$ & $0.183^{* *}$ \\
\hline & $(0.035)$ & $(0.023)$ & $(0.050)$ & $(0.037)$ \\
\hline \multirow[t]{2}{*}{ Product } & $0.069^{* *}$ & 0.010 & $0.075^{* *}$ & $0.073^{* *}$ \\
\hline & $(0.030)$ & $(0.020)$ & $(0.031)$ & $(0.032)$ \\
\hline \multirow[t]{2}{*}{ Service } & 0.065 & $0.066^{* *}$ & $0.108^{*}$ & $0.082^{*}$ \\
\hline & $(0.043)$ & $(0.027)$ & $(0.065)$ & $(0.044)$ \\
\hline \multirow[t]{2}{*}{ Work_exp } & $0.003^{*}$ & $0.003^{* *}$ & 0.004 & 0.002 \\
\hline & $(0.001)$ & $(0.001)$ & $(0.003)$ & $(0.002)$ \\
\hline Other_bus & $0.037 * *$ & 0.001 & $0.038 * *$ & $0.044^{* *}$ \\
\hline
\end{tabular}




\begin{tabular}{|c|c|c|c|c|}
\hline & $(0.011)$ & $(0.007)$ & $(0.011)$ & $(0.012)$ \\
\hline \multirow[t]{2}{*}{ Outside_equity } & -0.001 & -0.045 & -0.031 & -0.001 \\
\hline & $(0.069)$ & $(0.042)$ & $(0.076)$ & $(0.073)$ \\
\hline \multirow[t]{2}{*}{ Insider_equity } & -0.102 & $-0.079 *$ & $-0.144^{*}$ & -0.107 \\
\hline & $(0.073)$ & $(0.045)$ & $(0.086)$ & $(0.073)$ \\
\hline \multirow[t]{2}{*}{ Insider_debt } & $0.131^{* *}$ & -0.028 & $0.112^{* *}$ & $0.139 * *$ \\
\hline & $(0.048)$ & $(0.028)$ & $(0.051)$ & $(0.050)$ \\
\hline \multirow[t]{2}{*}{ Lnowners_equity } & 0.002 & -0.002 & 0.001 & 0.002 \\
\hline & $(0.004)$ & $(0.002)$ & $(0.004)$ & $(0.004)$ \\
\hline \multirow[t]{2}{*}{ Lnage_own } & -0.992 & $2.484^{* *}$ & 0.584 & -0.748 \\
\hline & $(1.440)$ & $(0.850)$ & $(2.452)$ & $(1.490)$ \\
\hline \multirow[t]{2}{*}{ Lnage_own2 } & 0.113 & $-0.324^{* *}$ & -0.092 & 0.080 \\
\hline & $(0.193)$ & $(0.114)$ & $(0.323)$ & $(0.199)$ \\
\hline \multirow[t]{2}{*}{ Asian } & 0.064 & $0.125^{* *}$ & 0.134 & 0.060 \\
\hline & $(0.101)$ & $(0.061)$ & $(0.137)$ & $(0.104)$ \\
\hline \multirow[t]{2}{*}{ Black } & -0.009 & $0.091^{*}$ & 0.034 & -0.000 \\
\hline & $(0.082)$ & $(0.051)$ & $(0.105)$ & $(0.086)$ \\
\hline \multirow[t]{2}{*}{ White } & $-0.151^{* *}$ & $0.107^{* *}$ & -0.083 & $-0.151^{* *}$ \\
\hline & $(0.068)$ & $(0.036)$ & $(0.107)$ & $(0.072)$ \\
\hline \multirow[t]{2}{*}{ College } & $0.113^{* *}$ & $0.084^{* *}$ & $0.160^{* *}$ & $0.086^{*}$ \\
\hline & $(0.049)$ & $(0.028)$ & $(0.076)$ & $(0.051)$ \\
\hline \multirow[t]{2}{*}{ Graduate } & $0.275^{* *}$ & $0.129^{* *}$ & $0.348^{* *}$ & $0.233^{* *}$ \\
\hline & $(0.058)$ & $(0.034)$ & $(0.108)$ & $(0.061)$ \\
\hline
\end{tabular}

Bus_credit

0.034 
New_machine

$0.043^{* *}$

Deviance residual

0.339

$(0.418)$

Observations

1374

3251

1369

1344

AIC

$1719.208 \quad 4371.865$

1714.828

1649.904

BIC

$1828.943 \quad 4505.773$

1829.708

1785.192

Log lik.

$-838.604 \quad-2163.933$

$-835.414$

$-798.952$

0.62

$(0.54)$

Notes: Coefficients represent Marginal Effects, Standard errors in parentheses, ${ }^{*}$ $p<0.10,{ }^{* *} p<0.05$.

Logit (teaming): is a Logit model with teaming dummy variable as its dependent variable.

Probit (Survival): is a Probit model with survival dummy as its dependent variable. The survival dummy is 1 if a firm survived until the end of 2011 .

Deviance residual: is the residuals obtained from the first stage. 
Probit (teaming $\mid \mathbf{S}=\mathbf{1}$ ): is a Probit model restricted to those firms that survived until the end of 2011. It also uses the Deviance residual to control for selection bias. Correlations: Using a biprobit model for new machinery equipment and survival dummies that entails only an intercept, the estimated $\rho$ turns out to be significant at $0.07^{* *}$, while the estimated $\rho$ from a similar biprobit model using new machinery equipment and teaming variables appears 0.03 and insignificant.

Heckman Probit: New machinery equipment is used in the selection model of Heckman Probit model; it is significant at $0.115^{* *}(0.050)$.

Calculated by the author. 
Table C.7: Balance Tests for Kernel Algorithm Based on MD Measure

\begin{tabular}{|c|c|c|c|c|c|c|}
\hline & \multicolumn{6}{|c|}{ Means (Set 1) } \\
\hline & \multicolumn{3}{|c|}{ Raw } & \multicolumn{3}{|c|}{ Matched (ATT) } \\
\hline & Treated & Untreatec & StdDif & Treated & Untreatec & StdDif \\
\hline Corporate & 0.695733 & 0.588024 & 0.225912 & 0.683516 & 0.667593 & 0.033399 \\
\hline Multiowner & 0.406308 & 0.348503 & 0.119371 & 0.375824 & 0.361748 & 0.029069 \\
\hline Credit score & 3.31911 & 3.37844 & -0.08575 & 3.31868 & 3.31876 & -0.00012 \\
\hline $\ln$ (hours) & 3.65408 & 3.37853 & 0.312236 & 3.6758 & 3.6148 & 0.06912 \\
\hline Female & 0.231911 & 0.250299 & -0.04297 & 0.213187 & 0.205099 & 0.018898 \\
\hline Intell property & 0.320965 & 0.158084 & 0.388471 & 0.283516 & 0.213232 & 0.167627 \\
\hline Product & 0.552876 & 0.469461 & 0.167327 & 0.516484 & 0.464719 & 0.103838 \\
\hline Service & 0.871985 & 0.876647 & -0.01405 & 0.896703 & 0.898144 & -0.00434 \\
\hline Work exp & 14.4416 & 13.4838 & 0.088409 & 14.6505 & 13.7074 & 0.087062 \\
\hline Other bus & 1.00928 & 0.712575 & 0.230622 & 0.920879 & 0.705636 & 0.167305 \\
\hline Outside equity & 0.059369 & 0.037126 & 0.103858 & 0.041758 & 0.041758 & 0 \\
\hline Insider equity & 0.033395 & 0.027545 & 0.034016 & 0.013187 & 0.013187 & 0 \\
\hline Insider debt & 0.142857 & 0.079042 & 0.20408 & 0.094505 & 0.087768 & 0.021546 \\
\hline $\ln$ (owners equity) & 8.26115 & 7.64939 & 0.15606 & 8.24699 & 8.45612 & -0.05335 \\
\hline $\ln ($ age $)$ & 3.78558 & 3.80301 & -0.07347 & 3.78449 & 3.7797 & 0.020212 \\
\hline $\ln (\text { age })^{2}$ & 14.3884 & 14.5176 & -0.07258 & 14.376 & 14.3276 & 0.027173 \\
\hline Asian & 0.057514 & 0.022754 & 0.177647 & 0.037363 & 0.037363 & 0 \\
\hline Black & 0.085343 & 0.050299 & 0.1396 & 0.063736 & 0.063736 & 0 \\
\hline White & 0.797774 & 0.891018 & -0.25919 & 0.859341 & 0.859341 & 0 \\
\hline
\end{tabular}




$\begin{array}{lllllll}\text { College } & 0.636364 & 0.697006 & -0.12881 & 0.659341 & 0.716574 & -0.12157 \\ \text { Graduate } & 0.302412 & 0.183234 & 0.280443 & 0.287912 & 0.232888 & 0.129479\end{array}$

Variances (Set 1)

Raw

Matched (ATT)

Treated Untreated Ratio Treated Untreated Ratio

\begin{tabular}{|c|c|c|c|c|c|c|}
\hline Corporate & 0.212082 & 0.242542 & 0.874413 & 0.216798 & 0.222401 & 0.974806 \\
\hline Multiowner & 0.24167 & 0.227321 & 1.06312 & 0.235097 & 0.231395 & 1.016 \\
\hline Credit score & 0.463036 & 0.494499 & 0.936374 & 0.459893 & 0.394413 & 1.16602 \\
\hline $\ln$ (hours) & 0.553872 & 1.0037 & 0.55183 & 0.52417 & 0.460316 & 1.13872 \\
\hline Female & 0.178459 & 0.187875 & 0.949885 & 0.168108 & 0.163392 & 1.02886 \\
\hline Intell property & 0.218351 & 0.133253 & 1.63862 & 0.203582 & 0.168134 & 1.21083 \\
\hline Product & 0.247664 & 0.249366 & 0.993173 & 0.250278 & 0.249303 & 1.00391 \\
\hline Service & 0.111835 & 0.108267 & 1.03295 & 0.092831 & 0.091682 & 1.01252 \\
\hline Work exp & 117.898 & 116.806 & 1.00934 & 115.122 & 95.5755 & 1.20451 \\
\hline Other bus & 1.97575 & 1.33455 & 1.48046 & 1.78227 & 1.20283 & 1.48173 \\
\hline Outside equity & 0.055948 & 0.03579 & 1.56323 & 0.040103 & 0.040103 & 1 \\
\hline Insider equity & 0.03234 & 0.026818 & 1.20589 & 0.013042 & 0.013042 & 1 \\
\hline Insider debt & 0.122677 & 0.072882 & 1.68323 & 0.085763 & 0.080241 & 1.06881 \\
\hline $\ln$ (owners equity) & 15.1747 & 15.5581 & 0.97536 & 14.5693 & 11.0967 & 1.31294 \\
\hline $\ln$ (age) & 0.057948 & 0.05472 & 1.05898 & 0.053679 & 0.04159 & 1.29068 \\
\hline $\ln (\text { age })^{2}$ & 3.24971 & 3.08249 & 1.05425 & 3.02413 & 2.34961 & 1.28708 \\
\hline Asian & 0.054307 & 0.022263 & 2.43929 & 0.036046 & 0.036046 & 1 \\
\hline Black & 0.078205 & 0.047827 & 1.63517 & 0.059805 & 0.059805 & 1 \\
\hline
\end{tabular}




\begin{tabular}{lcccccc} 
White & 0.161631 & 0.097221 & 1.6625 & 0.121141 & 0.121141 & 1 \\
College & 0.231835 & 0.211442 & 1.09645 & 0.225105 & 0.203543 & 1.10593 \\
Graduate & 0.211351 & 0.149838 & 1.41053 & 0.20547 & 0.179045 & 1.14759 \\
\hline
\end{tabular}

Notes:

Source: Confidential Kauffman Firm Survey (KFS). MD: Mahalanobis Distance approach. Set 1: The first set of variables. StdDif: Standardized mean difference between treated and untreated samples. Ratio: The ratio variance of treated and untreated samples.

Calculated by the author. 
Table C.8: Balance Tests for Kernel Algorithm Based on PS Measure

\begin{tabular}{|c|c|c|c|c|}
\hline & \multicolumn{4}{|c|}{ Means (Set 1) } \\
\hline \multirow[b]{3}{*}{ Corporate } & \multicolumn{2}{|r|}{ Raw } & \multicolumn{2}{|c|}{ Matched (ATT) } \\
\hline & \multicolumn{2}{|c|}{ Treated Untreated StdDif } & \multicolumn{2}{|c|}{ Treated Untreated StdDif } \\
\hline & 0.695733 & 0.5880240 .225912 & 0.695167 & $0.695209-8.7 \mathrm{E}-05$ \\
\hline Multiowner & 0.406308 & 0.3485030 .119371 & 0.407063 & 0.3881340 .039091 \\
\hline Credit score & 3.31911 & $3.37844-0.08575$ & 3.3197 & $3.28659 \quad 0.04786$ \\
\hline $\ln$ (hours) & 3.65408 & 3.378530 .312236 & 3.65297 & $3.67055-0.01992$ \\
\hline Female & 0.231911 & $0.250299-0.04297$ & 0.232342 & 0.2250190 .017111 \\
\hline Intell property & 0.320965 & 0.1580840 .388471 & 0.319703 & 0.3117730 .018912 \\
\hline Product & 0.552876 & 0.4694610 .167327 & 0.552045 & 0.5252060 .053837 \\
\hline Service & 0.871985 & $0.876647-0.01405$ & 0.871747 & $0.893203-0.06468$ \\
\hline Work exp & 14.4416 & 13.48380 .088409 & 14.4405 & $14.5305 \quad-0.0083$ \\
\hline Other bus & 1.00928 & 0.7125750 .230622 & 1.01115 & $1.04456-0.02597$ \\
\hline Outside equity & 0.059369 & 0.0371260 .103858 & 0.05948 & $0.074638-0.07078$ \\
\hline Insider equity & 0.033395 & 0.0275450 .034016 & 0.033457 & 0.0285220 .028698 \\
\hline Insider debt & 0.142857 & $0.079042 \quad 0.20408$ & 0.141264 & $0.150939-0.03094$ \\
\hline $\ln$ (owners equity) & 8.26115 & $7.64939 \quad 0.15606$ & 8.25639 & 8.164660 .023402 \\
\hline $\ln ($ age $)$ & 3.78558 & $3.80301-0.07347$ & 3.78611 & 3.77040 .066219 \\
\hline $\ln (\text { age })^{2}$ & 14.3884 & $14.5176-0.07258$ & 14.3924 & 14.2740 .066587 \\
\hline Asian & 0.057514 & 0.0227540 .177647 & 0.055762 & 0.0487220 .035979 \\
\hline Black & 0.085343 & 0.050299 & 0.085502 & 0.0822830 .012821 \\
\hline White & 0.797774 & $0.891018-0.25919$ & 0.799257 & $0.804013-0.01322$ \\
\hline
\end{tabular}




\begin{tabular}{|c|c|c|c|c|}
\hline College & 0.636364 & $0.697006-0.12881$ & 0.637546 & $0.667658-0.06396$ \\
\hline Grac & 0.302412 & 0.1832340 .280443 & O 301115 & $0.2749430 .($ \\
\hline
\end{tabular}

Variances (Set 1)

Raw Matched (ATT)

Treated Untreated Ratio Treated Untreated Ratio

\begin{tabular}{|c|c|c|c|c|c|c|}
\hline Corporate & 0.212082 & 0.242542 & 0.874413 & 0.212304 & 0.212288 & 1.00008 \\
\hline Multiowner & 0.24167 & 0.227321 & 1.06312 & 0.241812 & 0.237928 & 1.01632 \\
\hline Credit score & 0.463036 & 0.494499 & 0.936374 & 0.463708 & 0.520789 & 0.890395 \\
\hline $\ln$ (hours) & 0.553872 & 1.0037 & 0.55183 & 0.554245 & 0.544782 & 1.01737 \\
\hline Female & 0.178459 & 0.187875 & 0.949885 & 0.178691 & 0.17471 & 1.02279 \\
\hline Intell property & 0.218351 & 0.133253 & 1.63862 & 0.217898 & 0.21497 & 1.01362 \\
\hline Product & 0.247664 & 0.249366 & 0.993173 & 0.247752 & 0.249829 & 0.991686 \\
\hline Service & 0.111835 & 0.108267 & 1.03295 & 0.112012 & 0.095569 & 1.17205 \\
\hline Work exp & 117.898 & 116.806 & 1.00934 & 118.117 & 113.005 & 1.04523 \\
\hline Other bus & 1.97575 & 1.33455 & 1.48046 & 1.97753 & 2.18915 & 0.903333 \\
\hline Outside equity & 0.055948 & 0.03579 & 1.56323 & 0.056046 & 0.069196 & 0.809958 \\
\hline Insider equity & 0.03234 & 0.026818 & 1.20589 & 0.032398 & 0.02776 & 1.16709 \\
\hline Insider debt & 0.122677 & 0.072882 & 1.68323 & 0.121534 & 0.128395 & 0.946563 \\
\hline $\ln$ (owners equity) & 15.1747 & 15.5581 & 0.97536 & 15.1908 & 15.022 & 1.01123 \\
\hline $\ln ($ age $)$ & 0.057948 & 0.05472 & 1.05898 & 0.0579 & 0.058184 & 0.995113 \\
\hline $\ln (a g e)^{2}$ & 3.24971 & 3.08249 & 1.05425 & 3.24704 & 3.24468 & 1.00073 \\
\hline Asian & 0.054307 & 0.022263 & 2.43929 & 0.052751 & 0.046435 & 1.13602 \\
\hline Black & 0.078205 & 0.047827 & 1.63517 & 0.078337 & 0.075654 & 1.03547 \\
\hline
\end{tabular}




\begin{tabular}{lllllll} 
White & 0.161631 & 0.097221 & 1.6625 & 0.160744 & 0.157869 & 1.01821 \\
College & 0.231835 & 0.211442 & 1.09645 & 0.231511 & 0.222304 & 1.04142 \\
Graduate & 0.211351 & 0.149838 & 1.41053 & 0.210837 & 0.19972 & 1.05566 \\
\hline
\end{tabular}

Notes:

Source: Confidential Kauffman Firm Survey (KFS). PS: Propensity Scores approach. Set 1: The first set of variables. StdDif: Standardized mean difference between treated and untreated samples. Ratio: The ratio variance of treated and untreated samples.

Calculated by the author. 
Table C.9: Balance Tests for Kernel Algorithm Based on PS Measure

\begin{tabular}{|c|c|c|c|c|c|}
\hline & \multicolumn{5}{|c|}{ Means (Set 2) } \\
\hline \multirow[b]{3}{*}{ Business credit } & \multicolumn{3}{|c|}{ Raw } & \multicolumn{2}{|c|}{ Matched (ATT) } \\
\hline & \multicolumn{3}{|c|}{ Treated Untreated StdDif } & \multicolumn{2}{|c|}{ Treated Untreated StdDif } \\
\hline & 0.54731 & 0.49281 & 0.10918 & 0.54731 & $0.55557-0.01655$ \\
\hline Personal credit & 0.58256 & 0.55276 & 0.06014 & 0.58256 & 0.56920 .02695 \\
\hline Trade credit & 0.24675 & 0.22542 & 0.05021 & 0.24675 & 0.245320 .00338 \\
\hline Corporate & 0.69573 & 0.58753 & 0.22693 & 0.69573 & $0.70472-0.01884$ \\
\hline Multiowner & 0.40631 & 0.34772 & 0.12102 & 0.40631 & $0.39134 \quad 0.03091$ \\
\hline Credit score & 3.31911 & 3.3789 & -0.08639 & 3.31911 & $3.3048 \quad 0.02067$ \\
\hline $\ln$ (hours) & 3.65408 & 3.37749 & 0.31339 & 3.65408 & $3.68176-0.03137$ \\
\hline Female & 0.23191 & 0.2506 & -0.04366 & 0.23191 & $\begin{array}{lll}0.22322 & 0.02031\end{array}$ \\
\hline Intell property & 0.32097 & 0.15827 & 0.38795 & 0.32097 & $0.31894 \quad 0.00484$ \\
\hline Product & 0.55288 & 0.46883 & 0.16861 & 0.55288 & $0.53002 \quad 0.04585$ \\
\hline Service & 0.87199 & 0.8765 & -0.0136 & 0.87199 & $0.88975-0.05354$ \\
\hline Work exp & 14.4416 & 13.464 & 0.09027 & 14.4416 & $14.9199-0.04417$ \\
\hline Other bus & 1.00928 & 0.71343 & 0.22992 & 1.00928 & $1.10135-0.07156$ \\
\hline Outside equity & 0.05937 & 0.03717 & 0.10363 & 0.05937 & $0.07226-0.06015$ \\
\hline Insider equity & 0.0334 & 0.02758 & 0.03382 & 0.0334 & $0.02753 \quad 0.03409$ \\
\hline Insider debt & 0.14286 & 0.07914 & 0.20374 & 0.14286 & $0.14813-0.01687$ \\
\hline $\ln$ (owners equity) & 8.26115 & 7.64489 & 0.15721 & 8.26115 & $8.14055 \quad 0.03077$ \\
\hline $\ln ($ age $)$ & 3.78558 & 3.80288 & -0.07291 & 3.78558 & $\begin{array}{lll}3.78231 & 0.01377\end{array}$ \\
\hline $\ln (a g e)^{2}$ & 14.3884 & 14.5166 & -0.07203 & 14.3884 & $14.3628 \quad 0.01439$ \\
\hline
\end{tabular}




$\begin{array}{lcccccc}\text { Asian } & 0.05751 & 0.02278 & 0.17748 & 0.05751 & 0.05683 & 0.0035 \\ \text { Black } & 0.08534 & 0.05036 & 0.13933 & 0.08534 & 0.07397 & 0.04532 \\ \text { White } & 0.79777 & 0.89089 & -0.25877 & 0.79777 & 0.80652 & -0.0243 \\ \text { College } & 0.63636 & 0.69784 & -0.13064 & 0.63636 & 0.67179 & -0.07527 \\ \text { Graduate } & 0.30241 & 0.18345 & 0.27987 & 0.30241 & 0.26776 & 0.08153 \\ \text { High tech } & 0.18553 & 0.10432 & 0.23207 & 0.18553 & 0.19619 & -0.03047 \\ \text { Medium tech } & 0.37662 & 0.26379 & 0.24344 & 0.37662 & 0.34699 & 0.06393\end{array}$

\section{Variances (Set 2)}

Raw

Matched (ATT)

Treated Untreated Ratio Treated Untreated Ratio

$\begin{array}{lcccccc}\text { Business credit } & 0.24822 & 0.25025 & 0.9919 & 0.24822 & 0.24737 & 1.00344 \\ \text { Personal credit } & 0.24364 & 0.24751 & 0.98433 & 0.24364 & 0.24567 & 0.99173 \\ \text { Trade credit } & 0.18621 & 0.17482 & 1.06519 & 0.18621 & 0.18548 & 1.00394 \\ \text { Corporate } & 0.21208 & 0.24263 & 0.8741 & 0.21208 & 0.20848 & 1.01728 \\ \text { Multiowner } & 0.24167 & 0.22708 & 1.06423 & 0.24167 & 0.23864 & 1.01271 \\ \text { Credit score } & 0.46304 & 0.49492 & 0.93558 & 0.46304 & 0.45464 & 1.01847 \\ \text { ln(hours) } & 0.55387 & 1.004 & 0.55167 & 0.55387 & 0.51707 & 1.07119 \\ \text { Female } & 0.17846 & 0.18803 & 0.94913 & 0.17846 & 0.17371 & 1.02732 \\ \text { Intell property } & 0.21835 & 0.13338 & 1.63703 & 0.21835 & 0.21762 & 1.00336 \\ \text { Product } & 0.24766 & 0.24933 & 0.99333 & 0.24766 & 0.24956 & 0.99239 \\ \text { Service } & 0.11184 & 0.10838 & 1.03189 & 0.11184 & 0.09828 & 1.13796 \\ \text { Work exp } & 117.898 & 116.619 & 1.01097 & 117.898 & 113.32 & 1.04039 \\ \text { Other bus } & 1.97575 & 1.33555 & 1.47936 & 1.97575 & 2.39244 & 0.82583\end{array}$




\begin{tabular}{lccccccc} 
Outside equity & 0.05595 & 0.03583 & 1.56142 & 0.05595 & 0.06716 & 0.83307 \\
Insider equity & 0.03234 & 0.02685 & 1.20449 & 0.03234 & 0.02682 & 1.20568 \\
Insider debt & 0.12268 & 0.07296 & 1.68139 & 0.12268 & 0.12642 & 0.97036 \\
$\ln ($ owners equity) & 15.1747 & 15.5598 & 0.97525 & 15.1747 & 15.0122 & 1.01083 \\
$\ln ($ age $)$ & 0.05795 & 0.05477 & 1.05798 & 0.05795 & 0.05707 & 1.0154 \\
$\ln (\text { age })^{2}$ & 3.24971 & 3.08545 & 1.05324 & 3.24971 & 3.18509 & 1.02029 \\
Asian & 0.05431 & 0.02229 & 2.43643 & 0.05431 & 0.0537 & 1.01133 \\
Black & 0.07821 & 0.04788 & 1.63332 & 0.07821 & 0.06862 & 1.13965 \\
White & 0.16163 & 0.09732 & 1.66075 & 0.16163 & 0.15634 & 1.03385 \\
College & 0.23184 & 0.21111 & 1.09816 & 0.23184 & 0.2209 & 1.0495 \\
Graduate & 0.21135 & 0.14998 & 1.40921 & 0.21135 & 0.19643 & 1.07597 \\
High tech & 0.15139 & 0.09355 & 1.61832 & 0.15139 & 0.158 & 0.95819 \\
Medium tech & 0.23522 & 0.19444 & 1.20972 & 0.23522 & 0.22701 & 1.03614 \\
\hline
\end{tabular}

Notes:

Source: Confidential Kauffman Firm Survey (KFS). PS: Propensity Scores approach. Set 2: The second set of variables. StdDif: Standardized mean difference between treated and untreated samples. Ratio: The ratio variance of treated and untreated samples.

Calculated by the author. 
Table C.10: Combined Difference in Difference: Real Revenue Growth

\begin{tabular}{lccccccc}
\hline & \multicolumn{7}{c}{ Set 1: Mahalanobis Distance } \\
Algorithm & $\mathbf{n n}(\mathbf{1})$ & $\mathbf{n n}(\mathbf{2})$ & $\mathbf{n n}(\mathbf{3})$ & $\mathbf{n n}(\mathbf{4})$ & $\mathbf{n n}(\mathbf{5})$ & $\mathbf{K M}(\mathbf{p m})$ & $\mathbf{K M}(\mathbf{c v})$ \\
CDiD & 0.143 & 0.253 & 0.372 & 0.362 & 0.367 & $0.629^{* *}$ & 0.325 \\
Sd & $(0.366)$ & $(0.363)$ & $(0.431)$ & $(0.378)$ & $(0.355)$ & $(0.309)$ & $(0.320)$ \\
N & 1374 & 1374 & 1374 & 1374 & 1374 & 1374 & 1374 \\
N (cont. match) & 342 & 511 & 601 & 712 & 662 & 833 & 717
\end{tabular}

Set 1: Propensity Score

$\begin{array}{lccccccc}\text { Algorithm } & \mathbf{n n}(\mathbf{1}) & \mathbf{n n}(\mathbf{2}) & \mathbf{n n}(3) & \mathbf{n n}(4) & \mathbf{n n}(\mathbf{5}) & \mathrm{KM}(\mathbf{p m}) & \mathrm{KM}(\mathbf{c v}) \\ \text { CDiD } & 0.599 & 0.477 & 0.686 & 0.662^{*} & 0.562 & 0.44 & 0.622^{*} \\ \text { Sd } & (0.428) & (0.479) & (0.437) & (0.396) & (0.381) & (0.331) & (0.324) \\ \mathbf{N} & 1374 & 1374 & 1374 & 1374 & 1374 & 1374 & 1374 \\ \mathbf{N} \text { (cont. match) } & 303 & 469 & 585 & 657 & 703 & 785 & 829\end{array}$

Set 2: Propensity Score

\begin{tabular}{lccccccc} 
Algorithm & $\mathbf{n n}(\mathbf{1})$ & $\mathbf{n n}(\mathbf{2})$ & $\mathbf{n n}(3)$ & $\mathbf{n n}(\mathbf{4})$ & $\mathbf{n n}(5)$ & $\mathrm{KM}(\mathbf{p m})$ & $\mathrm{KM}(\mathbf{c v})$ \\
CDiD & $0.955^{* *}$ & $0.985^{* *}$ & $0.770^{*}$ & $0.752^{*}$ & 0.713 & 0.459 & $0.622^{* *}$ \\
$\mathbf{S d}$ & $(0.465)$ & $0.448)$ & $(0.474)$ & $(0.453)$ & $(0.447)$ & $(0.331)$ & $(0.330)$ \\
$\mathbf{N}$ & 1373 & 1373 & 1373 & 1373 & 1373 & 1373 & 1373 \\
$\mathbf{N}$ (cont. match) & 316 & 481 & 572 & 630 & 683 & 801 & 834 \\
\hline
\end{tabular}

Notes: Source: Confidential Kauffman Firm Survey (KFS). $p<0.10,{ }^{* *} p<0.05$. nn(k): K: minimum number of matches per observation for nearest-neighbour algorithm. $\mathbf{K M}(\mathbf{p m})$ : Kernel matching algorithm that selects a bandwidth using a pair-matching algorithm (Huber et al. (2015)). KM(cv): Kernel matching algorithm that selects the bandwidth by cross-validation (Galdo et al. (2008)). CDiD: Combined Difference in Difference. Sd: Standard error calculated using bootstrapping method with 100 iterations. N: Total number of observations in the control and the treatment groups considered in matching process. $\mathbf{N}$ (cont. match): Number of observations in the control group matched with about 539 firms in the treated group.

Calculated by the author. 
Table C.11: Combined Difference in Difference: Employment Growth

\begin{tabular}{|c|c|c|c|c|c|c|c|}
\hline \multirow[b]{2}{*}{ Algorithm } & \multicolumn{7}{|c|}{ Set 1: Mahalanobis Distance } \\
\hline & nn(1) & $\mathrm{nn}(2)$ & nn(3) & $\mathrm{nn}(4)$ & $\mathrm{nn}(5)$ & $\mathrm{KM}(\mathrm{pm})$ & $\mathrm{KM}(\mathrm{cv})$ \\
\hline CDiD & $0.103^{*}$ & 0.107 & $0.123^{*}$ & $0.134^{* *}$ & $0.142^{* *}$ & $0.179 * *$ & $0.126^{* *}$ \\
\hline Sd & $(0.036)$ & $(0.067)$ & $(0.066)$ & $(0.062)$ & $(0.057)$ & $(0.048)$ & $(0.057)$ \\
\hline $\mathbf{N}$ & 1367 & 1367 & 1367 & 1367 & 1367 & 1367 & 1367 \\
\hline \multirow[t]{2}{*}{$\mathrm{N}$ (cont. match) } & 339 & 504 & 599 & 662 & 708 & 829 & 733 \\
\hline & \multicolumn{7}{|c|}{ Set 1: Propensity Score } \\
\hline Algorithm & $\operatorname{nn}(1)$ & nn $(2)$ & nn $(3)$ & nn(4) & nn(5) & $\mathrm{KM}(\mathrm{pm})$ & $\mathrm{KM}(\mathrm{cv})$ \\
\hline CDiD & $0.141^{*}$ & $0.158^{* *}$ & $0.161^{* *}$ & $0.185^{* *}$ & $0.188^{* *}$ & $0.129^{* *}$ & $0.181^{* *}$ \\
\hline Sd & $(0.076)$ & $(0.080)$ & $(0.063)$ & $(0.068)$ & $(0.056)$ & $(0.057)$ & $(0.055)$ \\
\hline $\mathbf{N}$ & 1367 & 1367 & 1367 & 1367 & 1367 & 1367 & 1367 \\
\hline \multirow[t]{2}{*}{$\mathrm{N}$ (cont. match) } & 317 & 510 & 605 & 662 & 703 & 774 & 829 \\
\hline & \multicolumn{7}{|c|}{ Set 2: Propensity Score } \\
\hline CDiD & $0.175^{* *}$ & $0.156^{* *}$ & $0.137^{* *}$ & $0.133^{* *}$ & $0.131^{*}$ & $0.108^{*}$ & $0.159^{* *}$ \\
\hline Sd & $(0.087)$ & $(0.078)$ & $(0.070)$ & $(0.067)$ & $(0.066)$ & $(0.060)$ & $(0.058)$ \\
\hline $\mathbf{N}$ & 1365 & 1365 & 1365 & 1365 & 1365 & 1365 & 1365 \\
\hline $\mathrm{N}$ (cont. match) & 293 & 462 & 564 & 634 & 679 & 785 & 828 \\
\hline
\end{tabular}

Notes: Source: Confidential Kauffman Firm Survey (KFS). $p<0.10,^{* *} p<0.05$. nn(k): K: minimum number of matches per observation for nearest-neighbour algorithm. KM(pm): Kernel matching algorithm that selects a bandwidth using a pair-matching algorithm (Huber et al. (2015)). KM(cv): Kernel matching algorithm that selects the bandwidth by cross-validation (Galdo et al. (2008)). CDiD: Combined Difference in Difference. Sd: Standard error calculated using bootstrapping method with 100 iterations. N: Total number of observations in the control and the treatment groups considered in matching process. $\mathbf{N}$ (cont. match): Number of observations in the control group matched with about 536 firms in the treated group. Calculated by the author. 
Table C.12: Combined Difference in Difference: Per-capita Real Wage Growth

\section{Set 1: Mahalanobis Distance}

\begin{tabular}{lccccccc}
\hline Algorithm & $\mathbf{n n}(\mathbf{1})$ & $\mathbf{n n}(\mathbf{2})$ & $\mathbf{n n}(3)$ & $\mathbf{n n}(\mathbf{4})$ & $\mathbf{n n}(\mathbf{5})$ & $\mathbf{K M}(\mathbf{p m})$ & $\mathbf{K M}(\mathbf{c v})$ \\
CDiD & 0.314 & 0.435 & 0.492 & 0.509 & 0.484 & $0.67^{* *}$ & 0.475 \\
Sd & $(0.366)$ & $(0.390)$ & $(0.362)$ & $(0.380)$ & $(0.373)$ & $(0.252)$ & $(0.295)$ \\
$\mathbf{N}$ & 1346 & 1346 & 1346 & 1346 & 1346 & 1346 & 1346 \\
N (cont. match) & 334 & 499 & 585 & 655 & 693 & 817 & 762
\end{tabular}

Set 1: Propensity Score

$\begin{array}{lccccccc}\text { Algorithm } & \mathbf{n n}(\mathbf{1}) & \mathbf{n n}(\mathbf{2}) & \mathbf{n n}(\mathbf{3}) & \mathbf{n n}(\mathbf{4}) & \mathbf{n n}(\mathbf{5}) & \mathbf{K M}(\mathbf{p m}) & \mathbf{K M}(\mathbf{c v}) \\ \text { CDiD } & 0.913^{* *} & 1.007^{* *} & 0.787^{* *} & 0.730^{*} & 0.738^{*} & 0.907^{* *} & 0.732^{* *} \\ \text { Sd } & (0.438) & (0.437) & (0.359) & (0.418) & (0.438) & (0.328) & (0.298) \\ \text { N } & 1346 & 1346 & 1346 & 1346 & 1346 & 1346 & 1346 \\ \text { N (cont. match) } & 302 & 470 & 581 & 644 & 700 & 786 & 816\end{array}$

Set 2: Propensity Score

\begin{tabular}{lccccccc} 
Algorithm & $\mathbf{n n}(\mathbf{1})$ & $\mathbf{n n}(\mathbf{2})$ & $\mathbf{n n}(\mathbf{3})$ & $\mathbf{n n}(\mathbf{4})$ & $\mathbf{n n}(\mathbf{5})$ & $\mathbf{K M}(\mathbf{p m})$ & $\mathbf{K M}(\mathbf{c v})$ \\
$\mathbf{C D i D}$ & -0.024 & 0.554 & 0.424 & 0.377 & 0.45 & 0.54 & $0.636^{*}$ \\
$\mathbf{S d}$ & $(0.443)$ & $(0.415)$ & $(0.428)$ & $(0.463)$ & $(0.415)$ & $(0.341)$ & $(0.347)$ \\
$\mathbf{N}$ & 1345 & 1345 & 1345 & 1345 & 1345 & 1345 & 1345 \\
$\mathbf{N}$ (cont. match) & 296 & 457 & 555 & 620 & 659 & 799 & 813 \\
\hline
\end{tabular}

Notes: Source: Confidential Kauffman Firm Survey (KFS). $p<0.10,{ }^{* *} p<0.05$. nn(k): K: minimum number of matches per observation for nearest-neighbour algorithm. KM(pm): Kernel matching algorithm that selects a bandwidth using a pair-matching algorithm (Huber et al. (2015)). KM(cv): Kernel matching algorithm that selects the bandwidth by cross-validation (Galdo et al. (2008)). CDiD: Combined Difference in Difference. Sd: Standard error calculated using bootstrapping method with 100 iterations. N: Total number of observations in the control and the treatment groups considered in matching process. N (cont. match): Number of observations in the control group matched with about 527 firms in the treated group. Calculated by the author. 
Figure C.1: Selected Bandwidth and the Density Balancing

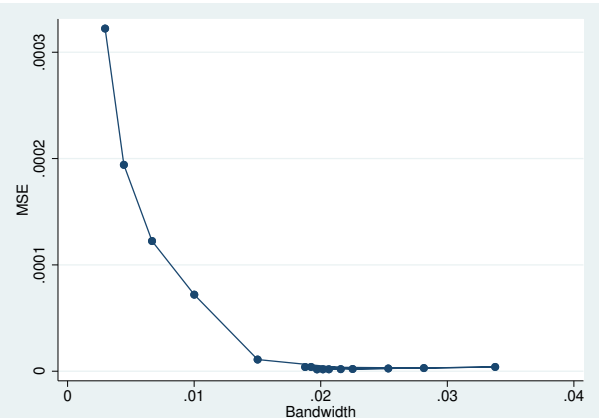

(a) Bandwidth (KM(cv), Set 1)

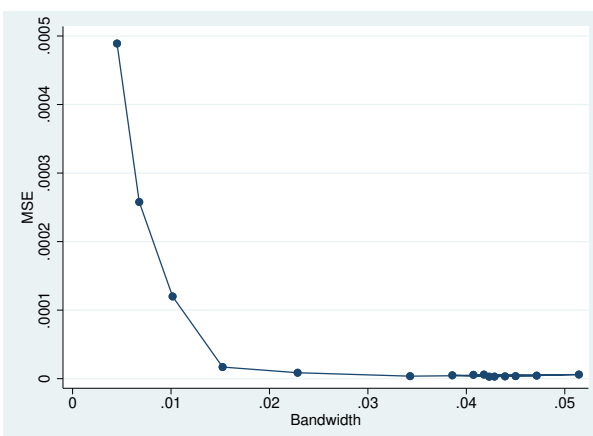

(c) Bandwidth (KM(cv), Set 2)

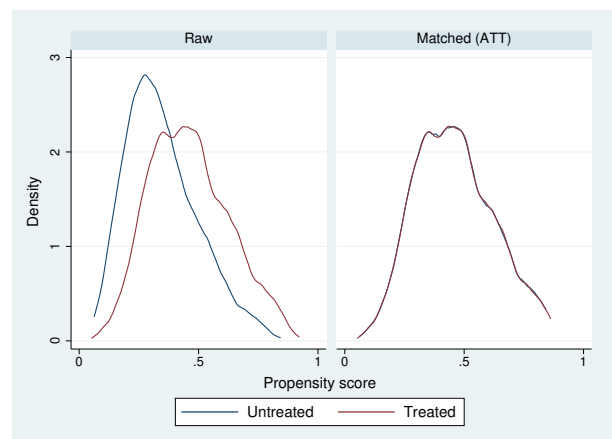

(b) PS density(Set 1)

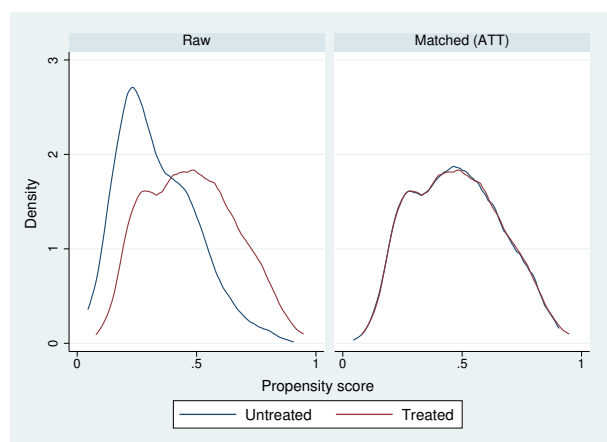

(d) PS density (Set 2) 